\title{
然
}

\section{EL SISTEMA ESPAÑOL DE PENSIONES EN EL SIGLO XXI: EVIDENCIA DISPONIBLE Y ANÁLISIS GRÁFICO}

El sistema español de pensiones públicas se compone de tres subsistemas: las pensiones contributivas de la Seguridad Social, las pensiones no contributivas y las pensiones de clases pasivas del Estado. Este último está llamado a desaparecer a lo largo del siglo XXI, tras la integración de los funcionarios públicos ingresados a partir de 2011 en el Régimen General de la Seguridad Social, a efectos de pensiones. Este trabajo recopila (con el aparato gráfico y en el Anexo) los datos disponibles sobre las principales variables del sistema y reconstruye su dinámica, estudiando los factores que la determinan, separando los coyunturales de los estructurales y aislando los tres «efectos» que impulsan el crecimiento del gasto: la «población», la «revalorización»y la «sustitución» de pensiones que se extinguen por pensiones nuevas. Tres cuadros sintetizan esta dinámica entre 1980 y 2016.

Palabras clave: pensiones de clases pasivas, pensiones contributivas, pensiones no contributivas.

Clasificación JEL: H55, J26.

\section{Introducción: los tres bloques de componentes del sistema}

El sistema español de pensiones públicas se compone actualmente de:

1. Las pensiones contributivas (PC), reguladas por la Ley General de la Seguridad Social (LGSS) ${ }^{1}$, incluidas aquellas consideradas como asimiladas a las mismas

\footnotetext{
* Consejero Técnico. Dirección General de Política Económica. Versión de mayo de 2017.

1 Ley General de la Seguridad Social en la versión recogida por el Real Decreto Legislativo 8/2015: http://www.seg-social.es/Internet_1/ Normativa/095093\#documentoPDF, que incorpora todas las modificaciones introducidas desde la Ley de Bases de la Seguridad Social (1966).
}

aunque los beneficiarios no hayan cotizado, junto a los complementos (por mínimos, para la persona que atiende al pensionista con gran invalidez, o por maternidad), así como las abonadas por las entidades que actúan como sustitutorias de las entidades gestoras de la SS (cada vez menos relevantes).

2. Las pensiones no contributivas (PNC) de la Seguridad Social (SS), reguladas por la misma ley, así como las pensiones extraordinarias originadas por actos de terrorismo (en número poco apreciable). La aparición de las pensiones no contributivas dio lugar a la rápida $D$ 


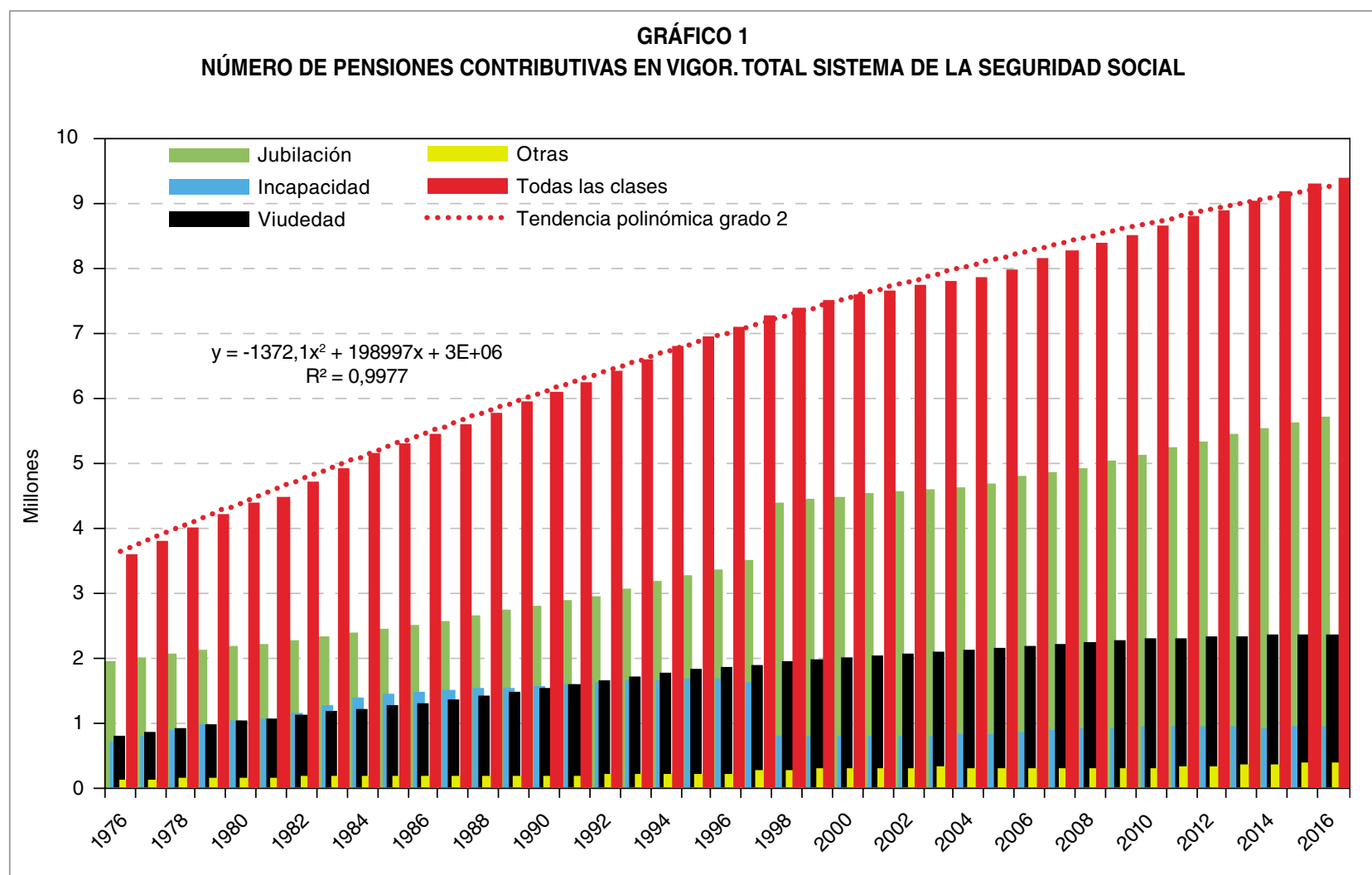

Fuente: elaboración propia a partir de las series del apéndice, de las fuentes de datos y de los métodos consignados en el texto (Cuadro A-1).

conversión en PNC de la mayor parte de las pensiones asistenciales, de modo que su número actual es muy poco relevante y decreciente. También entran en este bloque las pensiones destinadas a emigrantes retornados, en número muy pequeño.

3. Las pensiones del Régimen de Clases Pasivas del Estado, así como las de las mutualidades de funcionarios, civiles 0 militares $^{2}$.

No se incluye en este sistema el apoyo fiscal a los fondos de pensiones privados, pues se trata más bien de una redistribución de la carga a lo largo del ciclo vital.

2 Sobre sus antecedentes y su regulación inicial en 1926, véase Espina (2007, pp. 93 y ss.).

\section{Las pensiones contributivas: su número, evolución histórica desde 1976 y vicisitudes}

Con gran diferencia, las pensiones contributivas del primer bloque constituyen el colectivo numéricamente más importante (casi el 90 por 100 del total). Como se observa en el Gráfico 1, su evolución tendencial ha sido fuertemente creciente, aunque la tasa de crecimiento anual haya ido desacelerándose, pasando del 5,5 por 100 en el primer trienio del período, al 1,125 por 100 al final. Durante el cuatrienio 2001-2004 aparece una ligera inflexión coyuntural, situándose temporalmente la tasa de variación interanual en torno al 0,9 por 100, y durante todo el período 2002-2009 (como en 1981-1982) la cifra total se separa abiertamente de la tendencia polinómica de segundo grado dibujada en el gráfico, que da cuenta $\triangleright$ 

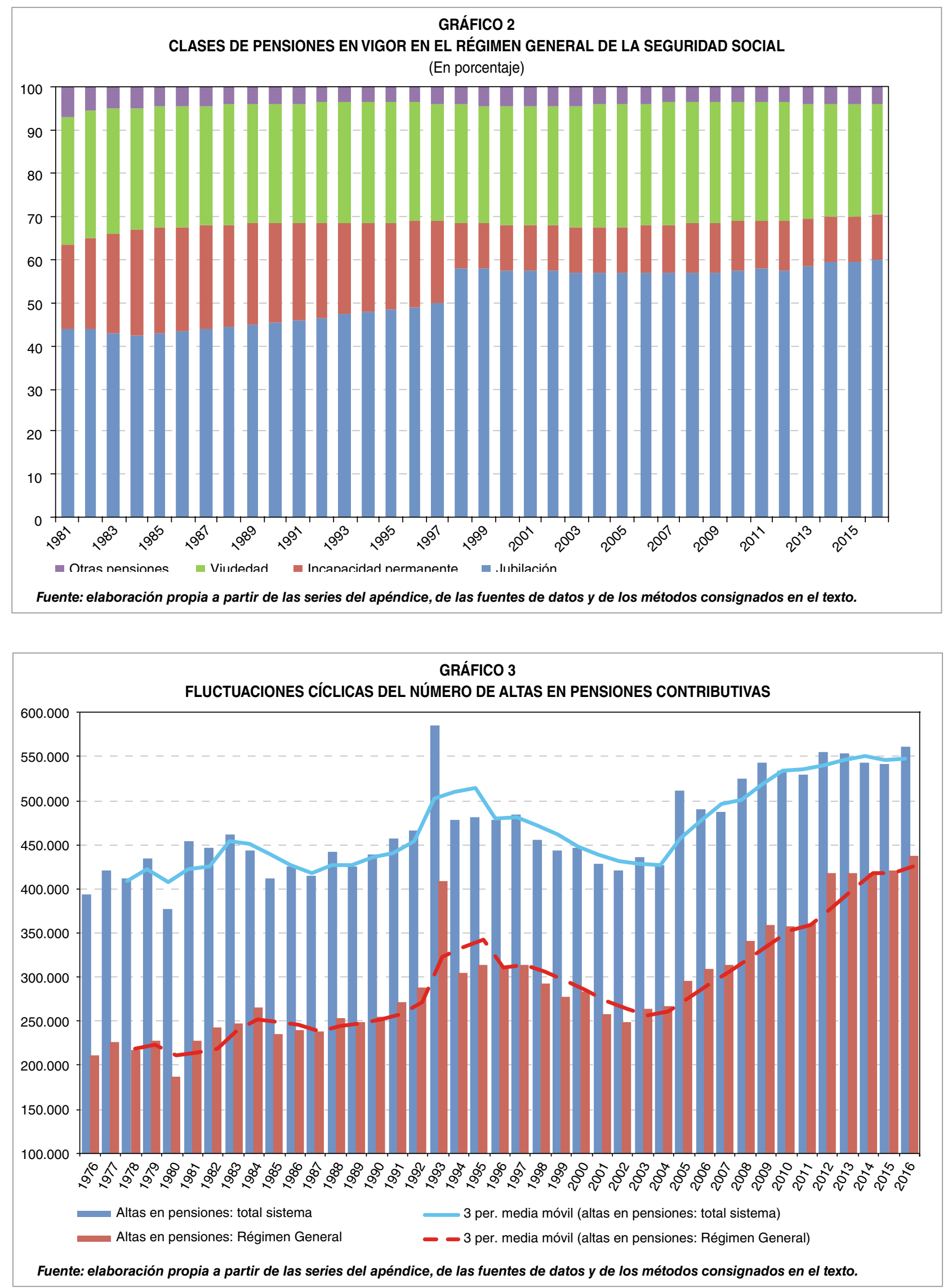
del 99,8 por 100 de la varianza de la serie temporal de pensiones.

A su vez, el grupo más numeroso de las pensiones contributivas de SS se encuentra en el Régimen General (RG), que tiene además vocación de ir integrando a los otros regímenes. De hecho, desde 2012 ya se integran en él los trabajadores del Régimen Especial de Empleados de Hogar y los asalariados del Régimen Especial Agrario (del mismo modo que desde 2008 los autónomos de ese régimen se integraron en el Régimen de Trabajadores Autónomos). Además, desde el ámbito de la función pública, en 1993 se integraron en el RG los funcionarios de la Administración local ${ }^{3}$. Finalmente, lo hicieron también todos los funcionarios públicos ingresados a partir del 1 de enero de 2011, aunque solo a efectos de las pensiones ${ }^{4}$.

Esta voluntad asimilacionista explica que, del número total de pensiones del Gráfico 1, el Régimen General pasase de representar el 46 por 100 en 1981 al 71 por 100 en 2016, y que este último creciera durante esos 35 años a una tasa acumulativa anual del 3,42 por 100 , frente a un crecimiento del 2,14 por 100 en el número total de pensiones ${ }^{5}$. Importa por ello observar también con especial detenimiento la evolución del Régimen General, como se hace en el Gráfico 2, que representa la distribución porcentual del número de pensiones dentro de ese régimen, según clases.

\footnotetext{
3 Por el Real Decreto 480/1993, de 2 de abril: http://www.seg-social. es/Internet_1/Normativa/097316

4 Real Decreto Ley 13/2010, de 3 de diciembre, artículo 20, apartado 1. Véase el epígrafe sobre clases pasivas.

5 En diciembre de 1997 las pensiones de incapacidad permanente de los mayores de 65 años se integraron en las pensiones de jubilación, lo que supuso un descenso de 900.000 en las primeras y un aumento equivalente en las segundas. Véase: https://explotacion.mtin.gob.es/ series/pdf/80-FyN.pdf. También se integraron en el Régimen General -y hasta 2001 figuran en su estadística de altas y bajas- los afiliados al Seguro Obligatorio de Vejez e Invalidez (SOVI), al extinguirse en 1967, siempre que no hubieran cubierto el período de cotización exigido o no hubieran estado afiliados antes de 1940 al Régimen del Retiro Obrero Obligatorio, antecesor del sistema actual (Espina, 2007, pp. 87 y ss.).
}

Puede observarse que la distribución es relativamente estable, ya que el principal salto se produjo en 1998 cuando, por razones legales, casi la mitad del número total de pensiones de incapacidad permanente se transformaron en pensiones de jubilación, lo que supuso en el Régimen General un aumento del 25 por 100 en estas pensiones. También se registra un descenso tendencial del número de pensiones de viudedad a lo largo de los años ochenta, y un leve descenso de las pensiones de orfandad y de familiares (del 5 por 100 inicial al 4 por $100)$, agregadas en el grupo «otras pensiones» del gráfico.

\section{1. ¿Tiene la serie de altas en pensiones carácter contracíclico?}

La escasa sensibilidad cíclica aparente que muestra el Gráfico 1 es ficticia, al diluirse las cifras de entradas en un stock fuertemente creciente.

En cambio, las fluctuaciones cíclicas aparecen con toda claridad al contemplar la evolución de las altas en el sistema de pensiones, como se observa en el Gráfico 3 y en los Cuadros A-6 y A-7: en medias móviles trianuales las altas en el sistema registran mínimos en 1980, 1987 y 2004, y máximos en 1983, 1995 y 2016, experimentando fuertes expansiones durante las etapas de crisis (1981-1984, 1992-1995 y 2008-2012).

En el caso del Régimen General, la tendencia al crecimiento de las altas durante la última etapa se prolonga debido a las incorporaciones de otros regímenes. En el Gráfico 4, que descompone el volumen de altas por clases de pensiones para el conjunto del sistema, se observa que los años que registran máximos en el número de altas son 1983, 1993 y 2016, aunque el segundo se debe en buena $\triangleright$ 
medida a la incorporación de funcionarios locales y transferidos a las CCAA. La expansión cíclica de las altas se prolonga hasta 1983 y 1995, cayendo después hasta mínimos locales en 1985-1987 y 2001-2004, para volver a niveles máximos desde 2012, tras los fuertes crecimientos de la última etapa de crisis.

En cualquier caso, debe matizarse mucho la hipótesis frecuentemente sostenida según la cual las fluctuaciones en el número de altas se deben al adelanto en la edad de jubilación provocado por el aumento del desempleo de larga duración en las edades superiores, que se traduciría siempre, según la hipótesis, en aumentos cíclicos de las jubilaciones anticipadas.

El análisis de los datos desagregados por edades, entre 60 y 65 años o más, que se realiza en los Gráficos 5 y $6^{6}$, permite afirmar que la distribución de las jubilaciones a las distintas edades sigue una pauta considerablemente estable. Los fuertes repuntes en la cifra de altas a la edad de 65 años (o por encima de esa cifra), que se observan en el Gráfico 5, en 1993 y en 2005 se deben a la incorporación de la Administración local, en el primer caso, y a la autorización para que las pensionistas viudas con derecho a pensiones de jubilación del SOVI pudieran compatibilizar ambas pensiones, en el segundo?.

6 En ambos gráficos las series son medias móviles de doce términos mensuales.

7 Según la regla de concurrencia establecida por la disposición adicional 58. a de la Ley de Presupuestos para 2006, incorporada como Disposición transitoria segunda de la LGSS (Prestaciones del extinguido Seguro Obligatorio de Vejez e Invalidez).

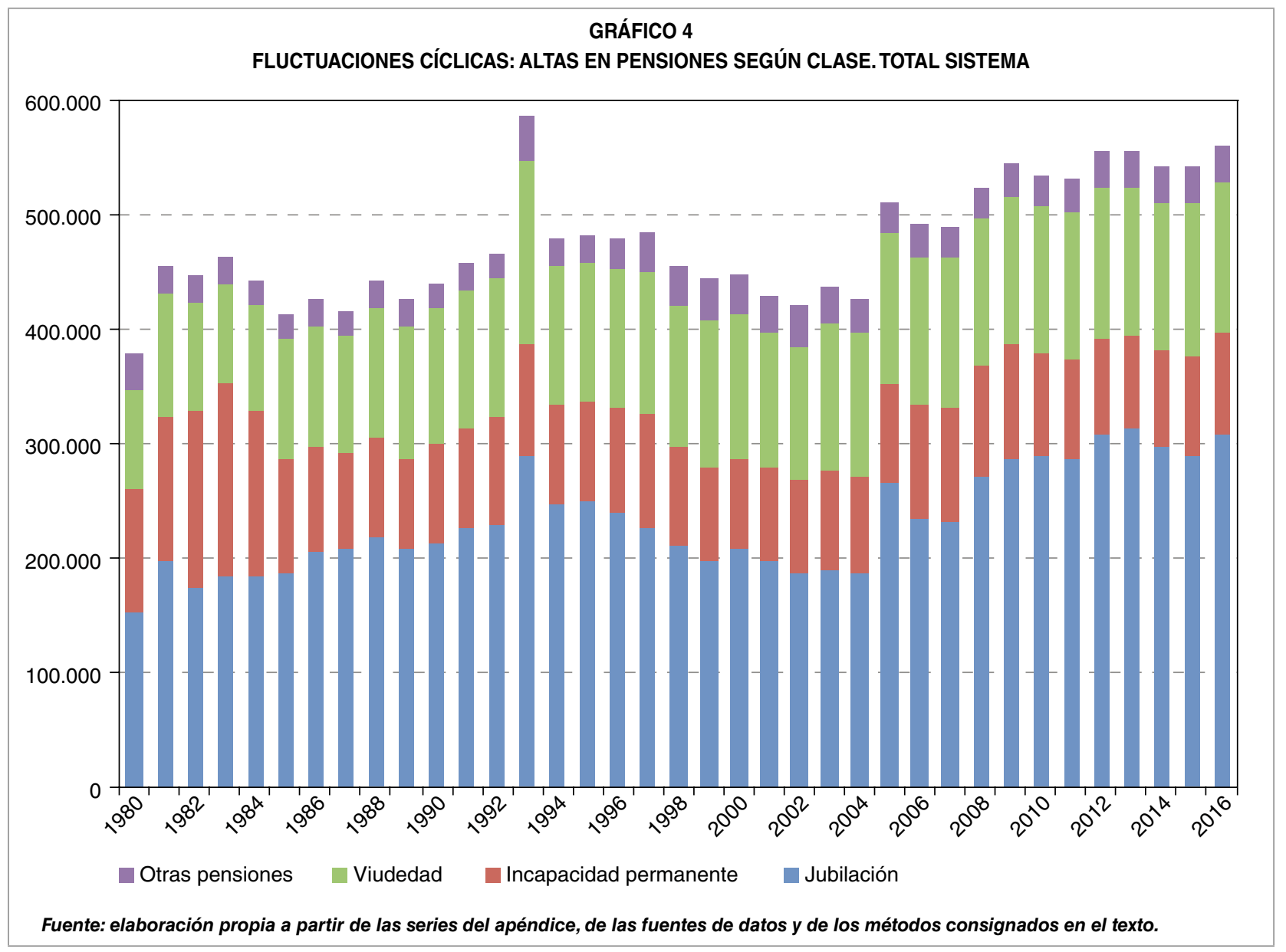




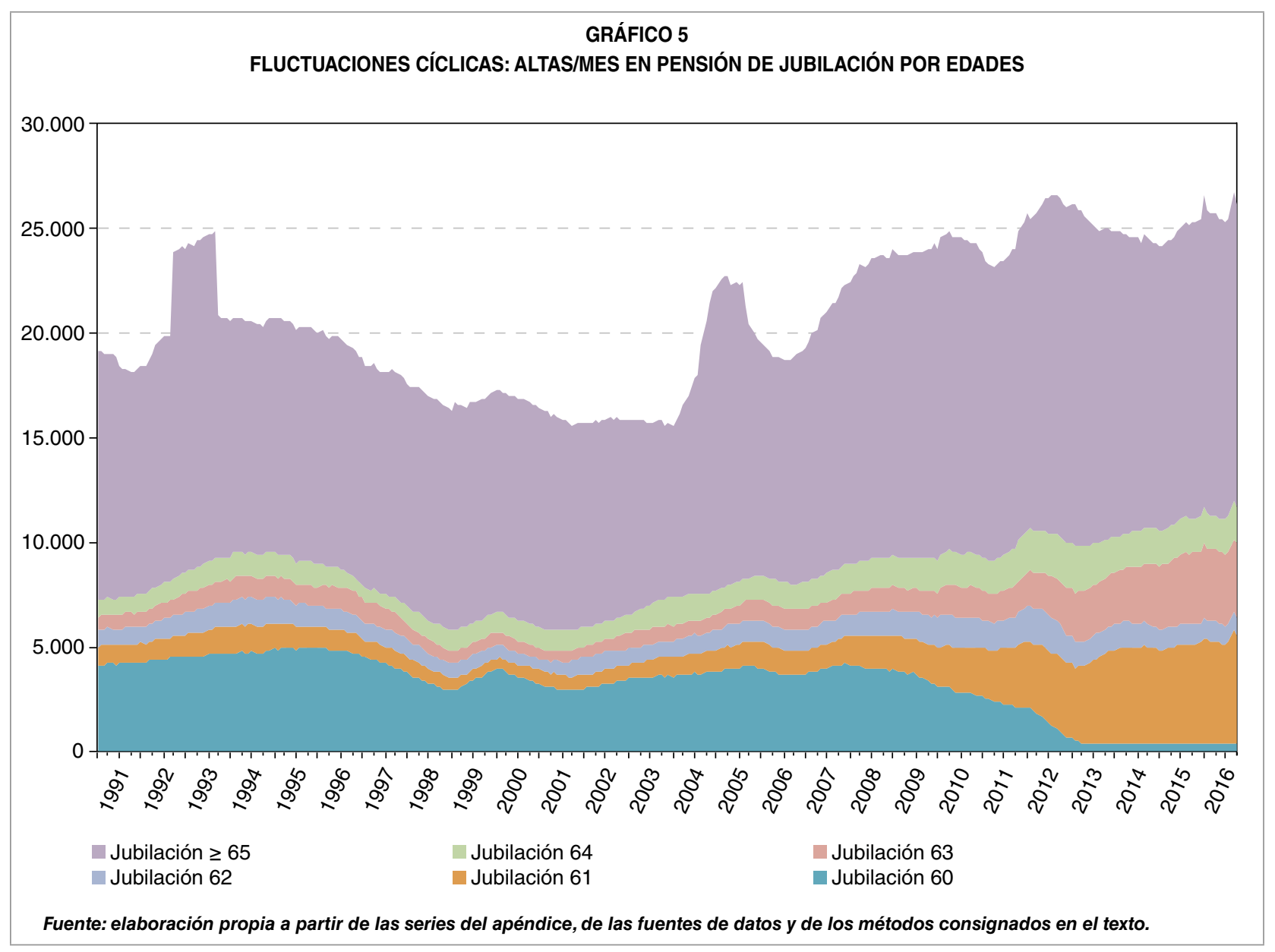

La secuencia de las altas en jubilación tiene además un fuerte componente demográfico. El primer máximo que se registra entre 1992 y 1996 coincide con la llegada a la edad de sesenta años de los nacidos antes de la guerra civil (1932-1936) y a la de 65 años de los nacidos entre 1927 y 1931, con fertilidad creciente. Unos y otros cumplirían en su mayor parte el requisito de haber sido mutualistas antes de 1967, pudiendo optar a la jubilación anticipada desde los 60 años con coeficientes reductores bonificados ${ }^{8}$, de modo que la hipótesis de adelanto cíclico es verosímil para ese período y este colectivo.

Ciertamente, el quinquenio 1999-2004 registra máximos de actividad económica, lo que

8 Disposición transitoria cuarta de la LGSS citada (Real Decreto Legislativo 8/2015). en teoría disminuiría la propensión a anticipar la edad de jubilación por causa del desempleo, pero durante el mismo llegan también a la edad de 65 años las cohortes mermadas de la guerra civil (1934-1939), y a la de 60 años las de los nacidos durante el primer quinquenio de la posguerra, lo que disminuyó la magnitud de quienes tenían derecho a la jubilación anticipada bonificada, ya que la cohorte más joven de este grupo tenía 21 años en 1966, habiéndose integrado anteriormente en el mercado y el mutualismo laboral.

El crecimiento del número de pensiones para todas las edades que se registra a partir de 2008 tampoco se deriva solo de la crisis económica subsiguiente, sino que debe relacionarse con la llegada a las edades $\triangleright$ 
de jubilación ordinaria de los activos nacidos inmediatamente después de la guerra civil y de quienes habían retrasado su integración durante la misma, incorporándose por primera vez a la actividad laboral a su término.

Debe tenerse en cuenta, además, que hasta 2013 no cumplieron 60 años los adolescentes nacidos antes de 1953, que cumplieron 14 años -edad mínima entonces de entrada en el mercado de trabajo— antes de 1967, última cohorte con derecho a jubilación anticipada y bonificada desde esa edad ${ }^{9}$, por lo que a partir de esa fecha en los Gráficos 5 y 6 solo aparece una cifra escasamente relevante para

9 El precepto citado en la nota anterior establece un coeficiente reductor del 8 por 100 por año de anticipación si la baja es voluntaria y se ha cotizado al menos durante 30 años. Si la baja es involuntaria, se aplica una escala entre el 6 por 100 y el 7,5 por 100 de reducción por año anticipado, al acreditar entre 44,5 y 38,5 años de cotización. las altas a esa edad, que corresponden a la jubilación anticipada «por razón de la actividad o en caso de discapacidad», regulada actualmente por el artículo 206 de la LGSS para los mayores de 52 años cuando la actividad o la discapacidad supongan una merma sustancial de la esperanza de vida. De este modo, a partir de 2006 la merma en los efectivos con derecho a jubilación a los 60 años se traduce en un aumento de peso de la jubilación a los 61 años, de modo que la suma de ambos colectivos solo desciende levemente durante el último decenio ${ }^{10}$.

10 La jubilación anticipada por causas involuntarias desde los 61 años es regulada por el artículo 207 de la LGSS, citado, con coeficientes reductores escalonados por trimestres: del 7,5 por 100 por año anticipado cuando se ha cotizado más de 38,5 años y de 6,5 por 100 habiendo cotizado más de 44,5 años. En cambio (art. 208), por causas voluntarias solo cabe anticipar los dos últimos años, con penalización algo superior (8 por 100 con 38,5 años).

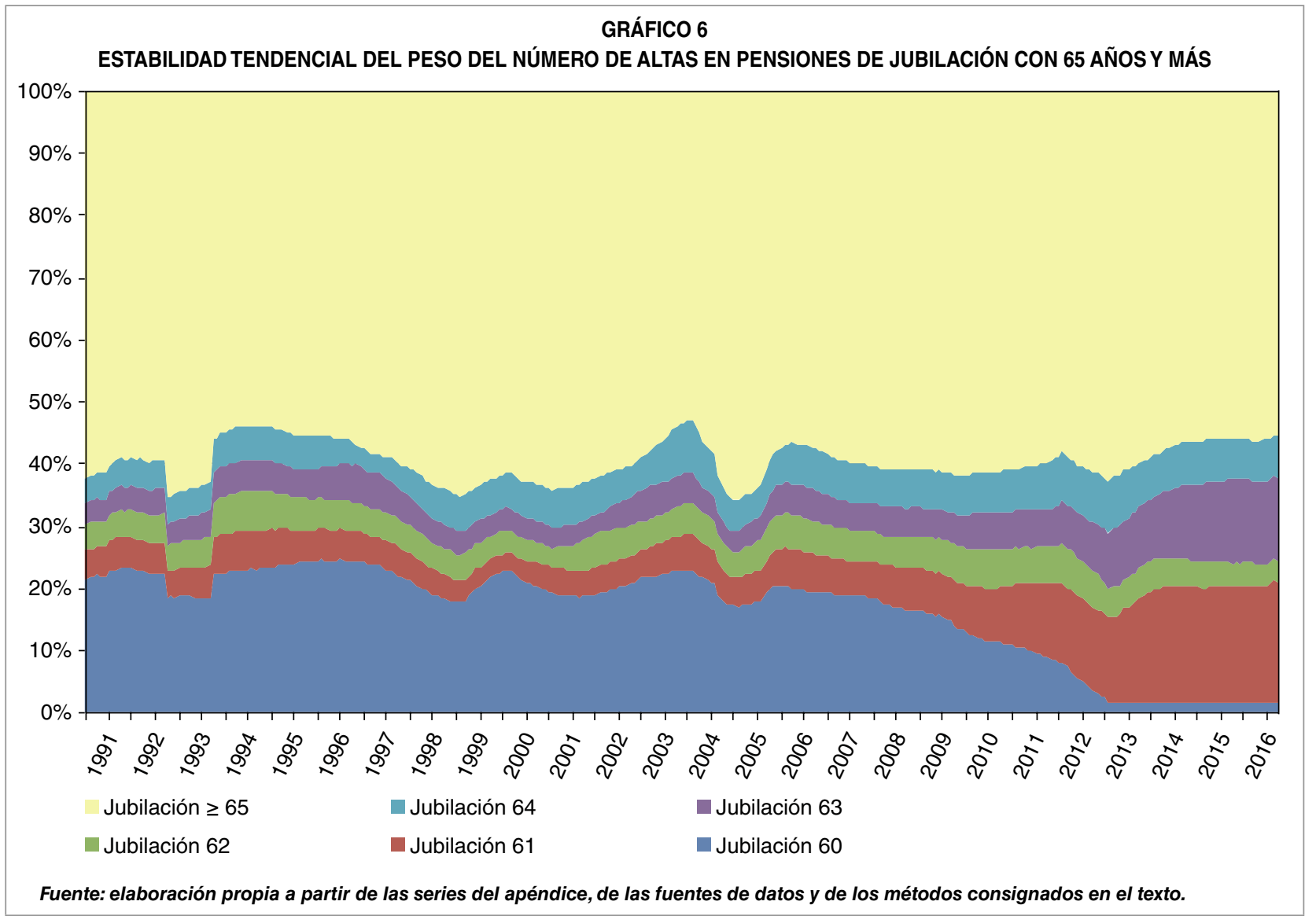




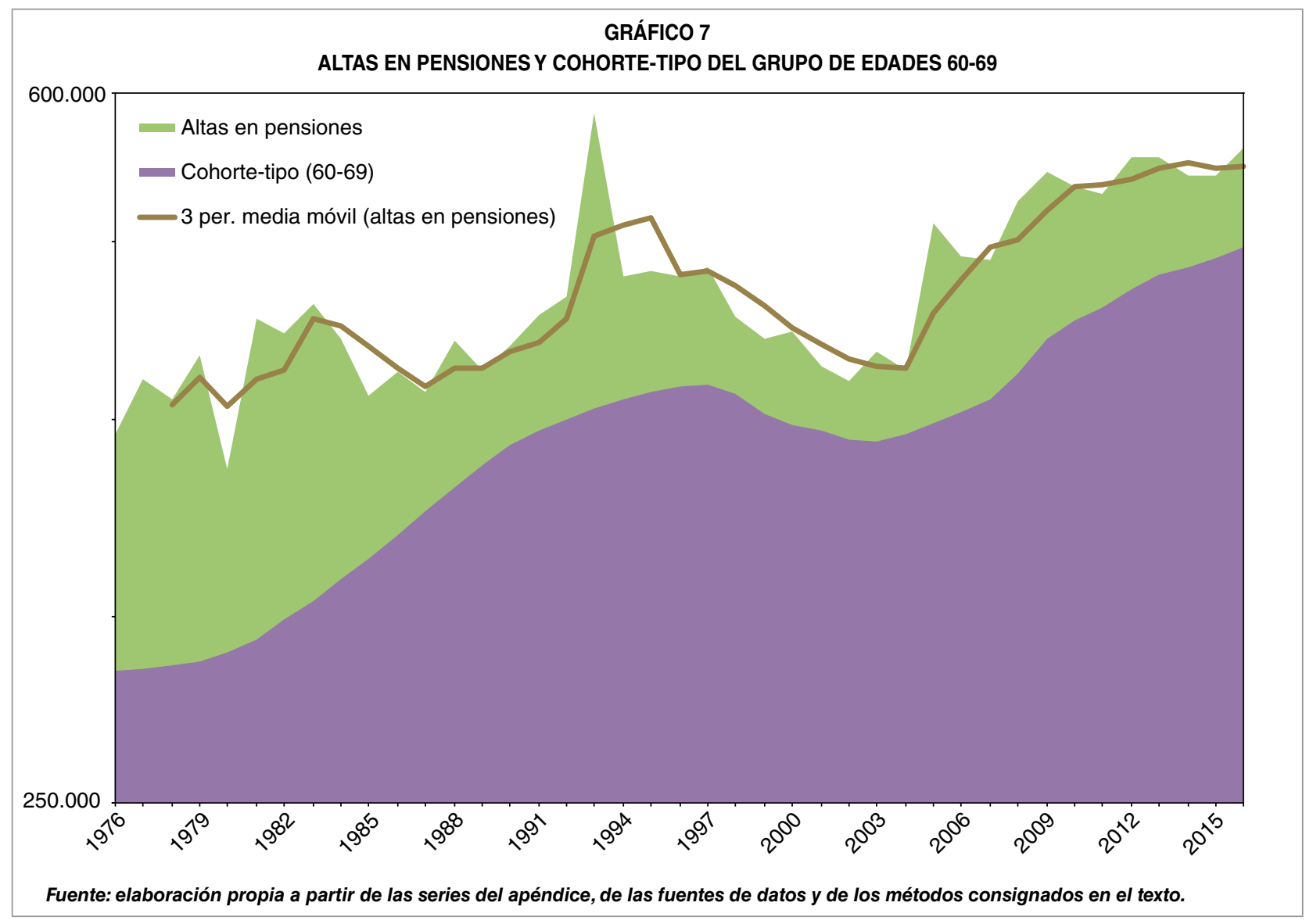

El Gráfico 6 normaliza a 100 las altas en pensiones de jubilación para eliminar los efectos derivados de la coyuntura demográfica y permite observar la proporción que representa cada grupo de edades sobre el total de altas. Las divisorias de 1993 y 2005 se deben a la inclusión de los funcionarios de la Administración local y a la de las viudas del SOVI con pensión de jubilación propia, que hunden el peso relativo de las altas de los jubilados con edades por debajo de 65 años durante esos años. Salvada esa peculiaridad, la proporción de las jubilaciones a los 65 años o más se mantiene a lo largo de todo el período, para el que disponemos de datos homogéneos, y especialmente durante la última crisis. A lo sumo, pues, esta solo ha contrarrestado la tendencia a retrasar voluntariamente la edad de jubilación en orden a beneficiarse de los incentivos establecidos a tal fin (a la espera todavía de que surta efecto sustancial el retraso legal de la edad de jubilación ordinaria).

\subsection{El peso de la demografía sobre el sistema de pensiones contributivas}

Por el contrario, el Gráfico 7 trata de captar el peso de la demografía sobre la serie de altas en pensiones, mostrando a la población relevante como la cohorte representativa del grupo de edad entre 60 y 69 años, equivalente a la décima parte de la suma de los grupos 60-64 y 65-6911. El gráfico es bien ilustrativo de la fuerte $\square$

11 Tomadas de: $h t t p: / / w w w \cdot i n e . e s / j a x i T 3 / T a b l a . h t m ? t=10258 \& L=0$ 
correlación entre ambas series, especialmente a partir de la reforma de la Ley $26 / 1985$, de 31 de julio, que según su preámbulo pretendió reforzar «el carácter profesional, contributivo y proporcional de las pensiones de jubilación e invalidez», evitándose a partir de entonces la fácil manipulación de la edad de jubilación según la conveniencia del beneficiario y a costa del sistema.

No por ello cabe descartar el impacto del ciclo sobre el número de altas, pero éste debe medirse a través de la ratio de las mismas respecto de la cohorte-tipo del grupo de edades 60-69. Además, para eliminar el efecto distorsionante que aparece en las altas de 1993 y de 2005, en el Gráfico 8 se han reestimado ambas cifras promediando las de los años adyacentes: el coeficiente de correlación entre ambas series, en este caso, se eleva a 0,71, lo que sirve para medir el impacto demográfico, mientras que el mayor efecto cíclico aparece durante los años ochenta, antes de las reformas de 1985, ya que la media móvil (3) centrada de la ratio alcanza su máximo histórico $(1,45)$ en 1982 , coincidiendo con la segunda crisis del petróleo. A partir del año siguiente a la entrada en vigor de la reforma de 1985 el promedio de la ratio se sitúa en 1,15, con fluctuaciones cíclicas muy leves: por encima hasta $1988,1992-1995$ y 2006-2012, y por debajo en 1997-2004 y 2014-2016.

Así pues, el carácter contracíclico del gasto total en pensiones se ha debido, hasta ahora, a la superposición del efecto demográfico (que casualmente ha coincidido, en buena medida durante los últimos decenios, con el ciclo económico, contrarrestándolo, pero no tiene por qué coincidir en el futuro) y a las fluctuaciones observadas en el número de pensionistas asociadas al mismo a través de las variaciones en la edad de jubilación efectiva, aunque desde mediados de los años ochenta este efecto ha resultado tenue. $Y$ si del volumen de las altas volvemos al stock total de las pensiones, como se hace en el Gráfico 9, se observa que el gran determinante del número de pensiones es el contingente demográfico de los mayores de 60 años: en promedio para los últimos cuarenta años, la población de ese grupo de edades creció en 159. 000 personas por año transcurrido, el número total de pensiones, en 141.000 y el de pensiones de jubilación, en 104. 000, con tendencias lineales que ofrecen coeficientes de correlación próximos a 0,99 (algo menor en el caso de las jubilaciones, por causa del salto de 1997 , pero igualmente elevado, haciendo abstracción del mismo).

\section{3. ¿Son los estabilizadores automáticos una «distorsión keynesiana»?}

La evidencia empírica de los países de la OCDE ofrece una relación sistemáticamente negativa entre el tamaño del Gobierno (o sea, de los impuestos y las cotizaciones) y la volatilidad del consumo y el PIB. No resulta extraño, por cuanto el diseño de la moderna política de seguridad social por Beveridge y Keynes se inscribe en el esfuerzo de la época por disponer de herramientas sólidas para la gestión de la política de demanda agregada (MoududZacharias, 1999). En cambio, para la corriente dominante en la literatura sobre el ciclo económico, esta relación no aparecería de existir un sistema impositivo «no distorsionante», bajo el supuesto de expectativas racionales con equivalencia ricardiana y políticas regladas no discrecionales (Christiano, 1984).

Por el contrario, en el modelo de Andrés, Doménech y Fatás (2008), los efectos anticíclicos del tamaño del Gobierno aparecen $\triangleright$ 


\section{Álvaro Espina}

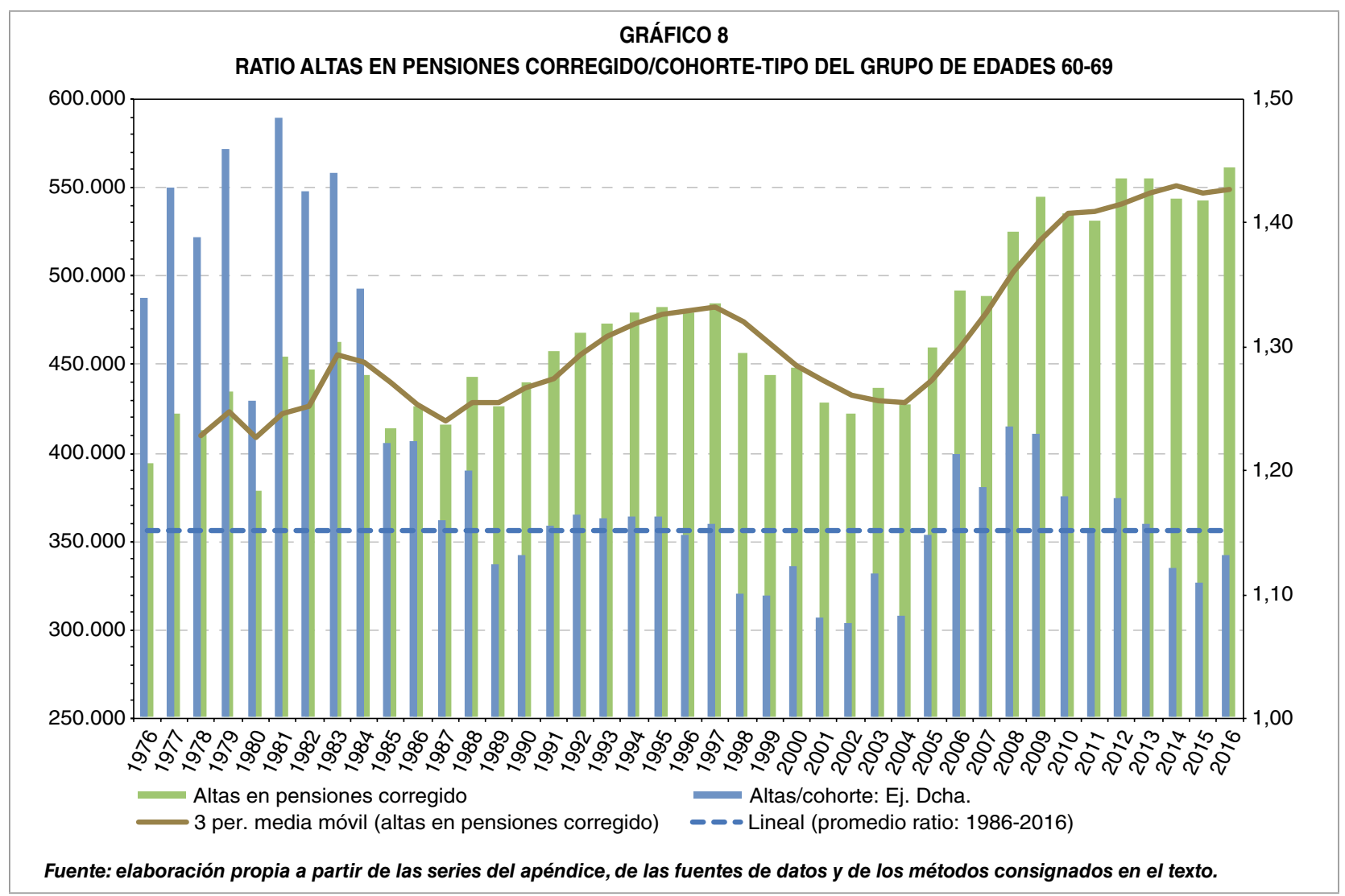

GRÁFICO 9

EL PESO DE LA DEMOGRAFÍA SOBRE EL SISTEMA DE PENSIONES: TRES TENDENCIAS

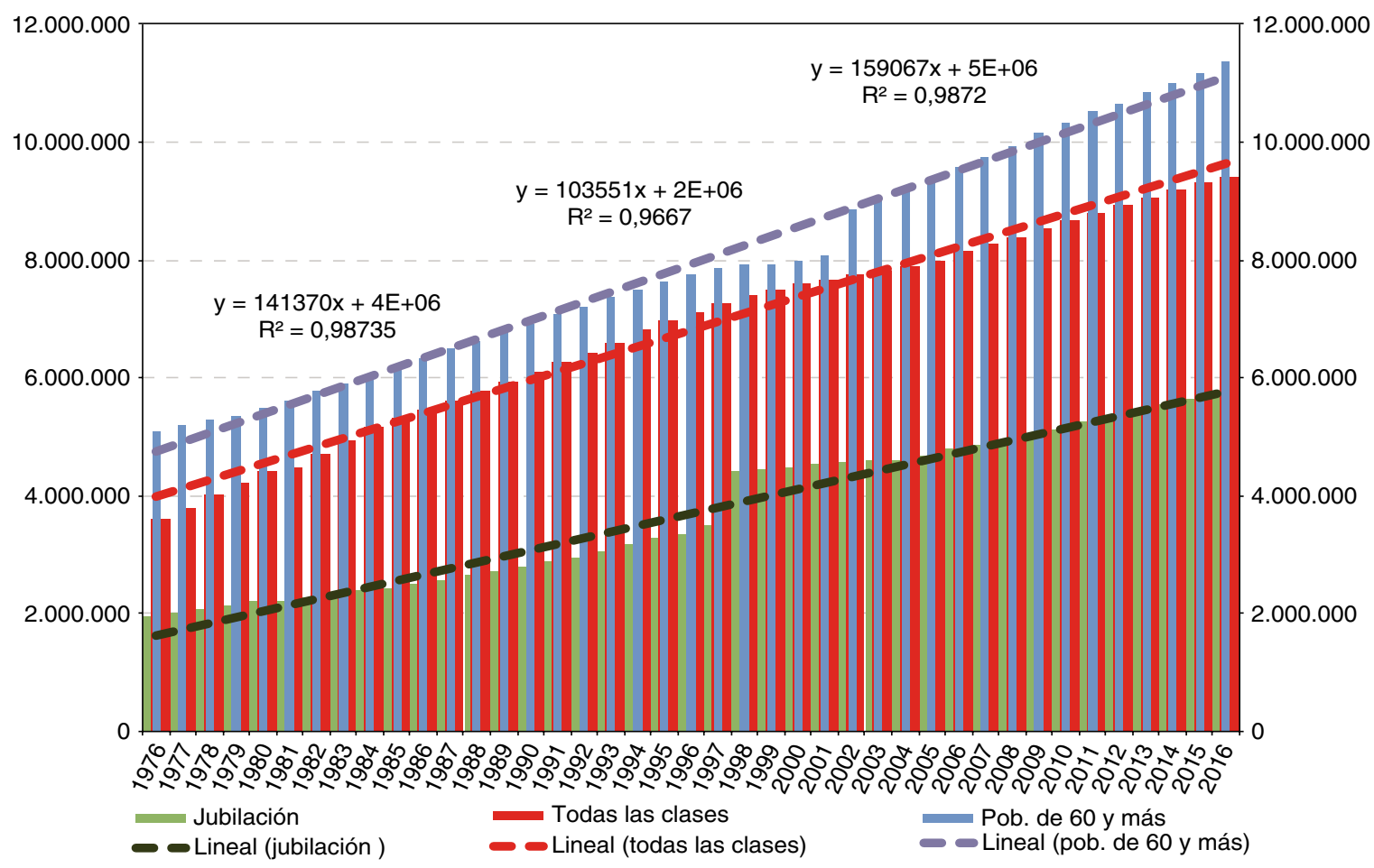

Fuente: elaboración propia a partir de las series del apéndice, de las fuentes de datos y de los métodos consignados en el texto. 
precisamente en la medida en que la economía opera con rigideces de precios nominales y salarios y con consumidores corrientes (no «ricardianos»), no así cuando se supone que la economía responde a los supuestos del ciclo económico real (RBC) y se analiza con el modelo DSGE genuino; esto es, solo los modelos keynesianos resultan aptos para explicar los estabilizadores automáticos que se observan en la realidad práctica, pero no la del RBC, impulsada por choques tecnológicos, que ni siquiera los estudiaba porque no son «eficientes» contra este tipo de choques (Christiano y Harrison, 1999). Bien es verdad que la gran recesión ha venido a modificar el panorama, ya que los multiplicadores se disparan con el tope del tipo de interés cero (Christiano et al., 2011), y en esas condiciones la consolidación fiscal puede ser políticamente prohibitiva (Alesina et al., 2017).

Para explicar la existencia de los estabilizadores automáticos con un modelo de tipo RBC, Janiak y Monteiro (2016) se ven obligados a dar un rodeo partiendo del supuesto de que la elasticidad de la oferta de trabajo de los jóvenes y mayores es muy superior a la de la población en edades plenamente activas (prime age), y sobre aquellos grupos recae el mayor peso de la adaptación entre oferta y demanda a lo largo del ciclo. A continuación, apelan al efecto «distorsionante» de los impuestos y las cotizaciones sociales sobre la oferta de trabajo de los jóvenes y los mayores, mucho menor -en su opinión-, cuanto mayor es el tamaño del Gobierno. Pero como el peso de tales grupos es más reducido cuanto mayor es la fiscalidad, la elasticidad de la oferta de trabajo también lo es, disminuyendo la capacidad del sistema para adaptarse a las fluctuaciones macroeconómicas. De modo que, según esta interpretación, la aparición de los estabilizadores sería imputable al «efecto distorsionante» de la fiscalidad.

Lo que sucede es que en el caso de España esta supuesta superior elasticidad de los activos de mayor edad no aparece por ningún lado, dada la estabilidad de las edades de jubilación que se observaba en el Gráfico 6, de modo que la participación de este grupo en la población activa no afecta para nada a la capacidad de adaptación cíclica de la oferta a la demanda de trabajo. Es más, contra una opinión bastante generalizada, la tasa de actividad de la población entre 50 y 65 años no ha dejado de crecer últimamente (Gráfico 10): la de 50-54, en más de 26 puntos porcentuales desde 1986; la de 55-59, en 25 puntos desde 1995, y la de 6064, en 11 puntos desde 1999. Además, según la proyección del INE, los dos primeros grupos crecerán de nuevo tres puntos hasta 2029.

En cambio, en lo que se refiere a las edades más jóvenes, sí parece existir un cierto grado de adaptación al ciclo, aunque con ciertos desfases temporales, especialmente visible en las dos desviaciones en forma de joroba que presenta la curva efectiva de las tasas de actividad de los jóvenes entre 20 y 24 años con respecto a su tendencia lineal durante las dos etapas de auge (1986-1993 y 2002-2012) y los tres valles, coincidentes grosso modo con las etapas de baja cíclica (1977-1986, 1994-2002, 2013...). Estos movimientos de «sobreanimación» y «desánimo», derivados obviamente de las fluctuaciones en la tasa de desempleo, aparecen también, aunque suavizados, en la curva de tasas de actividad de los jóvenes adultos, con edades entre 25 y 29 , y en la de los más jóvenes, aunque en este caso la desviación al alza solo se observa en la cresta que culmina en 2008, mientras que durante el período anterior la desviación a la baja desde 1985 aparenta deberse más bien a la tendencia hacia $\triangleright$ 


\section{Álvaro Espina}
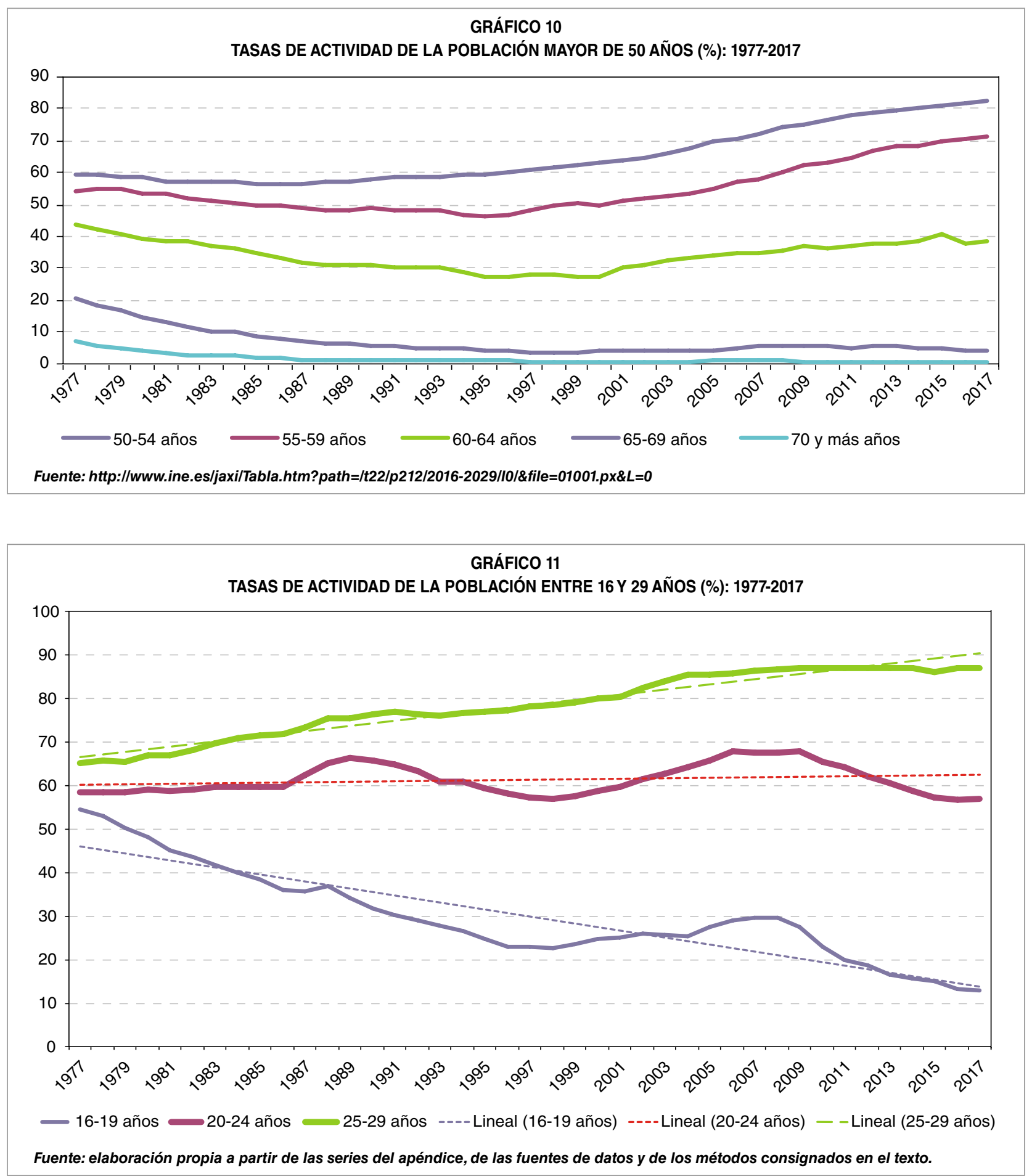

la prolongación de la edad de escolarización, interrumpida momentáneamente por la burbuja del siglo XXI (Gráfico 11).

No merece la pena dedicar más tiempo a falsar la hipótesis antikeynesiana para explicar la existencia evidente de estabilizadores automáticos $^{12}$. En el caso de España, la contribución de las cotizaciones y prestaciones $\triangleright$

12 En general, Bassanini (2011) concluye que dentro de la OCDE los efectos contracíclicos combinados de la fiscalidad y las políticas de transferencias de ingresos y de mercado de trabajo dependen de un adecuado equilibrio que evite prolongar las recesiones por una sobrecarga de fiscalidad, impulse la eficiencia y neutralice los efectos adversos de la regulación restrictiva sobre el empleo. 
del sistema de bienestar para contrarrestar los efectos del ciclo económico, reduciendo su volatilidad, puede observarse en los Gráficos 12 y 13, en los que se representa la evolución de estos dos agregados macroeconómicos, medidos en términos de Contabilidad Nacional.

\subsection{Los sistemas de pensiones y desempleo y los estabilizadores automáticos}

En el Gráfico $12^{13}$ se observa el juego de estabilizadores automáticos representado por la combinación del conjunto de la recaudación por cotizaciones ligadas a prestaciones sociales y

13 Con los datos del Cuadro A-4. Para el Gráfico 13: Cuadro A-5. el gasto en las prestaciones correspondientes: hasta 1991 la relación entre unas y otras resulta básicamente equilibrada; entre 1992 y 1997 es deficitaria, alcanzando un desnivel de $6.600 \mathrm{mi}$ llones de euros en 1993, para pasar a recaudaciones superavitarias durante el decenio 19982008, con niveles máximos de superávit en torno a 13.000 millones en 2006-2007. En cambio, los déficits reaparecen en 2009 y alcanzan su máximo en torno a 42.000 millones de euros al año durante el bienio 2012-2013, continuando durante el bienio subsiguiente por encima de 37. 000 millones. En proporción al gasto total en prestaciones, estas fluctuaciones suponen que antes de la gran recesión durante las etapas de auge las cotizaciones superaban al nivel de gasto hasta alcanzar máximos entre el 10 por 100 y el 13 por 100 (como sucedió en 19791980 y 2001-2007), mientras que los déficits $\triangleright$

GRÁFICO 12

COTIZACIONES SOCIALES Y PRESTACIONES LIGADAS (CONTABILIDAD NACIONAL)

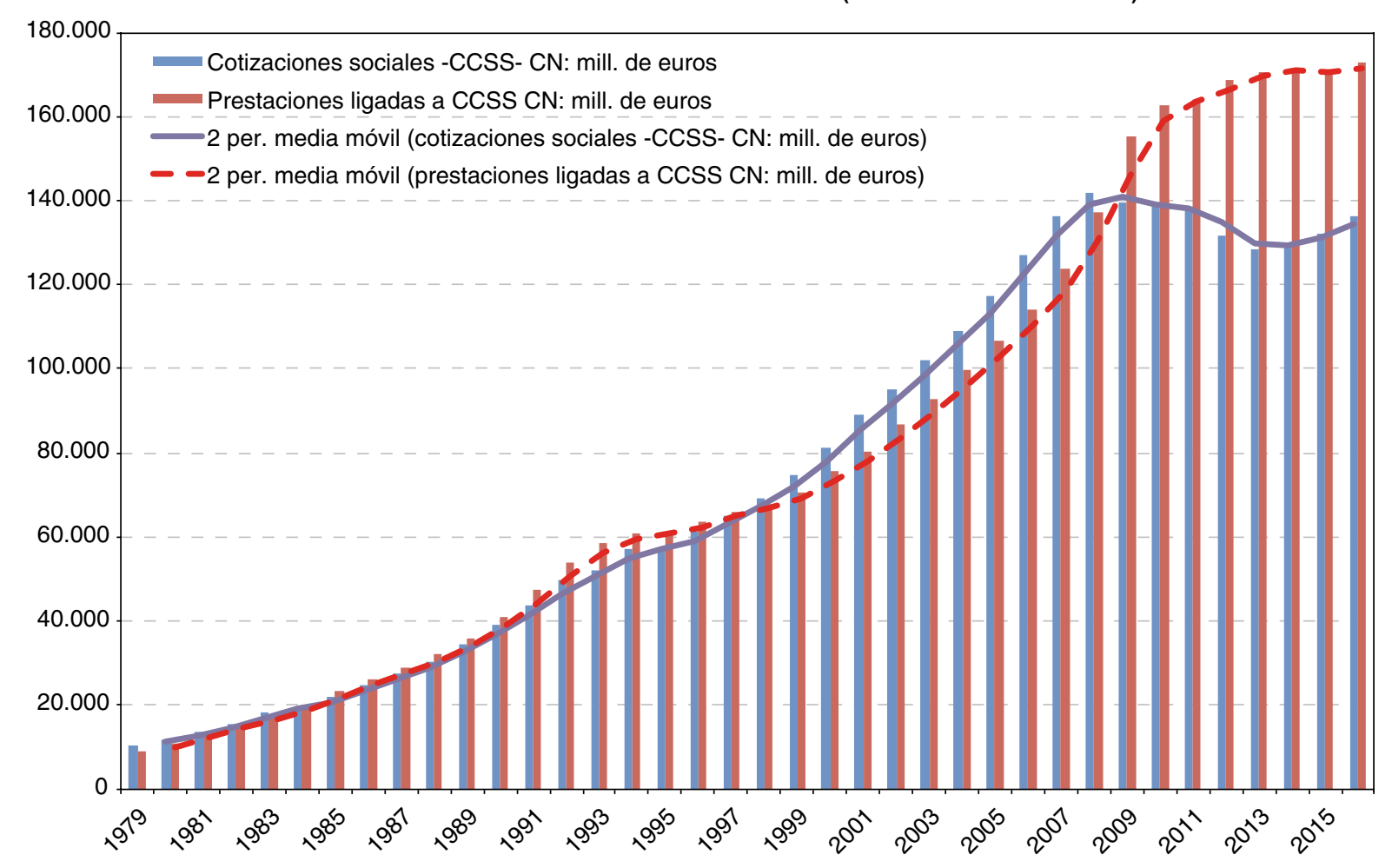

Fuente: elaboración propia a partir de las series del apéndice, de las fuentes de datos y de los métodos consignados en el texto. 
durante las recesiones se situaban a ese mismo nivel (como el máximo del 11,2 por 100 registrado en 1993). En cambio, la gran recesión ha significado un salto cualitativo sin precedentes, situándose ya el déficit de 2009 en torno al 10 por 100 , creciendo paulatinamente hasta llegar a suponer la cuarta parte del gasto en 2013 y permaneciendo por encima del 20 por 100 todavía en 2016.

Midiendo todo ello como proporción del PIB, obtenemos el Gráfico 13, que parece extraído de un manual de política keynesiana, de tan ajustados como resultan los comportamientos de déficit y superávit en relación con las crestas y bajas cíclicas. La excepción se produjo durante el período 1985-1991, en que el déficit resultó procíclico y, tras el cambio de coyuntura, tuvo que ser compensado con la elevación de un punto porcentual en el tipo de cotización por desempleo en 1992 y 1993, situándolo en el 7,3 por 100 (aumentando todavía medio punto más entre 1994 y 1999, hasta situarse en el 7,8 por 100 de la base de cotización: con una relación empresa/trabajador de 6,2 por $100 / 1,6$ por 100$)^{14}$, agudizando con ello el empuje procíclico de las mismas en plena crisis.

Sin embargo, tras alcanzarse el máximo histórico de cotizaciones en 1993 (con un 13,45 por 100 del PIB), ya en 1995 trató de compensarse este lastre procíclico reduciendo en un punto los tipos de cotización del conjunto del sistema ${ }^{15} \triangleright$

\footnotetext{
14 El tipo empresarial aumenta y se sitúa desde entonces en el 6,7 por 100 para los contratos temporales, y en el 7,7 por 100 si además son a tiempo parcial; en ambos casos el trabajador abona el 1,6 por 100.

15 Situándose desde entonces el tipo de cotización por contingencias comunes al Régimen General en el 28,3 por 100: 23,6 por 100 a cargo de la empresa y 4,7 por 100 a cargo del trabajador. La cotización por accidentes de trabajo y enfermedades profesionales varía para las diferentes actividades según el tipo de riesgo. Las primas se mantuvieron fijas desde 1979 hasta 2006. Desde 2007 son las establecidas por la Ley 42/2006 (con un mínimo de 0,9 por 100 , en confección o fotografía, y un máximo de 7,15 por 100 en minas y actividades extractivas).
}

GRÁFICO 13

COTIZACIONES Y PRESTACIONES LIGADAS (\% DEL PIB), CONY SIN DESEMPLEO

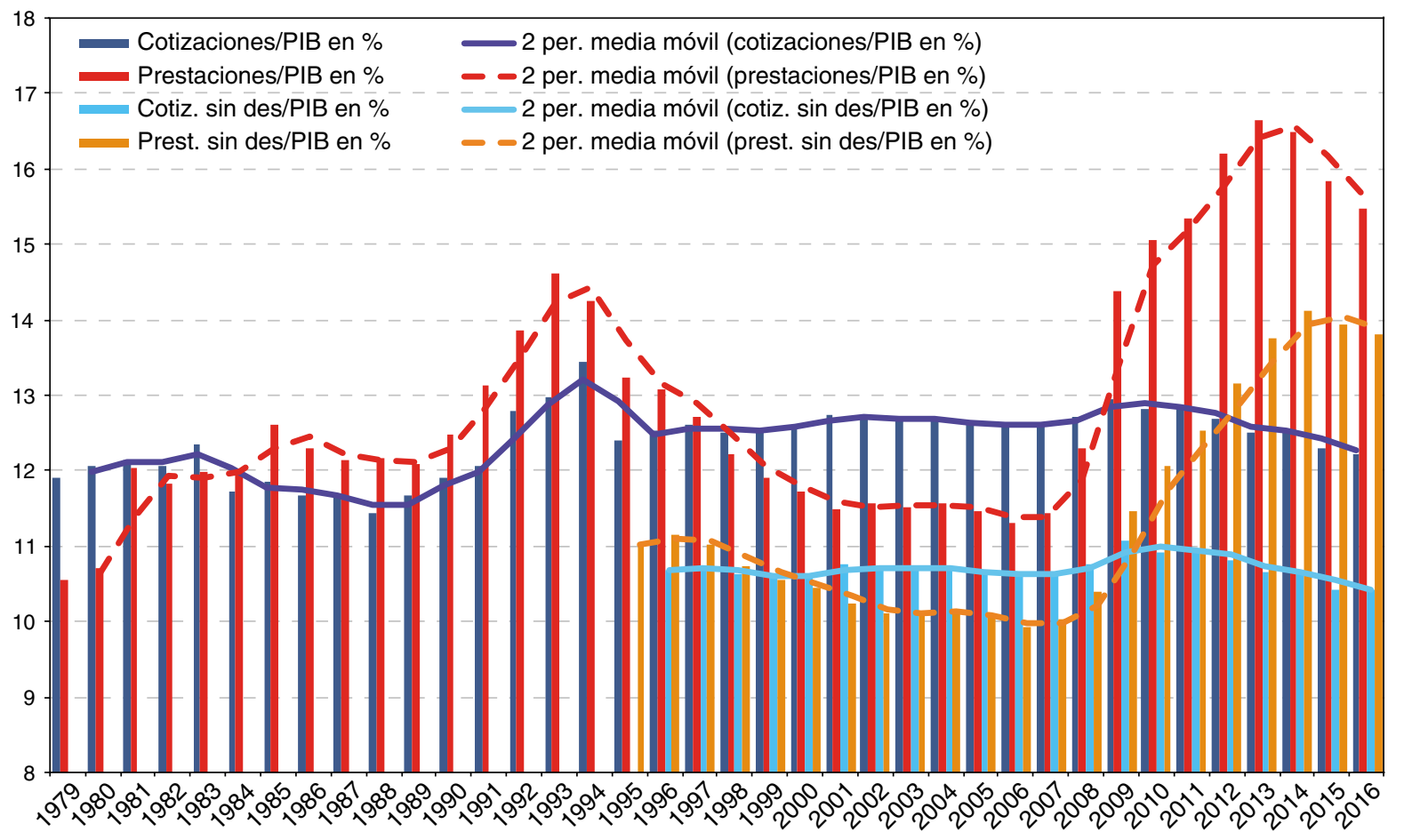

Fuente: elaboración propia a partir de las series del apéndice, de las fuentes de datos y de los métodos consignados en el texto. 
(aunque no los del desempleo) ${ }^{16}$, con la consiguiente caída de la recaudación, que tuvo efectos estabilizadores y anticipó la recuperación de 1996, inaugurando una larguísima etapa de estabilidad en la ratio cotizaciones/PIB que no flexionaría hasta 2011, cayendo en 0,73 puntos porcentuales entre 2009 y 2016.

\subsection{Las pensiones han actuado como estabilizador automático por «una sola vez»}

Del conjunto de contingencias en que las prestaciones se asocian a las cotizaciones, las más claramente contracíclicas son las prestaciones por desempleo, que alcanzaron máximos históricos del 3 por 100 del PIB entre 2009 y 2013 (3,05 por 100 en 2012). En el Gráfico 13 se observa, sin embargo, que al separar las series con y sin desempleo el poderoso efecto contracíclico del déficit cotizaciones/prestaciones se mantiene cuando el derivado del desempleo empieza a ceder, e incluso cuando desaparece en 2015, año en que la cifra de déficit, una vez excluida la contingencia por desempleo, alcanza el máximo histórico: 3,52 por 100, frente a un máximo total del 4,15 por 100 en 2013 de la serie con todas las contingencias (Cuadros A-4 y A-5).

La aportación parcial de las pensiones a este déficit se debe, por un lado, al fenómeno ya observado del rápido ascenso de la base demográfica, el cual, aunque en esta ocasión haya actuado como estabilizador automático, no lo hará en el futuro, dado que, según las proyecciones del INE (2017), el grupo de edades

16 Desde el 1/01/2000 hasta 30/06/2006 el tipo de cotización de trabajador se situaría en 1,55 por 100 y el de la empresa en 6,0 por 100: un 7,55 por 100 en total. A partir de esa fecha el tipo del trabajador no ha variado y el de la empresa se redujo a un 6 por 100 en 2006 y a un 5,5 por 100 en 2008, permaneciendo estable desde entonces en un tipo total del 7,05 por 100. El de cotización a FOGASA es del 0,2 por 100 y el de formación profesional, del 0,7 por 100. comprendido entre 60 y 69 años, del que se nutren las altas en las pensiones, resultando ser el principal determinante de su crecimiento, aumentará hasta 2038 aproximadamente en dos millones de personas, creciendo en un 43 por 100 y pasando de algo menos de cinco millones a algo más de siete (creciendo en un millón cada decenio), lo que sin duda presionará sobre el alza continuada de las pensiones, en cualquier coyuntura cíclica (Gráfico 14)17.

El segundo determinante de la evolución de los estabilizadores automáticos asociados al desequilibrio entre prestaciones y cotizaciones es la menor volatilidad que viene observándose en la recaudación de cotizaciones más que en el volumen de prestaciones, pese a las fuertes fluctuaciones en el número de altas en pensiones observado en los Gráficos 3 a 8 . Ello se debe a dos fenómenos complementarios.

El primero es la caída de las cotizaciones durante las recesiones duraderas, ya que, aunque los desempleados y el SPEE siguen cotizando por la misma base reguladora durante el período de percepción de la prestación por desempleo, solo lo hacen por las contingencias comunes y dejan de hacerlo al pasar a percibir el subsidio -excepto los mayores de 55 años, que cotizan por la base mínima, y los acogidos a convenios especiales con la Seguridad Social, que lo hacen por la base establecida en ellos-.

Además, las fluctuaciones cíclicas también producen movimientos de animación y desánimo en las tasas de actividad de las edades centrales, correlacionados negativamente con el desempleo, elevando o mermando su participación en el mercado de trabajo y sus cotizaciones (sobre todo en las edades por debajo de 50 años, mientras que la de los mayores $\triangleright$

17 http://www.ine.es/jaxi/Datos.htm?path=/t20/p270/2012-2052/ 10/\&file $=01001 . p x$ 


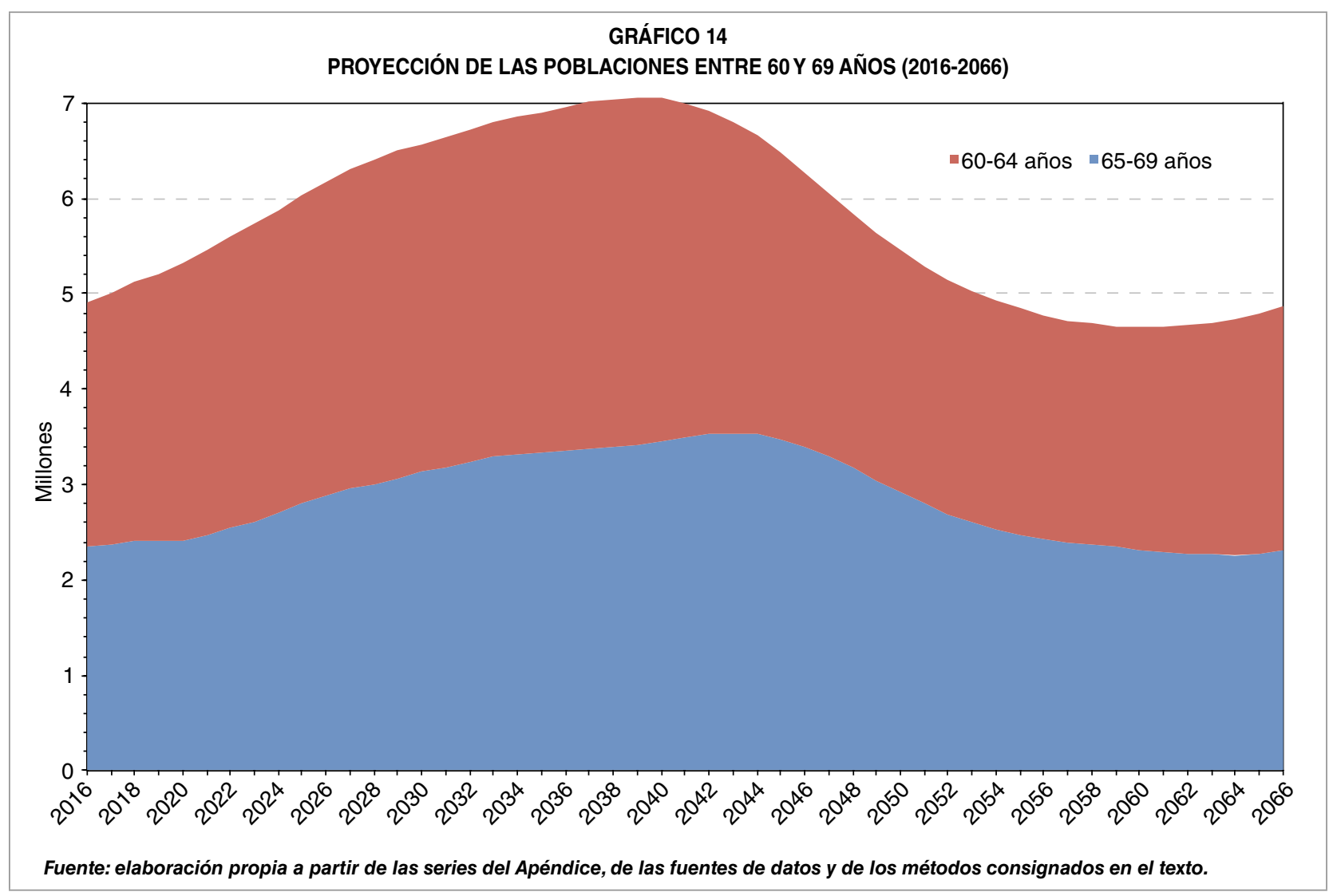

se rigen más bien por la tendencia de largo plazo, sin apenas inflexiones cíclicas, como se observa en el Gráfico 15). Por el contrario, las prestaciones por desempleo se disparan durante la recesión y se repliegan rápidamente con la expansión, como acabamos de ver. $\quad \square$

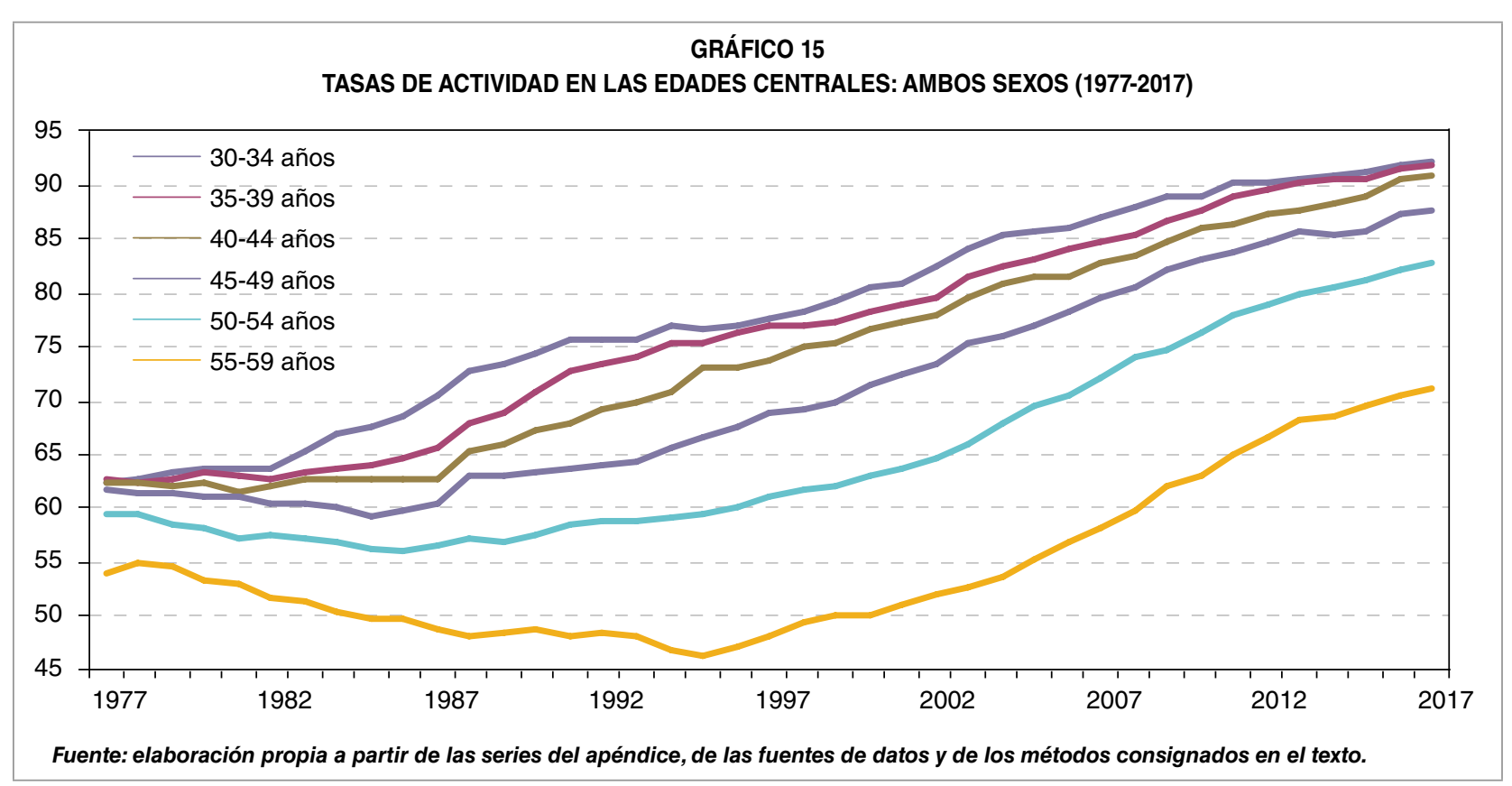




\subsection{Las tendencias de la tasa de sustitución pensión/salario y de sus componentes}

El otro factor compensatorio lo ha venido introduciendo la tendencia sistemáticamente creciente que se observa en la evolución de los importes medios de las pensiones. Aunque estas series experimentan una leve incidencia de las fluctuaciones cíclicas más duraderas —como se verá más adelante-, su evolución se mueve sobre todo también a impulsos de la tendencia de largo plazo, e incluso llega a tener un componente procíclico en las crisis más duraderas, como es el caso de la última, al reducirse sustancialmente las cotizaciones de los desempleados de larga duración en la etapa de prejubilación, cuando la fase de baja cíclica resulta ser muy prolongada, lo que reduce su derecho a pensión. Conviene por ello observar estas tendencias.

El indicador sintético más adecuado para observar la tendencia del importe medio de las pensiones en un sistema de reparto como el español -con prestaciones definidas en relación con la base de cotización- no es la cifra bruta, sino la tasa de sustitución pensión/salario, que mide por un lado el grado de sustitución que aporta la pensión respecto a las rentas salariales de los activos, distribuyendo la renta disponible a lo largo del ciclo vital, y por otro lado mide la carga que significa el aumento del pago de cada pensión en relación con el salario que sirve como base de cotización.

El Gráfico 16 y el Cuadro A-3 ${ }^{18}$ presentan las tasas de sustitución pensión/salario de

18 En el que las pensiones/mes son medias/año de la serie del INSS: https://explotacion.mtin.gob.es/series/ (Cuadro A-2). El coste salarial ordinario por trabajador y mes (total sectores) es el promedio anual de la encuesta trimestral de coste laboral de INE (Serie BDSICE: «460350») extrapolada hasta 1981 con las variaciones de la serie anterior de "pagos ordinarios por trabajador y mes (Serie BDSICE: «460000h»). cuatro clases de pensiones en el conjunto del sistema y en el Régimen General. Las menos elevadas son las de pensiones de viudedad en el conjunto del sistema (pese al repunte que experimentaron en 20022004 como consecuencia de la elevación al 46 por 100 de la base reguladora, realizado en 2001 -y hasta el 70 por 100 , en los casos con menores ingresos y mayores cargas familiares- ${ }^{19}$, y al nuevo aumento hasta el 52 por 100 , realizado en 2003 , como consecuencia de lo cual la tasa de sustitución de estas pensiones respecto al salario ordinario aumentó en cinco puntos porcentuales desde comienzos de 2000 hasta 2005) ${ }^{20}$. En el gráfico pueden observarse también las irregularidades en la serie de importes medios de las pensiones por incapacidad permanente, como consecuencia de los cambios de la definición y clasificación de estas pensiones cuando los beneficiarios cumplen 65 años y de la reclasificación en el año 2002 de las pensiones por accidentes de trabajo y enfermedades profesionales a partir de esa edad.

Como es lógico, las tasas de sustitución sistemáticamente más elevadas son las de jubilación en el Régimen General, que se situaron en el 72,6 por 100 en 2016, seguidas en los últimos años por las pensiones de jubilación en el conjunto del sistema $(63,7$ por 100) y de la pensión media en el RG $(61,1$ por 100). En la zona intermedia se sitúan las pensiones por incapacidad permanente $\triangle$

19 Hasta 2001 la cuantía de esta pensión venía regulada por el artículo 31 del Decreto 3158/1966, de 23 de diciembre, que la fijaba en el 45 por 100 de la base reguladora (y en el 60 por 100 si el causante había sido pensionista de vejez o invalidez, en cuyo caso la base reguladora era la pensión).

20 Véanse los RD 1465/2001, de 17 de diciembre, y 1795/2003, de 26 de diciembre. La nueva elevación paulatina a lo largo de ocho años hasta el 60 por 100 de la base reguladora para pensionistas mayores de 65 años con una sola pensión pública, adoptada en 2011, se encuentra suspendida como consecuencia de la crisis. 


\section{Álvaro Espina}
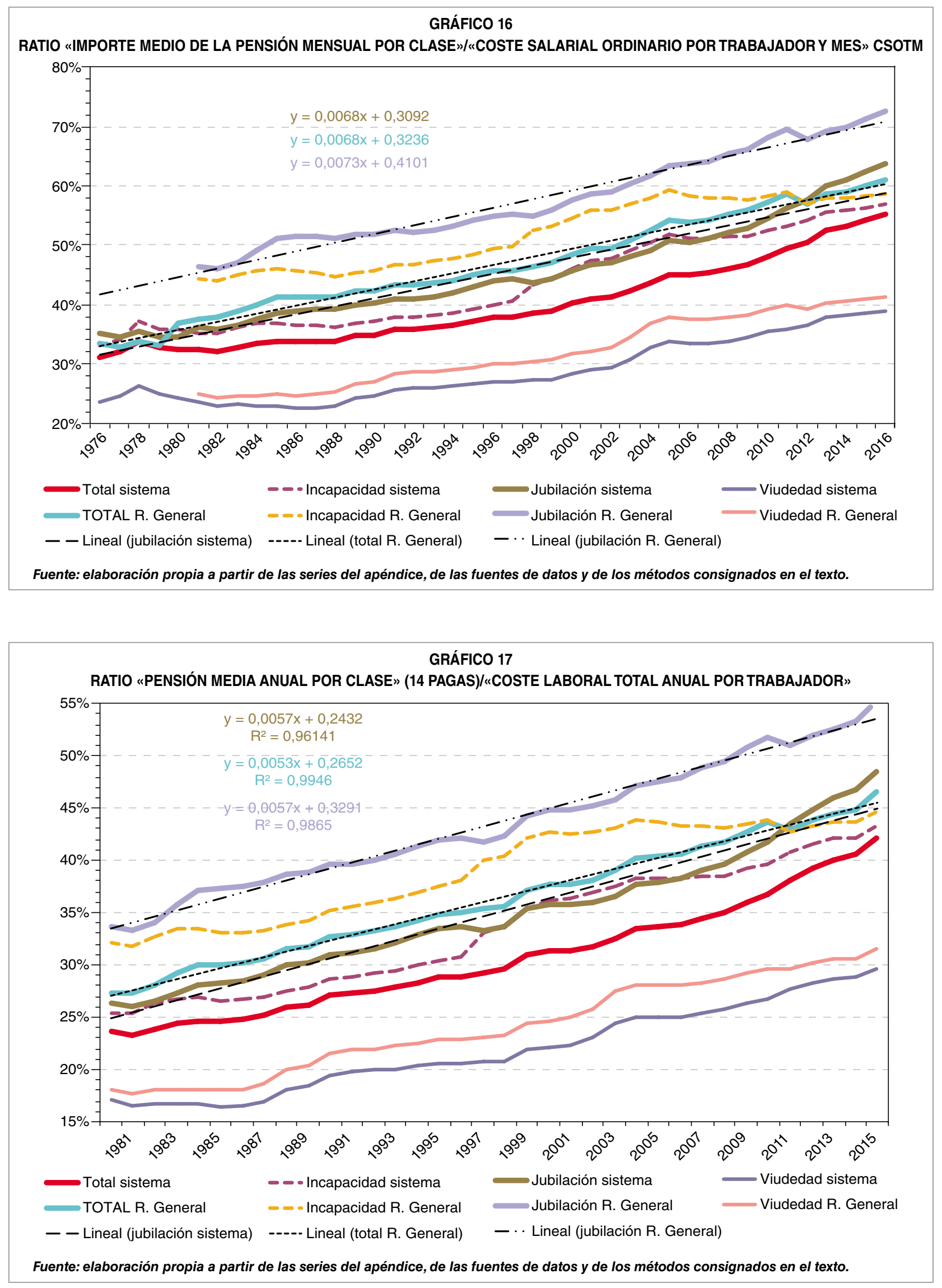
(58,6 por 100 y 56,8 por 100$)$, algo por encima de la pensión media del conjunto del sistema $(55,2$ por 100$)$, mientras que las de viudedad se sitúan en el 41,4 por 100 y el 39 por 100 , respectivamente.

El Gráfico 16 calcula la tasa de sustitución con relación al «coste salarial ordinario por trabajador y mes» (CSOTM), que es el concepto más próximo al de salario mensual y el que suele utilizarse para las comparaciones sobre pensiones con beneficios definidos. En ambos casos el importe medio consiste en catorce pagas anuales. En cambio, el Gráfico $17^{21}$ calcula la ratio de sustitución de la pensión anual con respecto al coste total anual por trabajador, que incluye las cotizaciones empresariales (por un 31,25 por 100), lo que rebaja las tasas de sustitución en la misma proporción, con una horquilla entre el 55,3 por 100 y el 29,7 por 100 (partiendo de otra de entre el 33,6 por 100 y el 17,2 por 100 en 1981).

El análisis de la evolución del numerador de la tasa de sustitución de las pensiones se realiza gráficamente en las dos imágenes del Gráfico 18. En la primera, referida a la pensión media anual del sistema, se observa que el importe de las altas se desacelera antes y más rápidamente que el de las bajas a partir de 2009-2010, de modo que la desaceleración de importe medio del stock total de pensiones resulta sistemático a partir de 2009.

El Gráfico 18B, que representa la evolución de los importes anuales de las pensiones de altas y bajas definitivas en el sistema,

21 En donde las pensiones son las del Gráfico 5 convertidas en cifra anual (multiplicando por 14). El coste laboral total anual por trabajador (total sectores) es el resultado de multiplicar por doce la serie del mismo nombre (por mes) de la encuesta de coste laboral del INE (Serie BDSICE: «460000»), extrapolada hasta 1981 con la serie anterior de «pagos totales por persona y mes (Serie BDSICE: «460000h»), ya que estas series distribuyen los costes en doce meses. Los mismos procedimientos se aplican en los Gráficos 18 y 19. muestra que las tendencias polinómicas de unas y otras tienden a neutralizarse, lo que permite detectar una tendencia lineal muy firme $\left(R^{2}=0,989\right)$ para la serie temporal del importe medio de las pensiones del sistema, según la cual cada año que transcurre esta pensión anual ha aumentado en 377,6 euros (cifra que se elevaría hasta 473,9 euros si solo computáramos la tendencia más reciente, desde 2000).

El Gráfico 19 compara la evolución de las pensiones de jubilación del sistema con las fluctuaciones en los costes laborales totales, lo que permite contrastar la firmeza de la tendencia lineal a muy largo plazo. Estas pensiones han venido aumentando en 381,56 euros/ año, aunque la tendencia se ha desacelerado algo en el período del siglo xxI, lo que parece deberse a que el sistema se acerca a su etapa de madurez y puede estar alcanzando su velocidad de crucero. Esto se produce igualmente en las pensiones medias totales (cuyo importe ha aumentado en 354.72 euros/año). En cambio, el coste laboral permanece casi constante desde 2009 (lo que ha repercutido a la baja en las altas en pensiones del Régimen General y mucho más en la recaudación por cotizaciones).

Finalmente, el Gráfico 20 traduce los crecimientos absolutos de las pensiones a tasas de crecimiento anual. Haciendo abstracción de las fluctuaciones cíclicas, la línea de tendencia logarítmica indica claramente que desde finales de los años setenta la evolución de estos importes se ha relacionado fundamentalmente con la marcha de la inflación: pasando de tasas del 30 por 100 en 1977 al 15 por 100 a comienzos de los ochenta y a tasas en torno al 2 por 100 en 2016. 
Álvaro Espina

GRÁFICO 18 A

IMPORTE MEDIO DE LA PENSIÓN ANUAL EN EL TOTAL DEL SISTEMA DE SEGURIDAD SOCIAL (STOCK, ALTASY BAJAS) Y MEDIAS MÓVILES BIANUALES

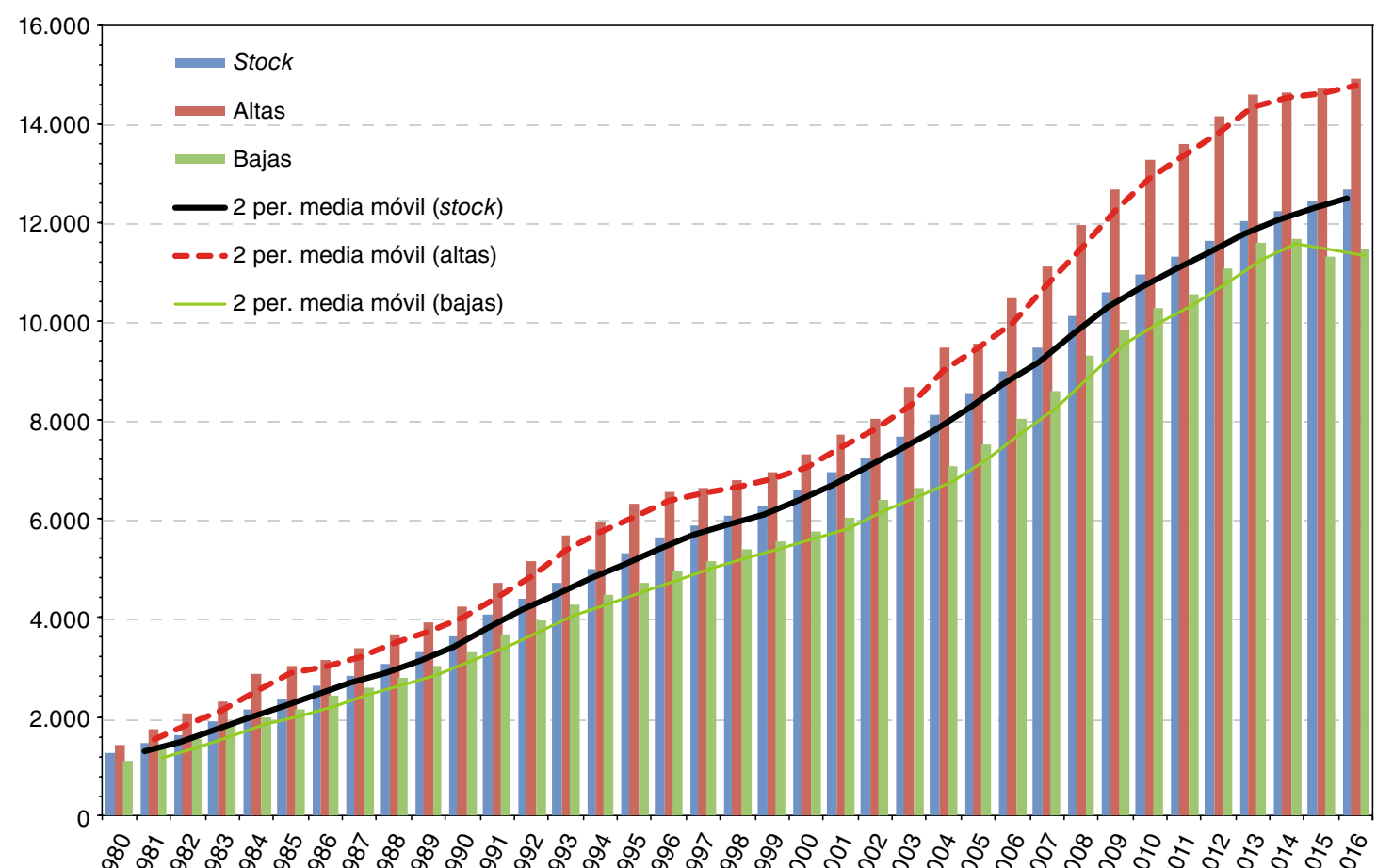

Fuente: construido con los datos del Cuadro A-6.

GRÁFICO 18 B

IMPORTE MEDIO SIMULADO DE LA PENSIÓN ANUAL DE JUBILACIÓN EN EL CONJUNTO DEL SISTEMA (STOCK, ALTASY BAJAS) Y TENDENCIA LINEAL PARA LAS TRES MEDIAS

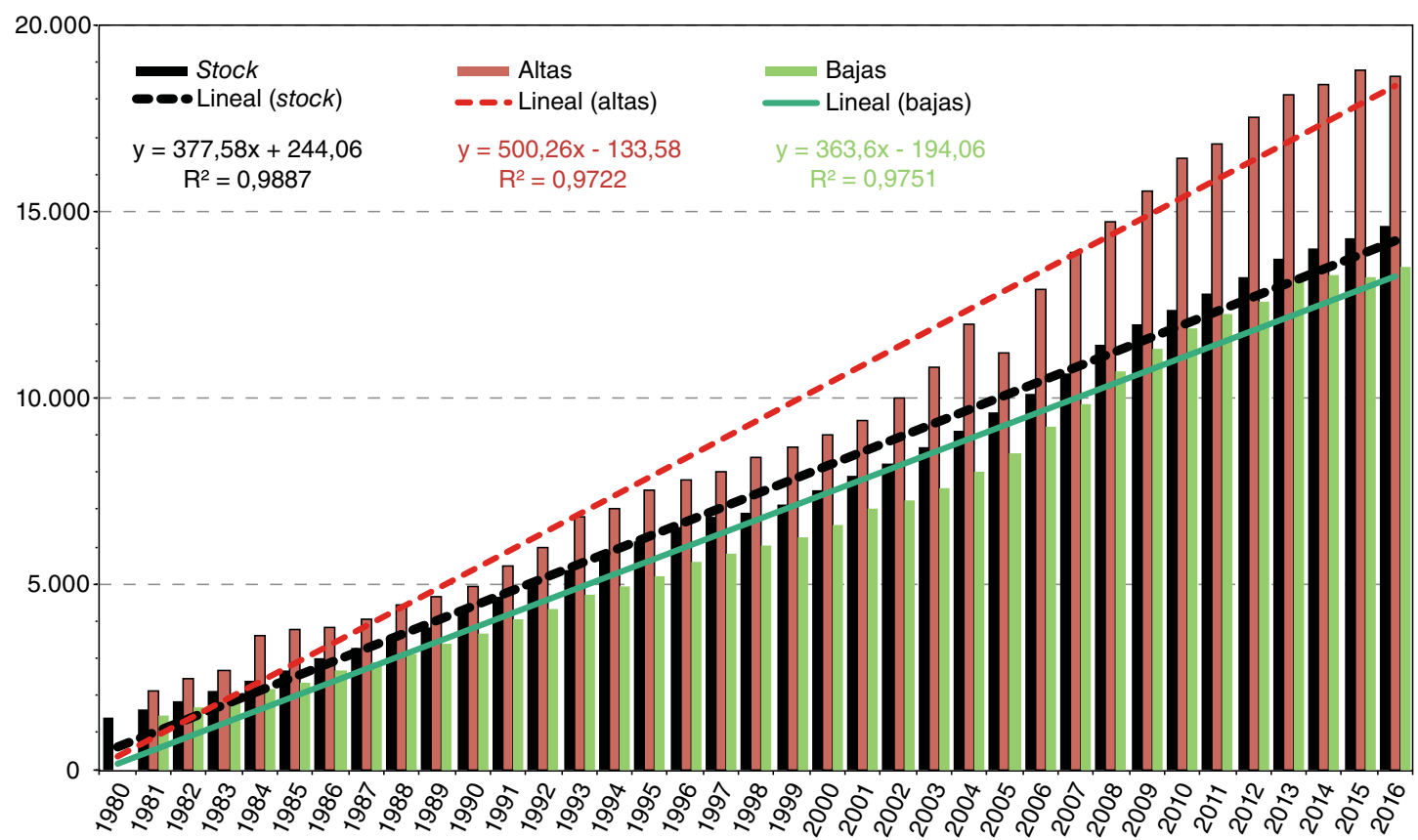

Fuente: construido con los datos del Cuadro A-7 

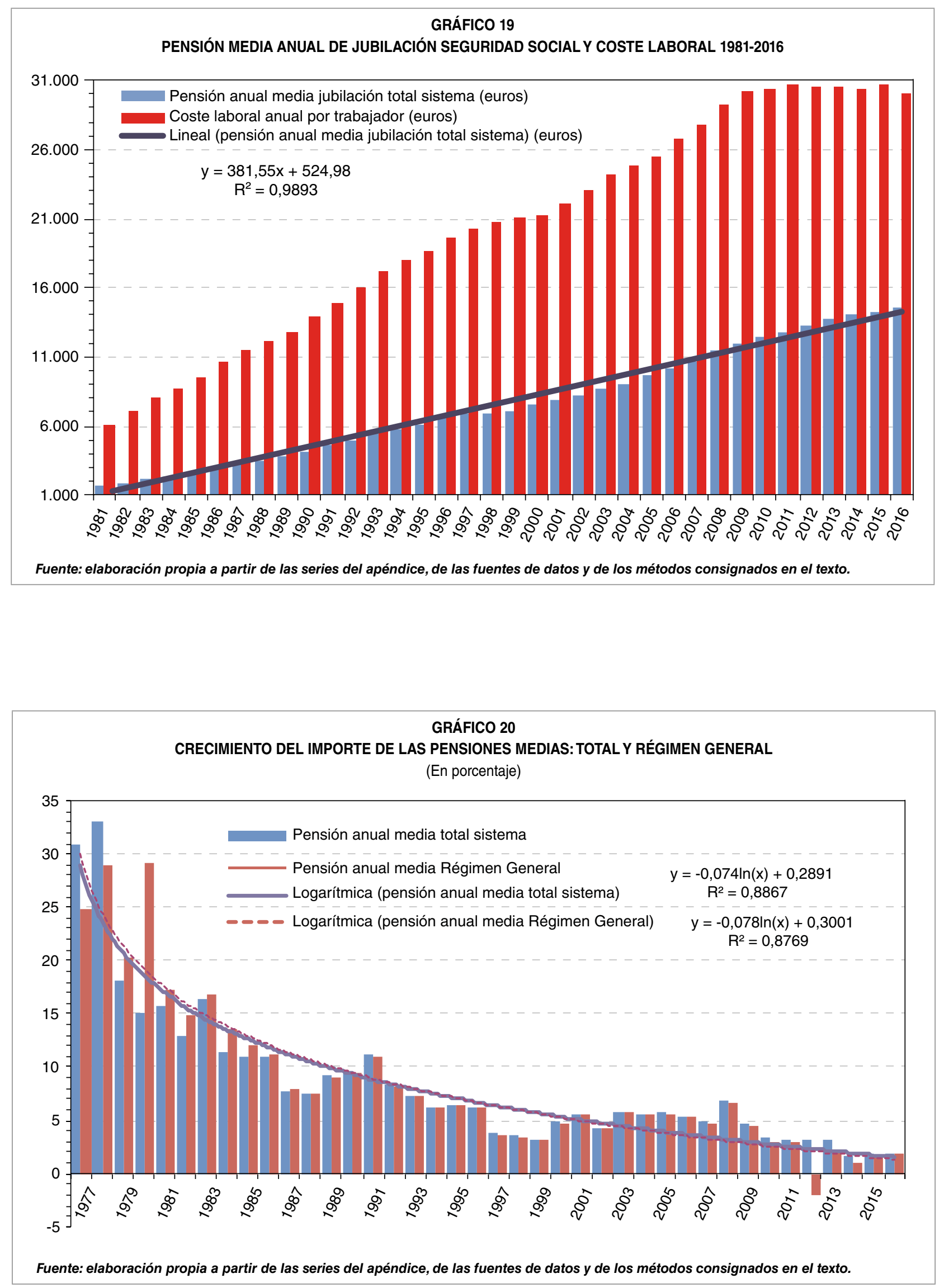


\subsection{La dinámica del gasto en pensiones: población, revalorización y «efecto composición»}

La evolución del gasto total en pensiones de cada año es el resultado de tres procesos: a) la revalorización de las pensiones que siguen en vigor; b) el "efecto sustitución», resultado de agregar el importe de las nuevas altas en pensiones multiplicado por el número de altas durante del año en curso y de sustraer el importe de las bajas en pensiones multiplicado por el número de bajas durante el año, y c) el crecimiento neto del número de pensiones, o «efecto población».
Esto es, siendo $G P_{t}$ el gasto total en pensiones del año $t$, denominando $P_{t-1}$ al número de pensiones del año anterior, $p_{t-1}$ al importe de cada una, $I R_{t}$ al índice de revalorización, $A_{t}$ al número de altas del año en curso, $B_{t}$ al número de bajas durante el mismo y $a_{t}$ y $b_{t}$ a los importes medios de las altas y las bajas, el gasto total del año en curso puede expresarse así:

[1] $G P_{t}=P_{t-1} \cdot p_{t-1} \cdot I R_{t}+A_{t} \cdot a_{t}-B_{t} \cdot b_{t}$

El número de pensiones del año en curso, $P_{t}$, es la suma de las del año anterior y el saldo en el número de altas y bajas:

IMPORTE MEDIO DE LAS PENSIONES: SIMULACIÓN DINÁMICA CON ALTAS/BAJAS* A) PENSIONES MENSUAL MEDIA Y DE JUBILACIÓN EN EL SISTEMA Y EN EL RÉGIMEN GENERAL

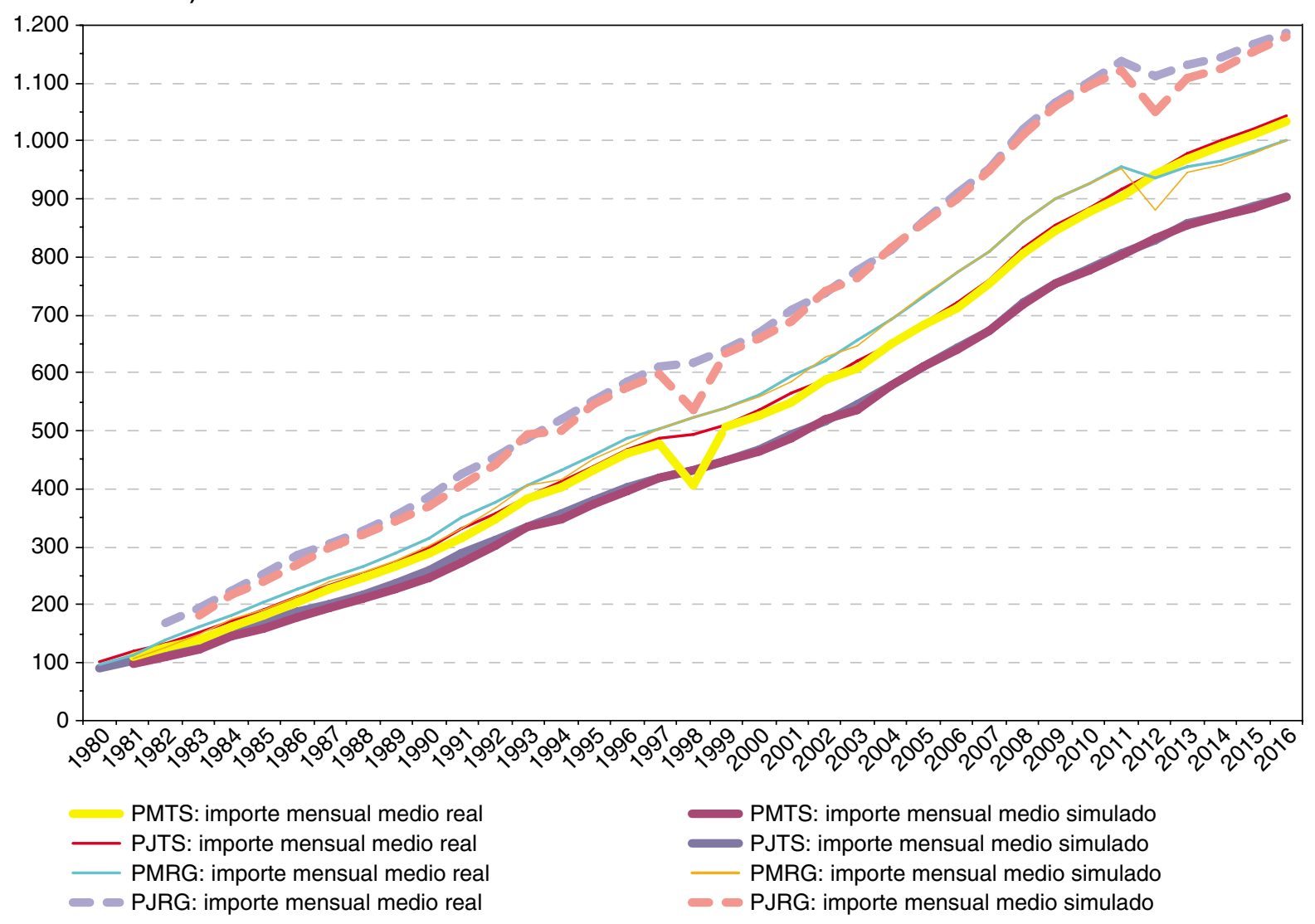

*TPTS = importe medio pensión del sistema; PJTS = importe medio pensión de jubilación del sistema. TPRG = importe medio pensión del R. General; PJRG = importe medio pensión de jubilación R. General.

Fuente: elaboración propia a partir de las series del apéndice, de las fuentes de datos y de los métodos consignados en el texto. 
[2] $P_{t}=P_{t-1}+A_{t}-B_{t}$

El importe medio de la pensión del año en curso, $p_{t,}$ equivale al cociente [1] / [2]:

[3] $p_{t}=G P_{t} / P_{t}=\left(P_{t-1} \cdot p_{t-1} \cdot I R_{t}+A_{t} \cdot a_{t}-B_{t} \cdot b_{t}\right) / P_{t}$

En las dos figuras del Gráfico 21 se compara la evolución de las series efectivas de pensiones medias (total y de jubilación; para el sistema y para el Régimen General), superponiéndolas a las series estimadas mediante [3] a partir de los Cuadros A-6 y A-7. Puede observarse la buena correspondencia, solo perturbada por la reclasificación de pensiones de incapacidad y jubilación en 1997-1998 y por la agregación en 2012 de los colectivos de empleados de hogar y asalariados agrarios en el
Régimen General (que incide también sobre la flexión de su tendencia). En la segunda figura del gráfico se estiman además las tendencias polinómicas de grado 2 de las series de pensiones (media y de jubilación) del sistema, con ajustes excelentes $\left(R^{2}=0,997\right)$.

Como ya se dijo, el crecimiento anual del gasto total en pensiones puede descomponerse en tres efectos: el de «población» $\left(E P_{t}\right)$, el de revalorización $\left(E R_{t}\right)$ y el de sustitución $\left(E S_{t}\right)$, definido este último como la «variación interanual de la pensión media del sistema en ausencia de revalorización” (o sea: $p_{t} / p_{t-1}$ para el caso de $I R_{t}=1$ ), de modo que:

[4] $E S_{t}=\left(P_{t-1} \cdot p_{t-1}+A_{t} \cdot a_{t}-B_{t} \cdot b_{t}\right) /\left(P_{t-1} \cdot p_{t-1}\right)$ $=1+\left(A_{t} \cdot a_{t}-B_{t} \cdot b_{t}\right) / P_{t-1} \cdot p_{t-1}$

GRÁFICO 21

IMPORTE MEDIO DE LAS PENSIONES: SIMULACIÓN DINÁMICA CON ALTAS/BAJAS*

B) TENDENCIAS DE LA PENSIÓN MENSUAL MEDIA Y DE JUBILACIÓN EN EL CONJUNTO DEL SISTEMA

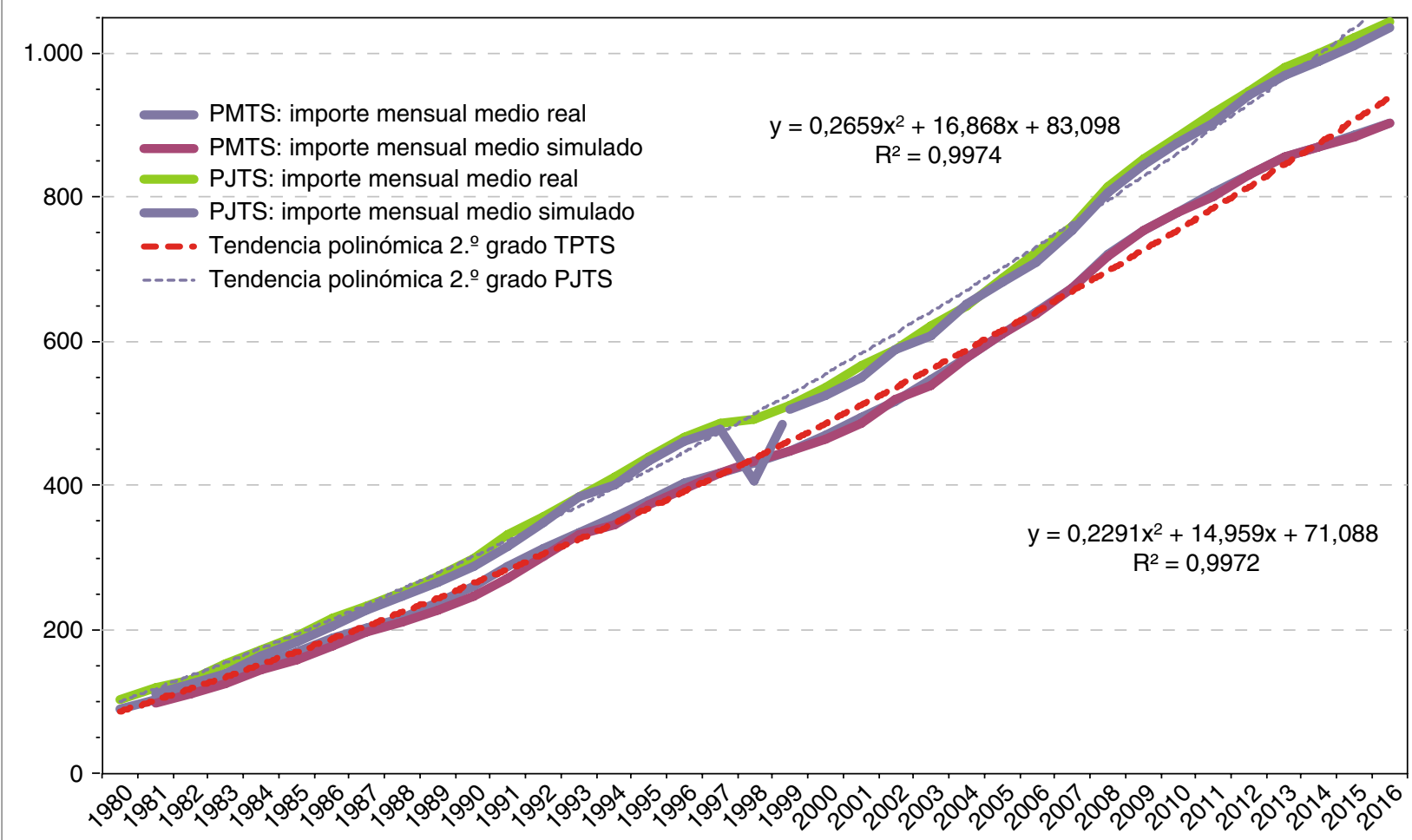

* TPTS = importe medio pensión del sistema; PJTS = importe medio pensión de jubilación del sistema.

TPRG = importe medio pensión del R. General; PJRG = importe medio pensión de jubilación R. General.

Fuente: elaboración propia a partir de las series del apéndice, de las fuentes de datos y de los métodos consignados en el texto. 
El «efecto población» se define fácilmente:

[5]

$$
E P_{t}=P_{t} / P_{t-1}=1+\left(A_{t}-B_{t}\right) / P_{t-1}
$$

Definiendo el crecimiento total del gasto en pensiones $\left(G P_{t} / G P_{t-1}\right)$ como el producto de los tres efectos ${ }^{22}$, el «efecto revalorización» queda definido residualmente (aunque también puede calcularse por cociente entre la pensión media del año en curso y la que resultaría en el caso de $\left.I R_{t}=1\right)^{23}$ :

$$
\text { [6] } \quad E R_{t}=G P_{t} /\left(G P_{t-1} \cdot E P_{t} \cdot E S_{t}\right)
$$

Los Cuadros 1 y 2, estimados a partir de las series $A-8$, ofrecen una visión panorámica de la evolución en grandes cifras del sistema español de pensiones contributivas durante los dos últimos decenios del siglo $\mathrm{xx}$ y los dos primeros del $\mathrm{xxI}$, lo que es tanto como

22 O la suma de los mismos, si trabajásemos con cifras en logaritmos.

23 Al calcular el efecto revalorización con carácter residual, como se hace el cuadro A-8, se acumulan en él los desajustes anuales derivados de los efectos de paga única por desviación del IPC, que aquí se contabilizan implícitamente cuando se abonan, y no con el criterio de devengo empleado por SESS (2015-16, p. 308). Además, se agregan también en el mismo los efectos de primeros pagos, las modificaciones de base reguladora para calcular la pensión de viudedad y por reconocimiento de la concurrencia de pensiones SOVI en 2005. decir del sistema de pensiones derivado de la Constitución de 1978. En síntesis, hasta el año 2000 el gasto total se multiplicó por 9 (por 10,8 las pensiones de jubilación). El Régimen General fue muy por delante, multiplicando su gasto por 14,9 (y por 12,1 las pensiones de jubilación). Para el período 2001-2016 la relación ordinal entre los diferentes múltiplos se mantiene, situándose todas las cifras relativas por debajo de 3: el gasto total se multiplicó por 2,4 (por 2,5 las pensiones de jubilación), y también fue por delante el Régimen General, multiplicando su gasto por 2,9 (y por 3 las pensiones de jubilación).

Hablando en términos de crecimientos acumulados y de tasas anuales, como se hace en estos cuadros, durante el siglo XXI (Cuadro 2) el número total de pensiones $\left(E P_{t}\right)$ creció un 24 por 100 (al 1,3 por 100 anual); el «efecto sustitución» $\left(E S_{t}\right)$ significó un crecimiento del 28 por 100 (1,5 por 100 anual) y el efecto de revalorización $\left(E R_{t}\right)$, un crecimiento equivalente a la suma de los otros dos efectos: un 51 por 100 (creciendo a tasas de 2,6 por 100 anual).

Este desequilibrio en favor de la contribución de la revalorización al crecimiento total $\triangleright$

CUADRO 1

\begin{tabular}{|c|c|c|c|c|c|c|c|c|}
\hline \multicolumn{9}{|c|}{ Descomposición en tres efectos: $\Delta$ acumulado y tasa anual (ambos en porcentaje) } \\
\hline \multicolumn{9}{|c|}{ Pensiones medias } \\
\hline & \multicolumn{4}{|c|}{ Total sistema } & \multicolumn{4}{|c|}{ Régimen General } \\
\hline & \multirow{2}{*}{ GP } & \multicolumn{3}{|c|}{ Efectos } & \multirow[b]{2}{*}{ GP } & \multicolumn{3}{|c|}{ Efectos } \\
\hline & & $\mathbf{E P}_{\mathrm{t}}$ & $E_{t}$ & $\mathrm{ES}_{\mathrm{t}}$ & & $\mathbf{E P}_{\mathrm{t}}$ & $E_{t}$ & $\mathrm{ES}_{\mathrm{t}}$ \\
\hline$\Delta$ Acumulado $\%$ & 802,2 & 72,8 & 228,1 & 59,1 & $1.393,2$ & 152,6 & 223,7 & 82,6 \\
\hline Tasa anual $\Delta \%$ & 14,7 & 3,5 & 7,7 & 2,9 & 18,4 & 6,0 & 7,6 & 3,8 \\
\hline \multicolumn{9}{|c|}{ Pensiones de jubilación } \\
\hline & \multicolumn{4}{|c|}{ Total sistema } & \multicolumn{4}{|c|}{ Régimen General } \\
\hline & \multirow{2}{*}{ GP } & \multicolumn{3}{|c|}{ Efectos } & & \multicolumn{3}{|c|}{ Efectos } \\
\hline & & $E P_{t}$ & $E_{t}$ & $E_{t}$ & GP & $E P_{t}$ & $E_{t}$ & $E_{t}$ \\
\hline$\Delta$ Acumulado $\%$ & 982,5 & 105,2 & 286,1 & 36,7 & $1.113,2$ & 213,5 & 198,4 & 34,0 \\
\hline Tasa anual $\Delta \%$ & 12,6 & 3,7 & 7,0 & 1,6 & 13,3 & 5,9 & 5,6 & 1,5 \\
\hline
\end{tabular}

VARIACIÓN ACUMULADA DEL GASTO TOTAL EN PENSIONES 1981-2000 
CUADRO 2

VARIACIÓN ACUMULADA DEL GASTO TOTAL EN PENSIONES 2001-2016

\begin{tabular}{|c|c|c|c|c|c|c|c|c|}
\hline \multicolumn{9}{|c|}{ Descomposición en tres efectos: $\Delta$ acumulado y tasa anual (ambos en porcentaje) } \\
\hline \multicolumn{9}{|c|}{ Pensiones medias } \\
\hline & \multicolumn{4}{|c|}{ Total sistema } & \multicolumn{4}{|c|}{ Régimen General } \\
\hline & \multirow{2}{*}{ GP } & \multicolumn{3}{|c|}{ Efectos } & \multirow[b]{2}{*}{ GP } & \multicolumn{3}{|c|}{ Efectos } \\
\hline & & $E P_{t}$ & $E_{t}$ & $\mathrm{ES}_{\mathrm{t}}$ & & $E_{t}$ & $E_{t}$ & $E_{t}$ \\
\hline$\Delta$ Acumulado $\%$ & 138,9 & 23,8 & 51,2 & 27,6 & 186,8 & 61,6 & 59,5 & 11,3 \\
\hline Tasa anual $\Delta \%$ & 5,6 & 1,3 & 2,6 & 1,5 & 6,8 & 3,0 & 3,0 & 0,7 \\
\hline \multicolumn{9}{|c|}{ Pensiones de jubilación } \\
\hline & \multicolumn{4}{|c|}{ Total sistema } & \multicolumn{4}{|c|}{ Régimen General } \\
\hline & \multirow{2}{*}{ GP } & \multicolumn{3}{|c|}{ Efectos } & & \multicolumn{3}{|c|}{ Efectos } \\
\hline & & $E P_{t}$ & $E R_{t}$ & $E_{t}$ & GP & $E P_{t}$ & $E_{t}$ & $\mathbf{E S}_{\mathrm{t}}$ \\
\hline$\Delta$ Acumulado $\%$ & 148,5 & 27,6 & 71,3 & 13,7 & 197,6 & 68,1 & 77,9 & $-0,5$ \\
\hline Tasa anual $\Delta \%$ & 5,9 & 1,5 & 3,4 & 0,8 & 7,1 & 3,3 & 3,7 & 0,0 \\
\hline
\end{tabular}

se acentúa en las pensiones de jubilación del conjunto del sistema. En cambio, en el Régimen General, la aportación de los efectos «población» y «revalorización» al crecimiento del gasto en pensiones medias es equilibrado, mientras que el efecto de sustitución resulta menos apreciable, debido lo uno y lo otro a la incorporación sucesiva de colectivos, que llegan a anular por completo este efecto en el caso de las pensiones de jubilación en este régimen. Además del impacto de la crisis, todo indica que el sistema ya está alcanzando su velocidad de crucero, como se manifiesta en el hecho de que el número medio de años cotizados de las nuevas altas de jubilación en el total del sistema se situó en 37,22 años durante $2016^{24}$.

Comparando la agregación, que se realiza en el Gráfico 22, de las tasas de crecimiento anual derivadas de los tres efectos con la tasa de crecimiento total del gasto en pensiones que aparece en el Gráfico 23, puede

24 Dato obtenido por la Tesorería General de la Seguridad Social a petición del autor (en Expte. 2017/41-576). Corresponde a las nuevas altas de primeros pagos de pensiones de jubilación en el sistema (287.360). Para el Régimen General, la cifra resultante, aunque solo para los jubilados a los 65 años (101.992), es de 34,5 años. El autor agradece a la Tesorería la información proporcionada y la pronta respuesta. observarse que la simple adición de tasas de un dígito proporciona una buena aproximación a la agregación multiplicativa de los tres efectos.

En el Gráfico 23 se observa además que el perfil de la tendencia del crecimiento del gasto total es extraordinariamente parecido al del «efecto revalorización», separados ambos por una distancia que, en promedio, es de 2,9 puntos porcentuales, derivada de la agregación multiplicativa de los otros dos efectos, que resulta mucho más estable, como se observa en el Gráfico 24, en el que la tendencia lineal indica que uno y otro pasaron de aportar un crecimiento de más del 3 por 100 cada uno al gasto total, a comienzos del período considerado, a aportar un 1 por 100 en la actualidad.

De este análisis puede concluirse que a la hora de proyectar la evolución futura del gasto en pensiones conviene separar nítidamente los tres efectos, ya que la tendencia del efecto revalorización está afectada por factores mucho más volátiles que las de los otros dos, además de ser la pieza clave de la reforma de 2012. 


\section{Álvaro Espina}

\section{GRÁFICO 22}

TASAS DE CRECIMIENTO ANUAL DEL GP: TOTAL DERIVADO DE TRES EFECTOS

(En porcentaje)

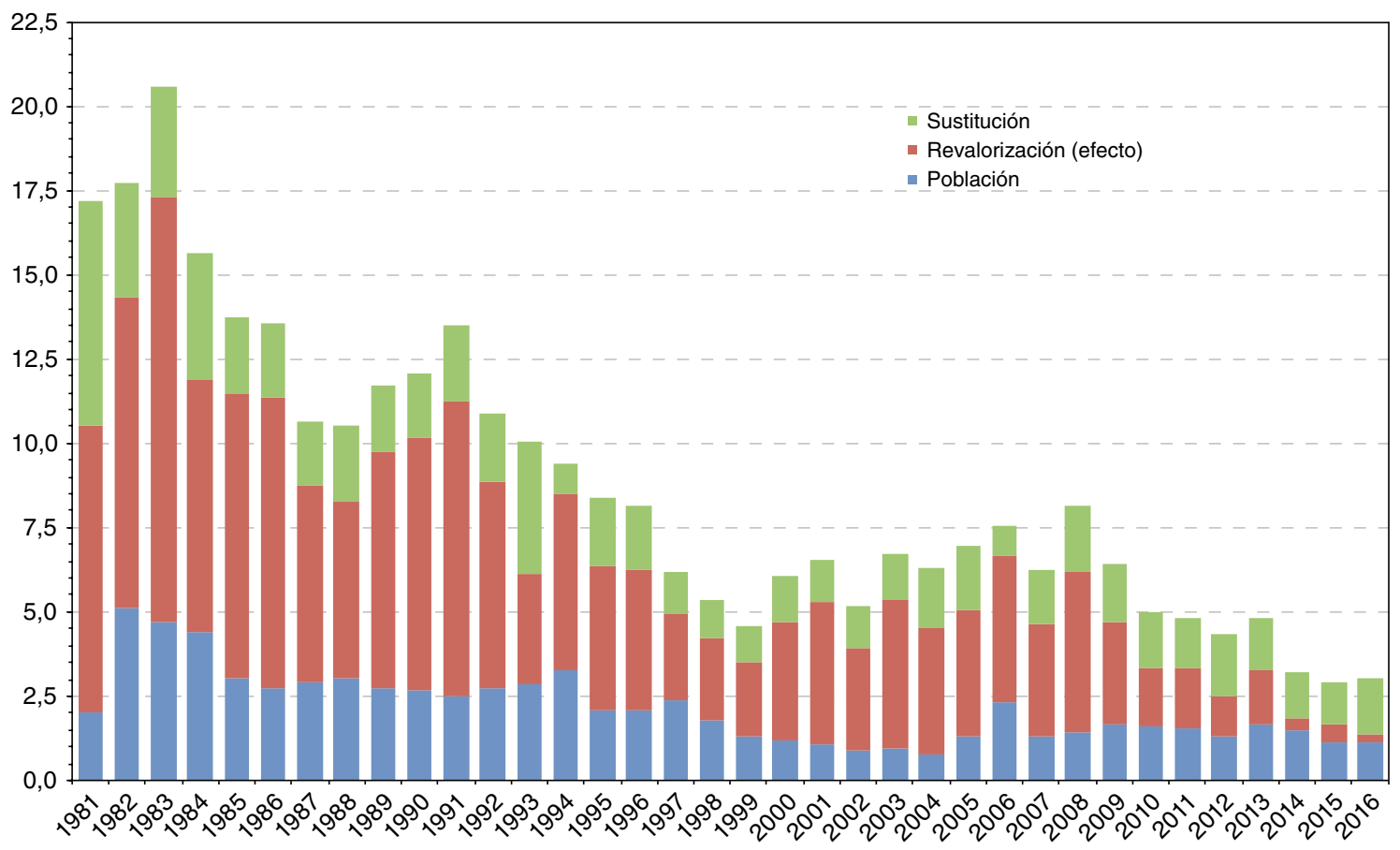

Fuente: elaboración propia a partir de las series del apéndice, de las fuentes de datos y de los métodos consignados en el texto.

GRÁFICO 23

TASAS DE CRECIMIENTO ANUAL DEL GP: TOTAL Y DERIVADO DE LA REVALORIZACIÓN

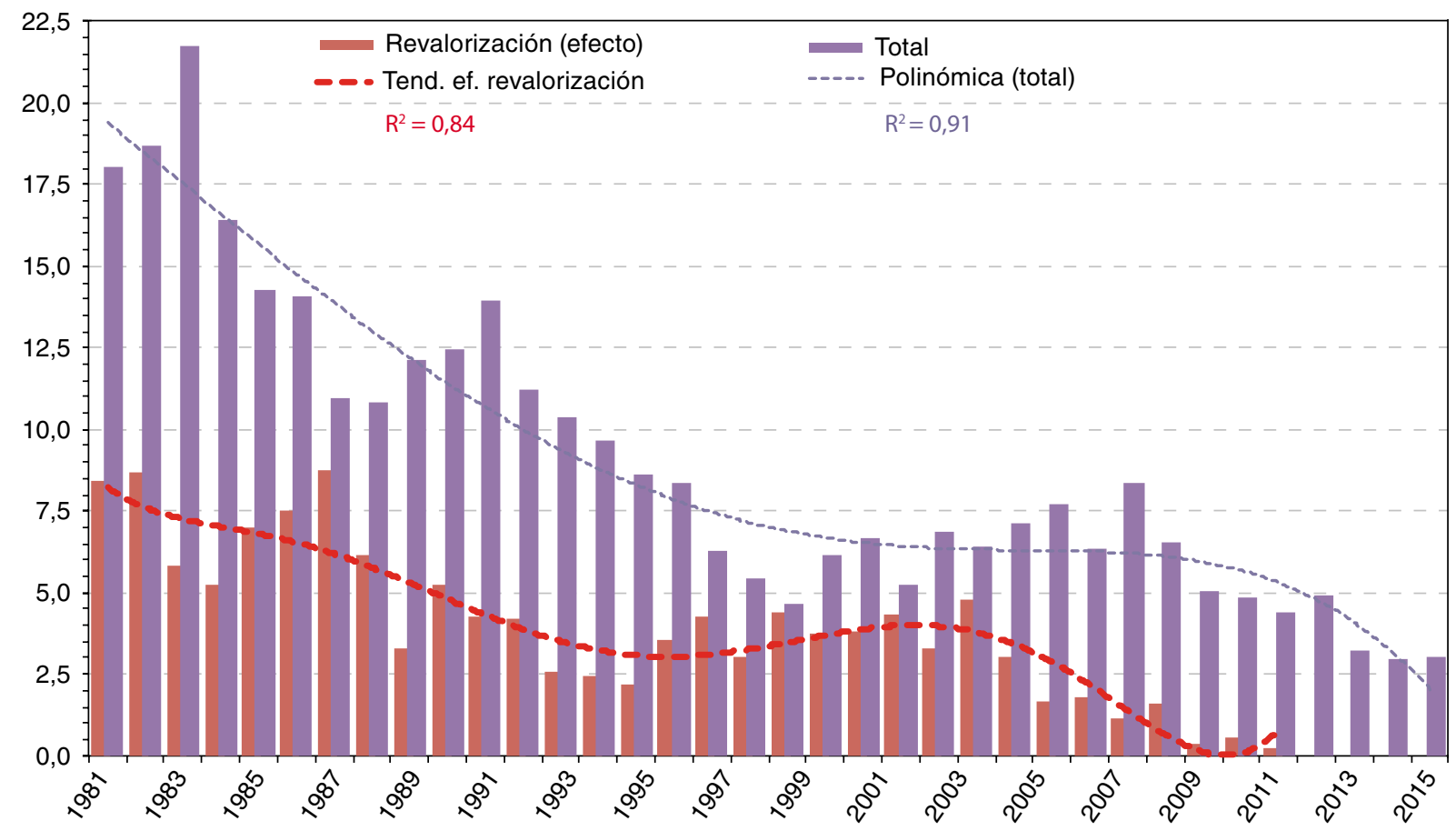

Fuente: elaboración propia a partir de las series del apéndice, de las fuentes de datos y de los métodos consignados en el texto. 


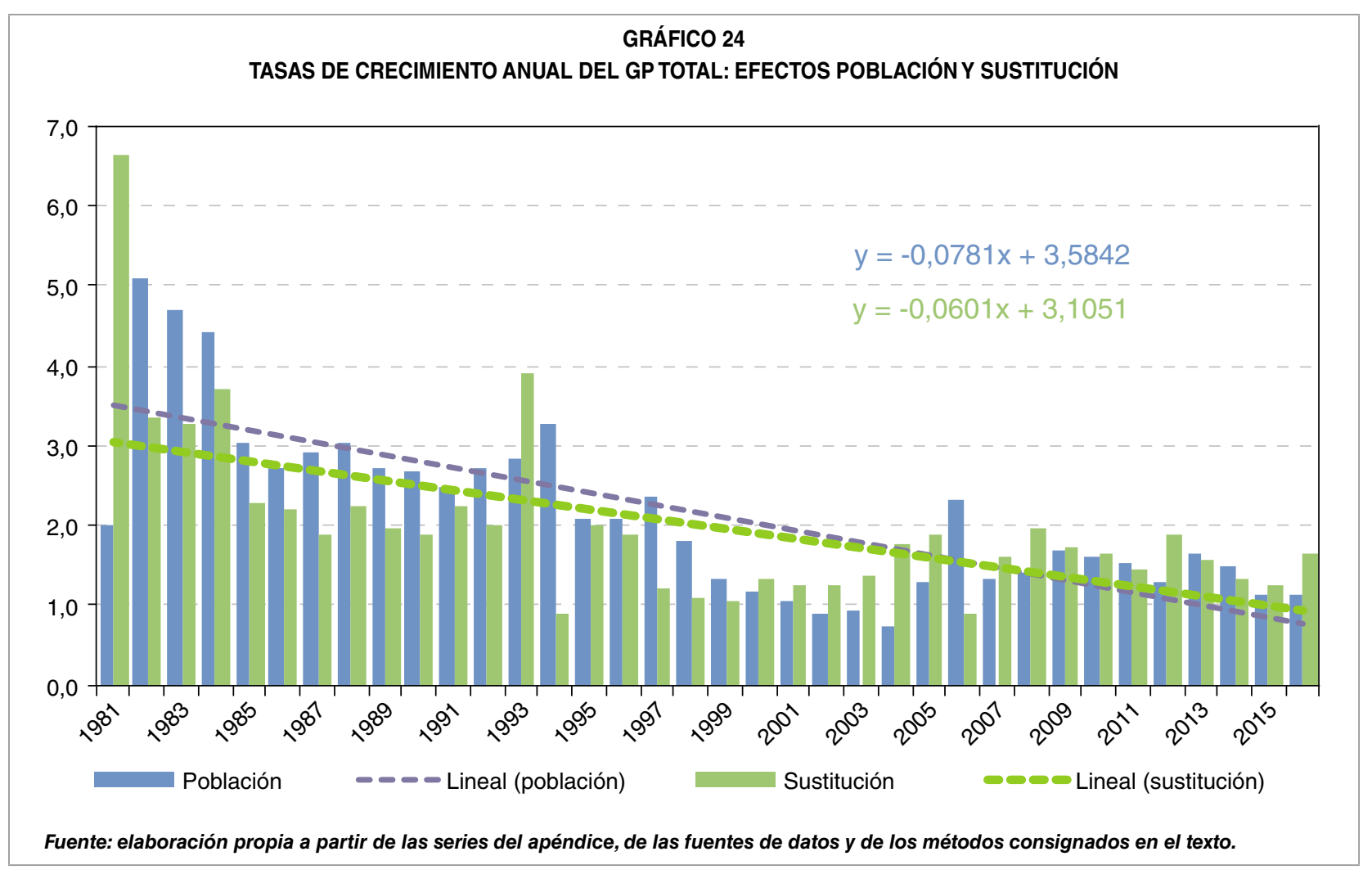

\section{Pensiones no contributivas de la Seguridad Social (PNC) y pensiones asistenciales (PAS)}

Aunque el artículo 86 de la LGSS considere de naturaleza no contributiva los complementos a mínimos de las pensiones - a los que se tiene derecho cuando la cuantía correspondiente de la pensión contributiva no alcanza un mínimo determinado y la renta del pensionista no supera un cierto límite, fijados uno y otro anualmente-, y conceptualmente tengan también esa consideración en nuestro análisis tridimensional (Espina, 2017, diagramas VIII y IX), estos mínimos se encuentran incluidos estadísticamente en las pensiones contributivas que se acaban de analizar y cabe perfectamente que así sea, siguiendo la lógica del aseguramiento, ya que este admite múltiples variantes de riesgo compartido. Algo parecido sucede con un cierto número de pensiones generadas con anterioridad a la aprobación en 1990 de la Ley de prestaciones no contributivas de la Seguridad Social ${ }^{25}$ que el legislador decidió equiparar a las $\mathrm{PC}$, como las pensiones SOVI ${ }^{26}$. De modo que en este epígrafe nos referimos exclusivamente a las PNC tal como quedaron definidas en la Ley de prestaciones no contributivas de 1990, así como a las pensiones asistenciales (PAS) de vejez e invalidez, que en su mayorparte quedaron subsumidas en las primeras. Las PNC y las PAS se financian por el presupuesto del Estado mediante transferencia a la Tesorería de la Seguridad Social.

25 Ley 26/1990, de 20 de diciembre, <https://www.boe.es/diario_boe/ txt.php?id=BOE-A-1990-30939>, derogada por Real Decreto Legislativo 1/1994, de 20 de junio (quedando subsumida en la LGSS).

26 Véase la enumeración y el contexto de integración en Fargas (2002), especialmente el capítulo I.2. Tampoco se incluyen aquí las pensiones «mixtas", como sucede con las de orfandad o de otros familiares, derivadas de una pensión contributiva, aunque su percepción esté sujeta a prueba de medios, ni el incremento de la pensión de gran invalidez, por mucho que unas y otras no deriven directamente de la cotización. 


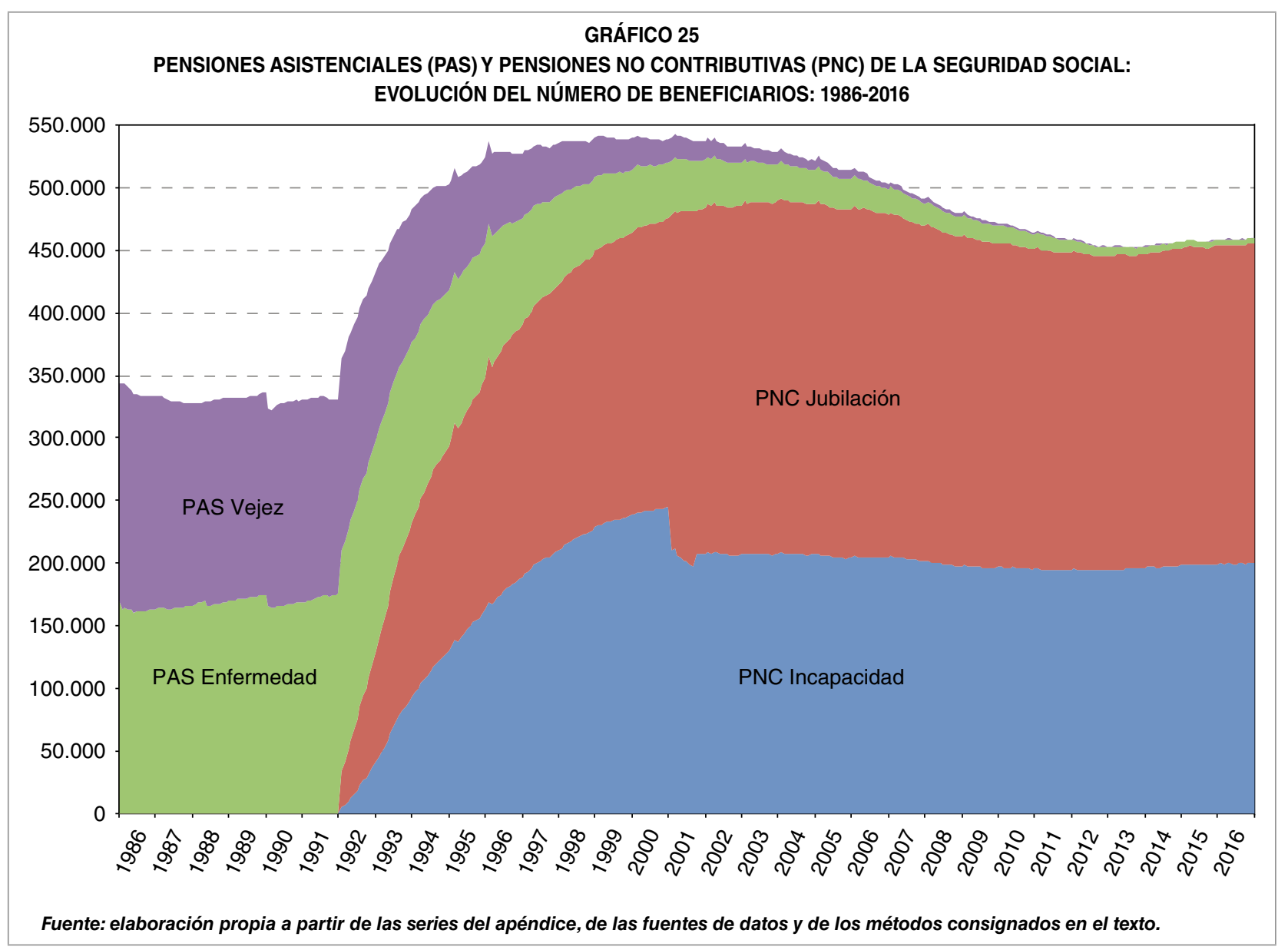

Las pensiones asistenciales -genéricamente denominadas pensiones FAS - fueron concediéndose para paliar situaciones de necesidad flagrante tras la creación (por la Ley 45/1960, de 21 de julio) de diferentes fondos nacionales que operaron como crédito limitativo para la concesión de este tipo de ayudas, por lo que la normativa no generó expectativa de derechos subjetivos, sino que su concesión quedó sometida a la disponibilidad de recursos ${ }^{27}$. Bien es verdad que, una vez concedidas, generalmente sí generaron tales derechos mientras se siguieran cumpliendo los requisitos de necesidad exigidos para su concesión, lo que obliga a

27 Estas pensiones quedaron suprimidas por el Real Decreto Ley $5 / 1992$, de 21 de julio, aunque las ya concedidas que no se transformaron en PNC subsistieron, en número rápidamente menguante. En cualquier caso, la percepción de alguna de estas pensiones es incompatible con la PNC (LGSS, disp. transitoria 24. a) . la Administración a realizar las previsiones presupuestarias para hacerles frente ${ }^{28}$.

Como puede observarse en el Gráfico 13 (y en los Cuadros A-9 y A-10) ${ }^{29}$, la aparición de las PNC se produjo en un momento en que el número de las PAS había alcanzado un nivel próximo a 350.000 y ya resultaba considerablemente estable, tras el rápido ascenso derivado de la sentencia del TS de 10 de abril de 1986, que sentó jurisprudencia, por la que el acceso a $\triangleright$

28 Para un tratamiento sistemático de la tipología de derechos generados por este tipo de prestaciones, véase la Ley 13/2006, de 27 de julio, de prestaciones sociales de carácter económico de la Generalidad de Cataluña (BOE-A-2006-15051), que las clasifica en tres grupos: a) con carácter de derecho subjetivo; b) con carácter de derecho de concurrencia, o c) con carácter de urgencia social. A su vez, por su forma, las prestaciones pueden ser: a) permanentes; b) temporales, o c) puntuales. La obligación de presupuestación figura en la disposición final primera de esta norma.

29 La irregularidad que se observa en las series de PNC en 2001 se debe a que a partir de esa fecha las pensiones de incapacidad se transforman en pensiones de jubilación al alcanzar el beneficiario los 65 años. 
las pensiones de la Ley 12/1982, de Integración Social del Minusválido (LISMI, de 13 de abril), no podía limitarse en función de los ingresos de la familia del beneficiario, sino solo por los suyos personales, indicando claramente que esta ley había significado en realidad franquear el paso entre las pensiones de carácter discrecional, propio de las prestaciones asistenciales - de acceso limitado por la disponibilidad de fondos-, a la generación de un «derecho subjetivo perfecto»30, propio del Régimen Público de Seguridad Social al que se refiere el artículo 41 de la Constitución Española, algo que ocurrió también con los afectados por el síndrome tóxico de 1981, especialmente tras la sentencia del TS de 23 de septiembre de 1997, y con otros grupos, determinados por leyes específicas (como los de víctimas del terrorismo o de violencia de género, refugiados residentes legales ${ }^{31}$, etcétera).

Al incluir estas pensiones en el ámbito de la Seguridad Social, su regulación básica y régimen económico es competencia del Estado, de acuerdo con la CE (art. 149.1.17), y están sujetas a todos los efectos a la competencia de la UE sobre coordinación de la Seguridad Social de los trabajadores migrantes en el Espacio Económico Europeo (Reglamento CEE 1408/71, del Consejo, de 14 de junio de 1971), aunque tanto la LGSS como el artículo 10 bis. 1 de ese reglamento prohíben la exportación de las PNC. Además, para acceder a estas pensiones, junto a los requisitos de edad (65 años para la jubilación), carencia de ingresos suficientes y/o discapacidad igual o superior al 65 por 100, se requiere haber residido en España al menos diez años (cinco para la pensión de invalidez de mayores

30 Que la exposición de motivos de la Ley 26/1990 atribuye a las PNC.

31 Estos últimos tras la Ley Orgánica 4/2000, de 11 de enero, sobre derechos y libertades de los extranjeros en España y su integración social. de 18 años que, cuando recae sobre beneficiarios cuya condición es la de hijos a cargo, no implica insuficiencia de ingresos), dos de ellos en el período inmediatamente anterior a la solicitud.

Sobre las características y vicisitudes de estas pensiones cabe decir que configuran la clave de cierre del sistema de pensiones, de acuerdo con el artículo 41 de la $C E$, que protege especialmente a quienes, estando en situación de necesidad ${ }^{32}$, han tenido escasa o nula integración en el mercado de trabajo, especialmente a mujeres (que son titulares de casi el 80 por 100 de la PNC de jubilación) y personas discapacitadas y/o dependientes (con una distribución de género bastante equilibrada) ${ }^{33}$. Para estas últimas, en caso de gran dependencia se proporciona también una ayuda adicional para asistente personal (equivalente al 50 por 100 de la pensión). Además, desde 2007 es posible acceder a un complemento para alquiler que asciende en 2017 a 525 euros anuales.

\section{Las pensiones de clases pasivas del Estado}

Las pensiones de clases pasivas del Estado constituyen el bloque más antiguo del sistema español de pensiones públicas tal como hoy $\triangleright$

\footnotetext{
32 Definida por carecer de rentas anuales superiores a la cuantía máxima de la pensión. Cuando existen rentas por debajo de ese límite, la cuantía concreta de la pensión se modula en función de las mismas (con límite del 25 por 100). Si se convive en una unidad familiar, el límite de rentas acumuladas responde a un baremo en función del número, que se calcula agregando al límite individual un 70 por 100 del mismo por cada persona adicional en la unidad familiar: http://imserso.es/InterPresent1/ groups/imserso/documents/binario/pncresumen2017.pdf

33 Aunque la mayor concentración por edades en los varones se produce entre los 40 y 49 años, mientras que en las mujeres esto sucede entre los 50 y 59 años. Para una síntesis véase MEYSS, 25 años de las pensiones no contributivas de la Seguridad Social, publicado en el portal de transparencia el 21 de septiembre de 2016: http://transparencia.gob.es/transparencia/ transparencia_Home/index/MasSobreTransparencia/Informes-de-interes/ Sociedad_y_bienestar/pensiones-no-contributivas.html
} 
las entendemos. Además, en muchos aspectos la experiencia adquirida por el Estado con sus funcionarios durante el siglo XIX sería adoptada como modelo para el diseño del sistema de pensiones del sector privado a lo largo del xx.

La ley de Presupuestos de 1835 estableció la obligación asumida por el Estado liberal de abonar las pensiones de jubilación de los empleados civiles con cargo al Tesoro público, dando pie a un sistema de reparto ni siquiera vinculado a cotizaciones previas. Reordenada, modificada y extendida por las leyes de presupuestos de 1842 y 1845 y por la creación de la Junta de Clases Pasivas en 1849-1850, esta legislación básica estaría vigente a grandes rasgos hasta el Estatuto de Clases Pasivas del Estado de 26 de octubre de $1926^{34}$. El principio aplicable durante toda aquella etapa fue similar al de la desamortización, ya que la traslación sucesiva de la carga de pensiones hacia el Estado fue paralela a la supresión, con incautación de su patrimonio, de los ocho montepíos creados a finales del Antiguo Régimen, entre 1763 y 1785, imitando el Montepío Militar, cuya organización y Reglamento (de 28 de mayo de 1761) fue obra del marqués de Esquilache.

Tales montepíos se regían por el principio de capitalización y se financiaban por aportaciones iniciales (seis mesadas en los dos primeros años de incorporación, o sea, un 25 por 100 del sueldo) y con descuentos permanentes del 1,7 por 100 en la nómina, practicados por los jefes de cada oficina y entregadas al jefe de tesorería de cada montepío. El principio de cotización se restablecería a partir de 1926, aunque solo parcialmente y con carácter voluntario para acogerse al régimen de mejoras, que exigía un descuento del 5 por 100 de

34 Véase la recopilación de toda la normativa previa en el Manual de Clases Pasivas (España, 1910). los haberes si se deseaba alcanzar «derechos pasivos máximos» 35 .

Tras la inextricable maraña de situaciones a que dio lugar la guerra civil (Alejandre, 2009), el Estatuto de 1926 mantuvo su vigencia, con sucesivos retoques - como el de generalizar la aportación del 5 por 100 para los funcionarios ingresados desde 1951-. La pérdida de poder adquisitivo derivada de la inflación y la congelación de los sueldos reguladores (como sucedió también con los salarios en las ordenanzas de trabajo -OT-), solo comenzó a corregirse en 1956, aumentando el sueldo regulador en un 25 por 100 y revalorizando las pensiones ya generadas en función del año de concesión hasta un 50 por 100. Además, desde comienzos de los años sesenta se establecieron pensiones mínimas y se generalizó la revalorización anual con arreglo a la de los sueldos reguladores, recuperando entre 1964 y 1968 (tras la aparición de la Ley de Funcionarios Civiles del Estado), los desfases en los que previamente se había incurrido.

Anteriormente, sin embargo, la corrección más importante se había producido con la reaparición del mutualismo administrativo preliberal (paralelo ahora al mutualismo laboral de las OT), que tuvo carácter obligatorio a partir de la ley de 1942 y permitió generar pensiones adicionales sin la más mínima homogeneidad ni equidad (pues las mutualidades se crearon de manera discrecional y con dotaciones económicas y cotizaciones dispares).

Tras la adopción entre 1965 y 1967 de las leyes de derechos pasivos de los funcionarios $\triangleright$

\footnotetext{
35 Para la etapa de transición desde 1917 hacia el Estatuto y sobre este último, véase Asensio (1928). Las principales características del mismo las sinteticé en Espina (2007/92-95): en general, tras veinte años de servicio se generaba una pensión vitalicia equivalente al 15 por 100 del haber regulador, con un tope máximo de 3.000 ptas.; con derechos máximos, tras veinte años la pensión era del 40 por 100 , aumentando progresivamente hasta el 80 por 100 a medida que lo hacían los años de servicio hasta 35 años, con un límite de 15.000 ptas. al año.
} 
públicos - a partir de la Ley de Bases de la Seguridad Social de 1963 y de su texto articulado en 1966 - se caminó nominalmente hacia un Régimen Especial de la Seguridad Social de los Funcionarios Públicos, pero en lo que se refiere a las pensiones este régimen no quedó claramente tipificado. Sin embargo, los derechos pasivos experimentaron los cambios derivados de la redefinición de los sueldos reguladores a partir de la Ley $31 / 1965$, de retribuciones de los funcionarios civiles, y de su aplicación sucesiva a los diferentes grupos de funcionarios ${ }^{36}$.

El régimen vigente de derechos pasivos -actualizado tras la reforma estructural de la función pública realizada en 1984-1985se encuentra regulado por el Real Decreto Legislativo 670/1987, de 30 de abril ${ }^{37}$. La principal peculiaridad de este sistema consiste en que, en lugar de calcularse la cotización del funcionario y el haber regulador de la pensión a partir de la remuneración real percibida a lo largo de su vida laboral —como sucede en el Régimen General de la Seguridad Social-, una y otra se determinan a partir de un sueldo o haber regulador homogéneo para los cinco grandes grupos de funcionarios, clasificados de acuerdo con su titulación inicial, establecidos anualmente por la Ley de Presupuestos del Estado, que fija también el límite máximo de las mismas, común a las pensiones de $\mathrm{SS}^{38}$.

36 En 1975 se crearon los regímenes especiales para las fuerzas armadas, los funcionarios civiles y los funcionarios al servicio de la Administración de Justicia, gestionados por las mutualidades ISFAS MUFACE y MUGEJU, pero nada de ello afectó a los derechos pasivos. Para un estudio sistemático de la historia y las características de estos, comparados con las pensiones del Régimen General de la SS, véase López (2007).

37 Y las sucesivas modificaciones recogidas en el texto refundido de Ley de Clases Pasivas del Estado. La más reciente es la de 30 de octubre de 2015: https://www.boe.es/buscar/pdf/1987/BOE-A-1987-12636consolidado.pdf

38 Para 2017 los haberes reguladores anuales son: A1.- 40.460; A2.31.843; B.- 27.884; C1.- 24.456; C2.- 19.349; D.- 16.496. El límite máximo, común a todas las pensiones públicas, es de 2.574 euros/mes. El conjunto de especificaciones figura en la URL: http://www.clasespasivas.sepg.
Para el cálculo de la pensión, a este sueldo regulador se le aplica el porcentaje que resulte del cómputo de los años de cotización. La escala de porcentajes acumulativos es muy diferente a la de las pensiones de Seguridad Social, en donde a los 15 años se sitúa en el 50 por 100 de la base reguladora, mientras que en clases pasivas (CCPP) es algo más de la mitad (26,92 por 100). A partir de 15 años en SS aumenta un 3 por 100 adicional cada año hasta los 25 , y en 2 por 100 hasta 35 años, que es la edad en que se alcanza el 100 por 100 en ambos casos; en cambio, en CCPP el aumento es de 3,654 por 100 durante los últimos 20 años. En caso de carreras laborales desarrolladas en ambos regímenes, la regla de cálculo es la del régimen en que se produce la jubilación, aplicable al período completo de cómputo acumulado en los dos sistemas.

El Gráfico 26 presenta la evolución reciente de las pensiones anuales medias ponderadas de CCPP y de sus tres clases principales, comparándola con la de la remuneración anual media en las Administraciones Públicas, según Contabilidad Nacional. Al igual que sucede con las pensiones de la SS, la tendencia creciente de las pensiones ${ }^{39}$, en comparación con la tendencia a la disminución de las remuneraciones hasta 2012, se traduce en el crecimiento de las ratios correspondientes a todas las pensiones de CCPP que se observa en el Gráfico 27.

A partir de 2013 el nuevo crecimiento de las remuneraciones propicia la desaceleración del crecimiento de la ratio media y la estabilización de las de jubilación y viudedad, que registran descensos desde 2014. Por lo que se refiere $D$

pap.minhafp.gob.es/sitios/clasespasivas/es-ES/PensionesPrestaciones/ PENSIONESCLASESPASIVAS/pensionesjubilacion/Paginas/ Normasgenerales.aspx

$39 \mathrm{El}$ ajuste lineal indica que las pensiones medias crecieron durante el sexenio en 656 euros/año y las de jubilación en 458 euros/año, con $R^{2}$ de 0,99 y 0,96 , respectivamente. 
a las pensiones de incapacidad, los descensos de la ratio se producen desde 2012, como consecuencia de la reforma en el sistema de cálculo de las mismas desde 2009, año a partir del cual se reduce el porcentaje de pensión en un 5 por 100 anual que falte para completar una carrera de 20 años (con un descuento máximo del 25 por 100) en el caso de las incapacidades no invalidantes para el ejercicio de otra profesión. Como consecuencia de esta evolución, la horquilla que separaba las tasas de sustitución entre CCPP y Régimen General de la SS se ha reducido desde 2012 en torno a cuatro puntos para las pensiones de jubilación e incapacidad, mientras que la brecha negativa de las pensiones de viudedad en CCPP ha aumentado en un punto, situándose la ratio de sustitución de las pensiones medias de uno y otro régimen en el mismo nivel desde ese año y manteniendo una evolución prácticamente idéntica.

Finalmente, el Régimen Especial de la Seguridad Social de los Funcionarios Públicos denominado de Clases Pasivas del Estado está llamado a extinguirse paulatinamente en lo que se refiere al subsistema de pensiones, puesto que los funcionarios ingresados desde 2011 han quedado integrados en el Régimen General de la Seguridad Social, de modo que a partir de 2055 las altas por jubilación por clases pasivas disminuirán drásticamente, para desaparecer durante el decenio subsiguiente (aunque los derechos generados en el mismo permanecerán vigentes prácticamente hasta el último cuarto del siglo).

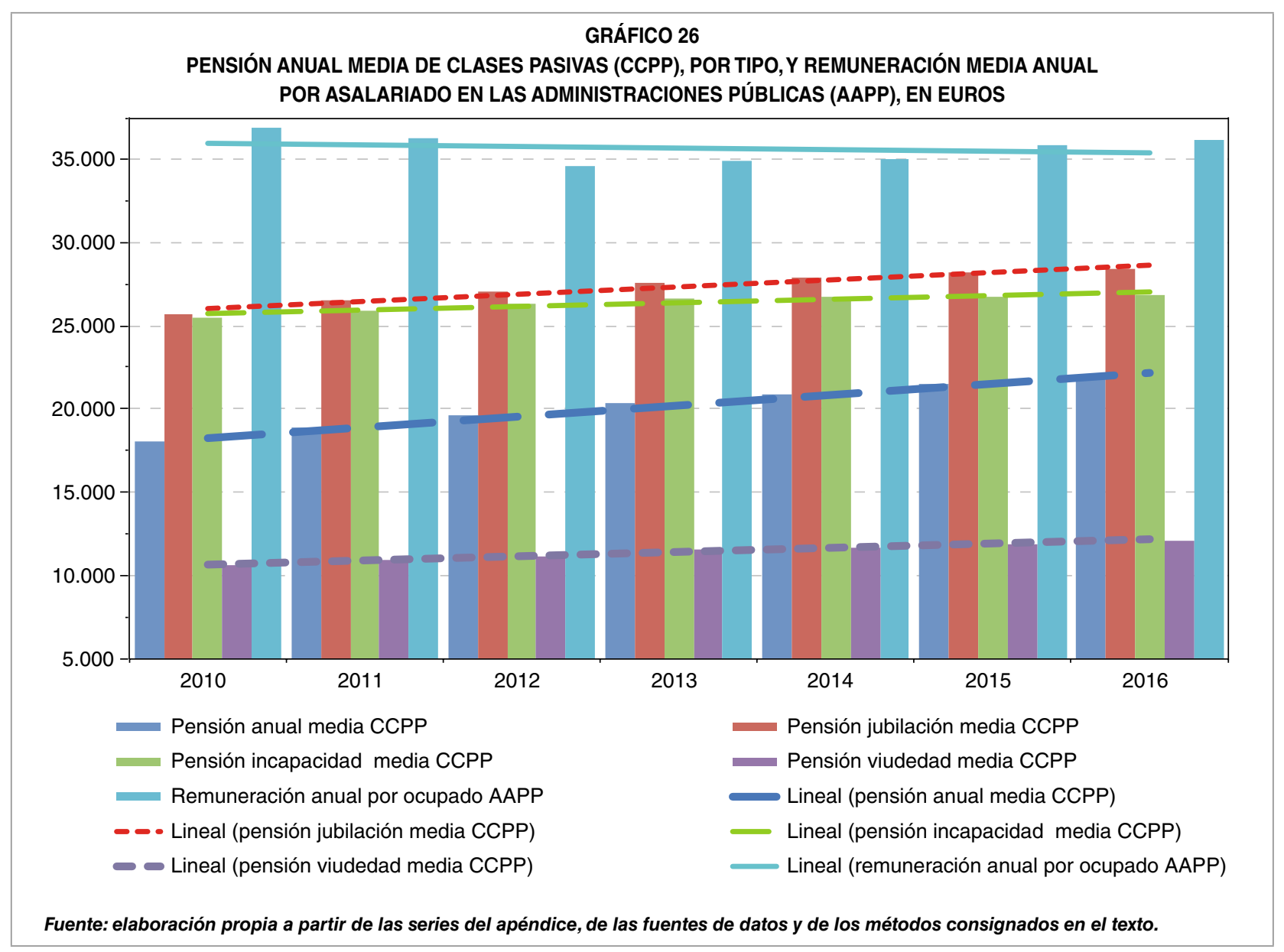




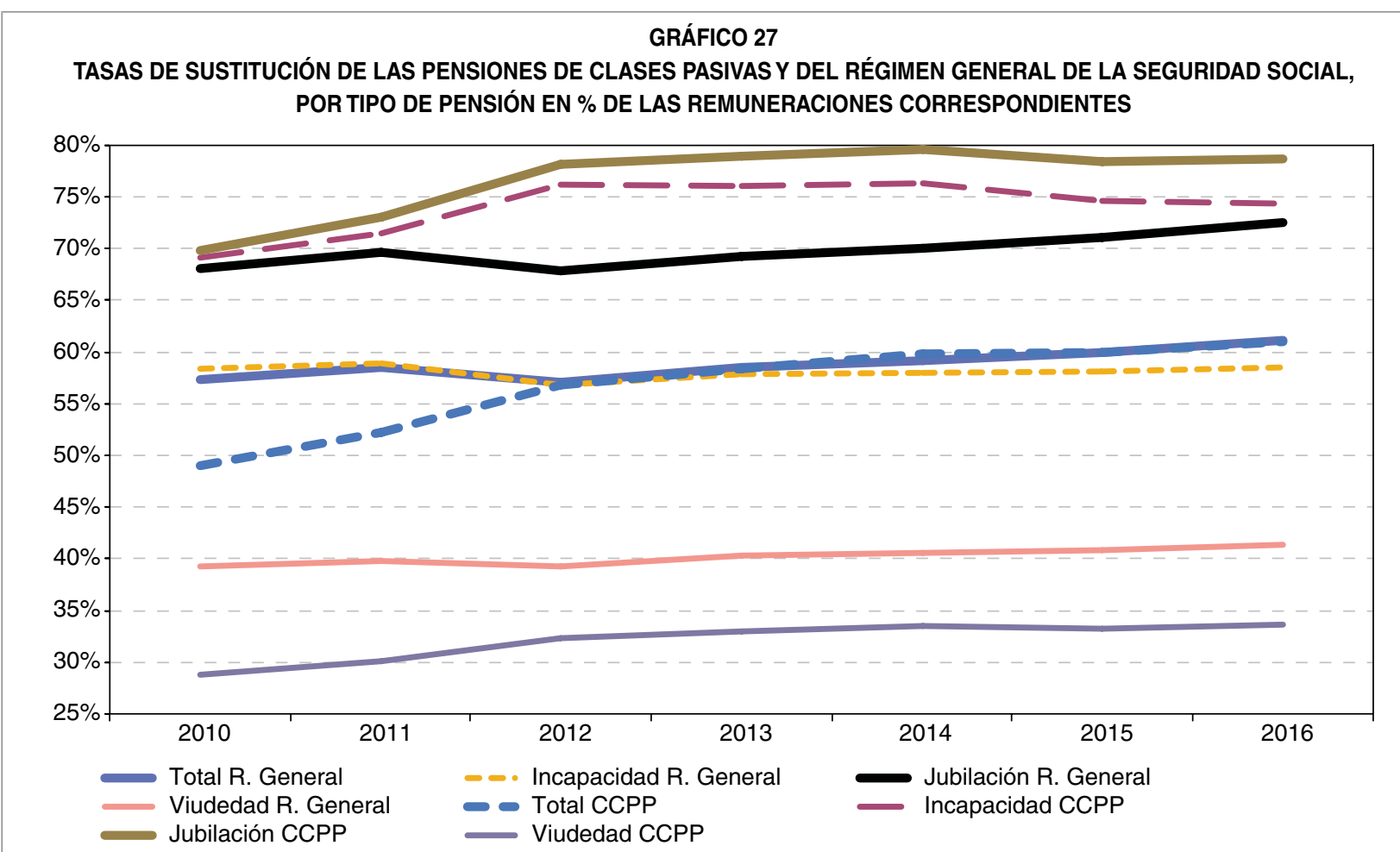

Fuente: elaboración propia a partir de las series del apéndice, de las fuentes de datos y de los métodos consignados en el texto.

Cabe afirmar que esta integración, además de llevar a cabo una armonización del sistema de pensiones claramente deseable en aras de la eliminación de condiciones discriminatorias no justificadas por las características de la actividad $^{40}$, contribuirá a equilibrar las cuentas del Régimen General de la SS, ya que durante un largo período (en torno a cuarenta años, que equivale a una carrera completa de cotización) el colectivo de funcionarios aportará sus ingresos al sistema, causando escaso número de prestaciones (ninguna por causa de jubilación) ${ }^{41}$.

40 El artículo 20 del Real Decreto Ley 13/2010, que estableció la integración, ya preveía el mantenimiento de especificidades para el personal militar, tanto no permanente como de carrera de los cuerpos y fuerzas de seguridad. Los funcionarios civiles quedaron integrados en el RG el 1 de enero de 2011. El proceso se completó en diciembre de 2015, mediante la integración del personal de las fuerzas armadas (Panizo, 2015).

41 La Exposición de Motivos del Real Decreto Ley 13/2010 ya señalaba que con la integración «se incrementa el número de cotizantes a la Seguridad Social, y, en consecuencia, los ingresos de la Tesorería General de la Seguridad Social, lo que propiciará una mayor estabilidad

\section{Conclusión: la situación actual del sistema de pensiones y la dinámica 2010-2016}

En el Cuadro 3 se hace balance de las grandes cifras del sistema español de pensiones en el año 2016. En síntesis, el número total del conjunto de pensiones públicas es casi de 10,5 millones. Aunque existan algunas duplicidades, esta cifra equivale al 22,6 por 100 de la población, y el grueso del sistema corresponde a las pensiones de jubilación (6,4 millones, que equivalen al 13,7 por 100 de la población).

Por grandes bloques, casi nueve de cada diez son pensiones contributivas de la Seguridad Social (el 89,7 por 100); seis de cada cien pertenecen al grupo de clases pasivas y 4,4 son pensiones no contributivas.

del sistema público de protección social, mediante el establecimiento de un único sistema contributivo y de reparto de las pensiones». 


\section{Bibliografía}

[1] ALEJANDRE, J. A. (2009). «La protección social en el primer franquismo: régimen jurídico de las pensiones y prestaciones extraordinarias originadas por la Guerra Civil». Anuario de Historia del Derecho Español, tomo LXXVIII-LXXIX, 2008-2009, pp. 371396. Disponible en: https://www.boe.es/ publicaciones/anuarios_derecho/articulo. php?id=ANU-H-2008-10037100396

[2] ALESINA, A.; BARBIERO, O.; FAVERO, C.; GIAVAZZI, F. y PARADISI, M. (2017). «The Effects of Fiscal Consolidations: Theory and Evidence». NBER Working Paper 23385. Disponible en: $h$ ttp://www.nber.org/papers/w23385

[3] ANDRÉS, J.; DOMÉNECH, R.y FATÁS, A. (2008). «The stabilizing role of government size». Journal of Economic Dynamics and Control, vol. 32, n.․ 2, febrero, pp. 571-593, version DT previa. Disponible en: http://www.bde.es/f/webbde/SES/Secciones/ Publicaciones/PublicacionesSeriadas/ DocumentosTrabajo/07/Fic/dt0710e.pdf

[4] ASENSIO CASANOVA, M. A. (1928). Derechos pasivos de los empleados del estado civiles y militares. Madrid: Imprenta del Ministerio de Marina.

[5] BASSANINI, A. (1911). «Aggregate Earnings and Macroeconomic Shocks. The Role of Labour Market Policies and Institutions». OECD Social, Employment and Migration Working Papers. Septiembre.

[6] CHRISTIANO, L.J. (1984). «A reexamination of the theory of automatic stabilizers». CarnegieRochester Conference Series on Public Policy vol. 20, n. 1, pp. 147-206.

[7] CHRISTIANO, L.J. y HARRISON, S.G. (1999). "Chaos, sunspots and automatic stabilizers". Journal of Monetary Economics n.. 44, pp. 3-31. Disponible en: http://citeseerx.ist.psu.edu/ viewdoc/download?doi=10.1.1.595.9778\&re$p=r e p 1 \&$ type $=p d f$

[8] CHRISTIANO, L.; EICHENBAUM, M. y REBELO, S. (2011). «When is the government spending multiplier large?». Journal of Political Economy, vol. 119, n.ำ 1. Versión WP en: https: //www.kellogg.northwestern.edu/faculty/rebelo/htm/multiplier.pdf
[9] ESPAÑA (1910). Manual de Clases Pasivas, civiles y militares: según la legislación y jurisprudencia aplicables para la declaración de derechos pasivos. Madrid: imprenta de la Gaceta Administrativa, URL: http://www.cervantesvirtual.com/nd/ark:/59851/bmcqj7c3

[10] ESPINA, Á. (2007). Modernización social y Estado de bienestar en España, Siglo xxı, versión previa. Disponible en: http://www.carm. es/ctra/cendoc/haddock/14422.pdf

[11] ESPINA, Á. (2017). «La reforma de las pensiones y el Estado de Bienestar: un marco conceptual». Boletín ICE n. ${ }^{\circ}$ 3085, marzo 2017.

[12] FARGAS, J. (2002). Análisis crítico del sistema español de pensiones no contributivas. Editorial Aranzadi, basada en su tesis doctoral (2001). Disponible en: http://www.tesisenred.net/bitstream/handle/10803/7306/tjff. pdf? sequence $=1$

[13] INE (2017). Proyecciones de población 20162066. Disponible en: $h t t p: / / w w w . i n e . e s / d y n t 3 /$ inebase/index.htm?type $=$ pcaxis \&path $=/ t 20 /$ p278/p01/2016-2066/\&file =pcaxis

[14] JANIAK, A. y MONTEIRO, P. (2016). «Towards a quantitative theory of automatic stabilizers: The role of demographics». Journal of Monetary Economics, n.․ 78 (2016), pp. 3549. Disponible en: http://repositorio.uchile.cl/ handle/2250/140952

[15] MOUDUD, J.K. y AJIT, Z. (1999). «The Social Wage, Welfare Policy, and the Phases of Capital Accumulation". Jerome Levy Economics Institute Working Paper, n.․ 291, diciembre. Disponible en: http://www.levy.org/pubs/wp291.pdf

[16] PANIZO ROBLES, J. A. (2015). Completado el proceso de integración de los funcionarios públicos en el Régimen General de la Seguridad Social... Disponible en: http:// www.laboral-social.com/sites/laboral-social. com/files/JAPANIZORD10872015-1.pdf

[17] SECRETARÍA GENERALDELASEGURIDAD SOCIAL: SGSS (1995). «La seguridad social en el umbral del siglo XX|». Estudio económico Actuarial. MTSS. Madrid, noviembre.

[18] SESS (2015). Informe sobre el desarrollo del Pacto de Toledo. Período 2011-2015. Anexo en: (6) http://www1.seg-social.es/Activalnternet/groups/ public/documents/rev_anexo/rev_035142.pdf 


\section{ANEXO ESTADÍSTICO}

\section{PENSIONES CONTRIBUTIVAS DEL SISTEMA DE LA SEGURIDAD SOCIAL}

CUADRO A-1

NÚMERO DE PENSIONES VIGENTES: MEDIA ANUAL,TOTAL Y POR CLASES *

\begin{tabular}{|c|c|c|c|c|c|}
\hline Año & Total & Jubilación & Incapacidad & Viudedad & Otras \\
\hline 1976 & 3.592 .005 & 1.959 .012 & 713.107 & 787.766 & 132.120 \\
\hline 1977 & 3.799 .908 & 2.019.397 & 801.581 & 847.465 & 131.465 \\
\hline 1978 & 4.015 .098 & 2.079 .288 & 883.044 & 912.651 & 140.115 \\
\hline 1979 & 4.217 .699 & 2.133 .515 & 962.319 & 974.093 & 147.772 \\
\hline 1980 & 4.398 .434 & 2.190 .247 & 1.024 .413 & 1.026 .614 & 157.160 \\
\hline 1981 & 4.487 .363 & 2.219 .504 & 1.054 .932 & 1.053 .233 & 159.694 \\
\hline 1982 & 4.716 .281 & 2.280 .219 & 1.152 .988 & 1.115 .933 & 167.141 \\
\hline 1983 & 4.937 .020 & 2.327 .058 & 1.272 .132 & 1.166 .100 & 171.729 \\
\hline 1984 & 5.154 .986 & 2.390 .162 & 1.378 .205 & 1.211 .635 & 174.985 \\
\hline 1985 & 5.311 .867 & 2.439 .129 & 1.438 .289 & 1.257 .291 & 177.158 \\
\hline 1986 & 5.456 .054 & 2.493 .946 & 1.472 .062 & 1.310 .374 & 179.672 \\
\hline 1987 & 5.615 .614 & 2.571 .186 & 1.502 .562 & 1.360 .374 & 181.492 \\
\hline 1988 & 5.785 .557 & 2.655 .536 & 1.528 .057 & 1.417 .732 & 184.231 \\
\hline 1989 & 5.942 .768 & 2.730 .367 & 1.547 .719 & 1.477 .529 & 187.153 \\
\hline 1990 & 6.102 .121 & 2.803 .825 & 1.567 .871 & 1.541 .042 & 189.382 \\
\hline 1991 & 6.253 .364 & 2.877 .618 & 1.588 .784 & 1.595 .910 & 191.053 \\
\hline 1992 & 6.422 .633 & 2.963 .822 & 1.613 .374 & 1.652 .008 & 193.429 \\
\hline 1993 & 6.605 .647 & 3.058 .267 & 1.638 .414 & 1.710 .623 & 198.343 \\
\hline 1994 & 6.822 .425 & 3.176 .361 & 1.658 .166 & 1.777 .766 & 210.132 \\
\hline 1995 & 6.966 .074 & 3.265 .191 & 1.672 .280 & 1.817 .537 & 211.066 \\
\hline 1996 & 7.110 .211 & 3.350 .335 & 1.684 .042 & 1.856 .946 & 218.889 \\
\hline 1997 & 7.279 .277 & 3.502 .531 & 1.626 .580 & 1.897 .528 & 252.637 \\
\hline 1998 & 7.410 .732 & 4.400 .863 & 804.549 & 1.936 .732 & 268.587 \\
\hline 1999 & 7.509 .280 & 4.450 .248 & 798.017 & 1.973 .263 & 287.752 \\
\hline 2000 & 7.598 .890 & 4.493 .404 & 792.618 & 2.009 .571 & 303.297 \\
\hline 2001 & 7.677 .923 & 4.545 .617 & 788.618 & 2.042 .438 & 301.250 \\
\hline 2002 & 7.745 .782 & 4.575 .293 & 787.388 & 2.073 .304 & 309.798 \\
\hline 2003 & 7.819 .456 & 4.603 .381 & 796.720 & 2.106 .219 & 313.136 \\
\hline 2004 & 7.878 .636 & 4.619 .622 & 815.097 & 2.136.349 & 307.568 \\
\hline 2005 & 7.979 .707 & 4.678 .269 & 832.789 & 2.165 .881 & 302.768 \\
\hline 2006 & 8.165 .336 & 4.809 .298 & 859.780 & 2.196 .934 & 299.323 \\
\hline 2007 & 8.273 .939 & 4.863 .256 & 888.776 & 2.225 .501 & 296.404 \\
\hline 2008 & 8.390 .796 & 4.936 .839 & 906.835 & 2.249 .904 & 297.219 \\
\hline 2009 & 8.531 .935 & 5.038 .861 & 920.863 & 2.270 .283 & 301.927 \\
\hline 2010 & 8.671 .018 & 5.140 .554 & 933.730 & 2.290 .090 & 306.645 \\
\hline 2011 & 8.805 .164 & 5.246 .241 & 938.491 & 2.309 .332 & 311.100 \\
\hline 2012 & 8.919 .997 & 5.330 .195 & 943.296 & 2.322 .938 & 323.568 \\
\hline 2013 & 9.065 .830 & 5.451 .465 & 935.220 & 2.336 .240 & 342.905 \\
\hline 2014 & 9.201 .080 & 5.558 .964 & 929.484 & 2.348 .388 & 364.245 \\
\hline 2015 & 9.304 .555 & 5.641 .908 & 931.668 & 2.353 .257 & 377.722 \\
\hline 2016 & 9.409 .174 & 5.731 .951 & 938.343 & 2.358 .667 & 380.213 \\
\hline
\end{tabular}


CUADRO A-2

IMPORTE MEDIO DE PENSIONES POR CLASES: MEDIA EUROS/MES. TOTAL Y RÉGIMEN GENERAL *

\begin{tabular}{|c|c|c|c|c|c|c|c|c|}
\hline \multirow[b]{2}{*}{ Año } & \multicolumn{4}{|c|}{ Total sistema: euros / mes (14 pagas) } & \multicolumn{4}{|c|}{ Régimen General: euros / mes (14 pagas) } \\
\hline & Media & $\begin{array}{l}\text { Incapacidad } \\
\text { permanente }\end{array}$ & Jubilación & Viudedad & Media & $\begin{array}{l}\text { Incapacidad } \\
\text { permanente }\end{array}$ & Jubilación & Viudedad \\
\hline 1976 & 37,9 & 40,1 & 43,0 & 28,9 & 40,9 & - & - & - \\
\hline 1977 & 49,6 & 52,8 & 53,8 & 38,2 & 51,0 & - & - & - \\
\hline 1978 & 66,0 & 72,4 & 69,4 & 51,1 & 65,7 & - & - & - \\
\hline 1979 & 78,0 & 85,6 & 82,4 & 59,8 & 79,1 & - & - & - \\
\hline 1980 & 89,7 & 99,3 & 95,7 & 67,3 & 102,3 & - & - & - \\
\hline 1981 & 103,8 & 112,0 & 115,6 & 75,6 & 119,8 & 141,6 & 148,0 & 79,6 \\
\hline 1982 & 117,2 & 127,7 & 131,1 & 83,6 & 137,8 & 160,0 & 167,7 & 88,7 \\
\hline 1983 & 136,3 & 150,4 & 152,1 & 96,0 & 160,8 & 186,7 & 195,1 & 102,7 \\
\hline 1984 & 152,0 & 167,5 & 170,7 & 104,8 & 182,6 & 208,9 & 224,0 & 112,8 \\
\hline 1985 & 168,6 & 183,8 & 191,9 & 114,0 & 204,9 & 229,4 & 254,2 & 123,8 \\
\hline 1986 & 187,2 & 202,7 & 215,4 & 125,1 & 227,9 & 252,5 & 284,1 & 136,9 \\
\hline 1987 & 201,8 & 217,6 & 233,0 & 134,1 & 245,9 & 270,3 & 306,3 & 147,8 \\
\hline 1988 & 217,1 & 232,5 & 251,5 & 146,7 & 264,3 & 287,4 & 328,1 & 161,9 \\
\hline 1989 & 237,0 & 251,7 & 273,7 & 165,1 & 287,9 & 310,0 & 354,5 & 182,4 \\
\hline 1990 & 259,6 & 276,0 & 299,6 & 182,4 & 315,0 & 339,3 & 385,8 & 202,0 \\
\hline 1991 & 288,6 & 306,2 & 331,6 & 207,4 & 349,3 & 376,2 & 424,0 & 229,1 \\
\hline 1992 & 312,5 & 331,1 & 357,8 & 228,1 & 378,0 & 408,0 & 455,4 & 251,5 \\
\hline 1993 & 335,4 & 356,4 & 385,1 & 243,0 & 405,6 & 440,0 & 487,9 & 268,6 \\
\hline 1994 & 356,1 & 377,2 & 411,3 & 256,8 & 430,5 & 466,2 & 519,2 & 284,9 \\
\hline 1995 & 378,8 & 400,1 & 439,0 & 271,3 & 458,4 & 495,0 & 552,4 & 301,4 \\
\hline 1996 & 402,2 & 424,8 & 467,5 & 286,7 & 486,4 & 525,1 & 586,1 & 318,8 \\
\hline 1997 & 417,5 & 445,5 & 487,4 & 296,5 & 504,5 & 549,2 & 609,5 & 330,5 \\
\hline 1998 & 432,3 & 487,5 & 492,6 & 305,7 & 522,0 & 591,1 & 618,1 & 341,2 \\
\hline 1999 & 446,4 & 508,8 & 509,8 & 314,8 & 538,6 & 610,5 & 639,9 & 351,5 \\
\hline 2000 & 468,4 & 536,4 & 535,3 & 331,5 & 563,4 & 637,5 & 670,8 & 369,3 \\
\hline 2001 & 494,5 & 571,2 & 565,0 & 348,8 & 594,8 & 673,2 & 708,4 & 388,8 \\
\hline 2002 & 516,0 & 599,5 & 588,4 & 367,6 & 620,4 & 700,9 & 737,9 & 410,9 \\
\hline 2003 & 546,0 & 634,7 & 620,1 & 395,8 & 656,4 & 736,5 & 777,7 & 444,3 \\
\hline 2004 & 576,6 & 665,1 & 648,9 & 432,1 & 693,0 & 766,1 & 812,8 & 488,4 \\
\hline 2005 & 609,7 & 700,0 & 686,6 & 455,3 & 731,8 & 801,7 & 859,7 & 513,1 \\
\hline 2006 & 641,8 & 731,5 & 722,7 & 476,7 & 771,6 & 834,3 & 909,2 & 536,1 \\
\hline 2007 & 673,7 & 760,7 & 760,0 & 498,3 & 807,6 & 862,6 & 953,5 & 558,6 \\
\hline 2008 & 719,7 & 801,5 & 814,5 & 529,0 & 861,2 & 903,2 & $1.020,5$ & 591,2 \\
\hline 2009 & 754,0 & 831,5 & 854,1 & 553,9 & 899,6 & 929,6 & $1.066,9$ & 616,7 \\
\hline 2010 & 779,5 & 849,9 & 884,0 & 571,7 & 926,9 & 943,2 & $1.100,5$ & 634,3 \\
\hline 2011 & 804,9 & 869,5 & 915,2 & 586,4 & 955,3 & 959,9 & $1.136,0$ & 649,6 \\
\hline 2012 & 829,8 & 887,3 & 946,3 & 601,5 & 935,2 & 930,6 & $1.112,1$ & 643,2 \\
\hline 2013 & 856,3 & 907,6 & 979,5 & 617,6 & 955,8 & 945,0 & $1.132,2$ & 658,4 \\
\hline 2014 & 871,0 & 915,6 & 999,8 & 624,0 & 965,8 & 947,9 & $1.143,2$ & 663,9 \\
\hline 2015 & 886,8 & 923,3 & $1.021,2$ & 630,6 & 982,2 & 953,7 & $1.165,5$ & 670,3 \\
\hline 2016 & 903,5 & 929,7 & $1.042,6$ & 637,9 & 999,8 & 957,9 & $1.187,7$ & 677,7 \\
\hline
\end{tabular}


CUADRO A-3

RATIO IMPORTE MEDIO DE PENSIÓN/SALARIO ORDINARIO (CSOTM): TOTAL Y RÉGIMEN GENERAL

(En porcentaje)

\begin{tabular}{|c|c|c|c|c|c|c|c|c|}
\hline Año & $\begin{array}{c}\text { Total } \\
\text { sistema }\end{array}$ & $\begin{array}{l}\text { Incapacidad } \\
\text { sistema }\end{array}$ & $\begin{array}{l}\text { Jubilación } \\
\text { sistema }\end{array}$ & $\begin{array}{l}\text { Viudedad } \\
\text { sistema }\end{array}$ & $\begin{array}{c}\text { Total } \\
\text { R. General }\end{array}$ & $\begin{array}{l}\text { Incapacidad } \\
\text { R. General }\end{array}$ & $\begin{array}{l}\text { Jubilación } \\
\text { R. General }\end{array}$ & $\begin{array}{l}\text { Viudedad } \\
\text { R.General }\end{array}$ \\
\hline 1976 & 31,1 & 33,0 & 35,3 & 23,7 & 33,6 & - & - & - \\
\hline 1977 & 31,9 & 34,0 & 34,7 & 24,6 & 32,8 & - & - & - \\
\hline 1978 & 33,9 & 37,2 & 35,7 & 26,3 & 33,8 & - & - & - \\
\hline 1979 & 32,7 & 35,9 & 34,6 & 25,1 & 33,2 & - & - & - \\
\hline 1980 & 32,4 & 35,9 & 34,6 & 24,3 & 36,9 & - & - & - \\
\hline 1981 & 32,5 & 35,0 & 36,1 & 23,6 & 37,5 & 44,3 & 46,3 & 24,9 \\
\hline 1982 & 32,2 & 35,0 & 36,0 & 22,9 & 37,8 & 43,9 & 46,0 & 24,3 \\
\hline 1983 & 32,9 & 36,3 & 36,7 & 23,2 & 38,8 & 45,0 & 47,1 & 24,8 \\
\hline 1984 & 33,3 & 36,8 & 37,4 & 23,0 & 40,1 & 45,8 & 49,2 & 24,8 \\
\hline 1985 & 33,8 & 36,9 & 38,5 & 22,9 & 41,1 & 46,1 & 51,0 & 24,9 \\
\hline 1986 & 33,9 & 36,7 & 39,0 & 22,6 & 41,3 & 45,7 & 51,5 & 24,8 \\
\hline 1987 & 33,9 & 36,5 & 39,1 & 22,5 & 41,3 & 45,4 & 51,4 & 24,8 \\
\hline 1988 & 33,9 & 36,3 & 39,3 & 22,9 & 41,3 & 44,9 & 51,2 & 25,3 \\
\hline 1989 & 34,7 & 36,9 & 40,1 & 24,2 & 42,2 & 45,4 & 51,9 & 26,7 \\
\hline 1990 & 34,9 & 37,1 & 40,3 & 24,5 & 42,4 & 45,6 & 51,9 & 27,2 \\
\hline 1991 & 35,8 & 38,0 & 41,1 & 25,7 & 43,3 & 46,6 & 52,6 & 28,4 \\
\hline 1992 & 35,8 & 37,9 & 41,0 & 26,1 & 43,3 & 46,7 & 52,2 & 28,8 \\
\hline 1993 & 36,0 & 38,3 & 41,4 & 26,1 & 43,6 & 47,3 & 52,4 & 28,9 \\
\hline 1994 & 36,5 & 38,6 & 42,1 & 26,3 & 44,1 & 47,7 & 53,2 & 29,2 \\
\hline 1995 & 37,1 & 39,2 & 43,0 & 26,6 & 44,9 & 48,5 & 54,1 & 29,5 \\
\hline 1996 & 37,8 & 39,9 & 43,9 & 26,9 & 45,7 & 49,3 & 55,0 & 29,9 \\
\hline 1997 & 37,9 & 40,5 & 44,3 & 26,9 & 45,9 & 49,9 & 55,4 & 30,0 \\
\hline 1998 & 38,5 & 43,4 & 43,8 & 27,2 & 46,4 & 52,6 & 55,0 & 30,4 \\
\hline 1999 & 38,9 & 44,4 & 44,4 & 27,4 & 47,0 & 53,2 & 55,8 & 30,6 \\
\hline 2000 & 40,1 & 46,0 & 45,9 & 28,4 & 48,3 & 54,6 & 57,5 & 31,6 \\
\hline 2001 & 41,0 & 47,3 & 46,8 & 28,9 & 49,3 & 55,8 & 58,7 & 32,2 \\
\hline 2002 & 41,2 & 47,9 & 47,0 & 29,4 & 49,6 & 56,0 & 59,0 & 32,8 \\
\hline 2003 & 42,3 & 49,2 & 48,0 & 30,7 & 50,8 & 57,1 & 60,2 & 34,4 \\
\hline 2004 & 43,7 & 50,4 & 49,2 & 32,8 & 52,6 & 58,1 & 61,6 & 37,0 \\
\hline 2005 & 45,1 & 51,8 & 50,8 & 33,7 & 54,1 & 59,3 & 63,6 & 37,9 \\
\hline 2006 & 45,0 & 51,2 & 50,6 & 33,4 & 54,0 & 58,4 & 63,7 & 37,6 \\
\hline 2007 & 45,3 & 51,1 & 51,1 & 33,5 & 54,3 & 58,0 & 64,1 & 37,5 \\
\hline 2008 & 46,1 & 51,3 & 52,2 & 33,9 & 55,2 & 57,9 & 65,4 & 37,9 \\
\hline 2009 & 46,8 & 51,6 & 53,0 & 34,4 & 55,8 & 57,7 & 66,2 & 38,3 \\
\hline 2010 & 48,3 & 52,6 & 54,7 & 35,4 & 57,4 & 58,4 & 68,1 & 39,3 \\
\hline 2011 & 49,4 & 53,3 & 56,1 & 36,0 & 58,6 & 58,9 & 69,7 & 39,8 \\
\hline 2012 & 50,6 & 54,1 & 57,7 & 36,7 & 57,1 & 56,8 & 67,9 & 39,2 \\
\hline 2013 & 52,4 & 55,6 & 60,0 & 37,8 & 58,5 & 57,8 & 69,3 & 40,3 \\
\hline 2014 & 53,3 & 56,0 & 61,2 & 38,2 & 59,1 & 58,0 & 70,0 & 40,6 \\
\hline 2015 & 54,1 & 56,3 & 62,3 & 38,5 & 59,9 & 58,2 & 71,1 & 40,9 \\
\hline 2016 & 55,2 & 56,8 & 63,7 & 39,0 & 61,1 & 58,6 & 72,6 & 41,4 \\
\hline
\end{tabular}


CUADRO A-4

COTIZACIONES SOCIALES Y PRESTACIONES LIGADAS A ELLAS EN TÉRMINOS DE C.N. *

\begin{tabular}{|c|c|c|c|c|c|c|}
\hline Año & $\begin{array}{l}\text { Cotizaciones } \\
\text { Sociales (CN): } \\
\text { mill. de euros }\end{array}$ & $\begin{array}{l}\text { Prestaciones } \\
\text { Ligadas } \mathrm{CN} \text { ) } \\
\text { mill. de euros }\end{array}$ & $\begin{array}{c}\text { PIB } \\
\text { mill. de euros }\end{array}$ & $\begin{array}{l}\text { 4. Cotizaciones } \\
\text { en } \% \text { PIB }\end{array}$ & $\begin{array}{l}\text { 5. Prestaciones } \\
\text { en } \% \text { PIB }\end{array}$ & $\begin{array}{c}\text { Equilibrio: 4-5 } \\
\text { en } \% \text { PIB }\end{array}$ \\
\hline 1979 & 10.348 & 9.162 & 86.898 & 11,9 & 10,5 & 1,4 \\
\hline 1980 & 12.037 & 10.702 & 99.845 & 12,1 & 10,7 & 1,3 \\
\hline 1981 & 13.632 & 13.499 & 112.200 & 12,1 & 12,0 & 0,1 \\
\hline 1982 & 15.659 & 15.360 & 129.827 & 12,1 & 11,8 & 0,2 \\
\hline 1983 & 18.331 & 17.783 & 148.319 & 12,4 & 12,0 & 0,4 \\
\hline 1984 & 19.691 & 20.126 & 167.986 & 11,7 & 12,0 & $-0,3$ \\
\hline 1985 & 21.999 & 23.410 & 185.636 & 11,9 & 12,6 & $-0,8$ \\
\hline 1986 & 24.817 & 26.181 & 212.777 & 11,7 & 12,3 & $-0,6$ \\
\hline 1987 & 27.751 & 28.893 & 237.923 & 11,7 & 12,1 & $-0,5$ \\
\hline 1988 & 30.218 & 32.145 & 264.351 & 11,4 & 12,2 & $-0,7$ \\
\hline 1989 & 34.624 & 35.865 & 296.509 & 11,7 & 12,1 & $-0,4$ \\
\hline 1990 & 39.288 & 41.210 & 330.088 & 11,9 & 12,5 & $-0,6$ \\
\hline 1991 & 43.609 & 47.463 & 361.567 & 12,1 & 13,1 & $-1,1$ \\
\hline 1992 & 49.773 & 53.916 & 389.067 & 12,8 & 13,9 & $-1,1$ \\
\hline 1993 & 52.043 & 58.632 & 401.229 & 13,0 & 14,6 & $-1,6$ \\
\hline 1994 & 57.361 & 60.767 & 426.631 & 13,4 & 14,2 & $-0,8$ \\
\hline 1995 & 57.005 & 60.753 & 459.337 & 12,4 & 13,2 & $-0,8$ \\
\hline 1996 & 61.166 & 63.854 & 487.992 & 12,5 & 13,1 & $-0,6$ \\
\hline 1997 & 65.262 & 65.907 & 518.049 & 12,6 & 12,7 & $-0,1$ \\
\hline 1998 & 69.333 & 67.707 & 554.042 & 12,5 & 12,2 & 0,3 \\
\hline 1999 & 74.617 & 70.761 & 594.316 & 12,6 & 11,9 & 0,6 \\
\hline 2000 & 81.425 & 75.762 & 646.250 & 12,6 & 11,7 & 0,9 \\
\hline 2001 & 89.128 & 80.302 & 699.528 & 12,7 & 11,5 & 1,3 \\
\hline 2002 & 95.003 & 86.679 & 749.288 & 12,7 & 11,6 & 1,1 \\
\hline 2003 & 102.090 & 92.588 & 803.472 & 12,7 & 11,5 & 1,2 \\
\hline 2004 & 109.168 & 99.608 & 861.420 & 12,7 & 11,6 & 1,1 \\
\hline 2005 & 117.460 & 106.559 & 930.566 & 12,6 & 11,5 & 1,2 \\
\hline 2006 & 127.099 & 113.976 & 1.007 .974 & 12,6 & 11,3 & 1,3 \\
\hline 2007 & 136.417 & 123.760 & 1.080 .807 & 12,6 & 11,5 & 1,2 \\
\hline 2008 & 142.049 & 137.120 & 1.116 .207 & 12,7 & 12,3 & 0,4 \\
\hline 2009 & 139.727 & 155.074 & 1.079 .034 & 12,9 & 14,4 & $-1,4$ \\
\hline 2010 & 138.649 & 162.693 & 1.080 .913 & 12,8 & 15,1 & $-2,2$ \\
\hline 2011 & 137.802 & 164.182 & 1.070 .413 & 12,9 & 15,3 & $-2,5$ \\
\hline 2012 & 131.859 & 168.472 & 1.039 .758 & 12,7 & 16,2 & $-3,5$ \\
\hline 2013 & 128.217 & 170.763 & 1.025 .634 & 12,5 & 16,6 & $-4,1$ \\
\hline 2014 & 130.052 & 171.053 & 1.037 .025 & 12,5 & 16,5 & $-4,0$ \\
\hline 2015 & 132.290 & 170.401 & 1.075 .639 & 12,3 & 15,8 & $-3,5$ \\
\hline 2016 & 136.267 & 172.670 & 1.114 .841 & 12,2 & 15,5 & $-3,3$ \\
\hline \multicolumn{7}{|c|}{$\begin{array}{l}\text { * En millones de euros/año. Hasta } 1994 \text { las cotizaciones son la series BDSICE "700120" (suma de las series de cotizaciones reales y ficticias («700121 } \\
\text { y «700122»). Desde } 1995 \text { son la suma de las CC.SS de empleadores, hogares y CC. ficticias (series «770a001150», «770a001151», «770a001152») } \\
\text { lgualmente, hasta } 1994 \text { las «prestaciones ligadas a cotizaciones» resultan de sumar las ligadas a CC. reales y a CC. ficticias (series «700251») } \\
\text { «700252»), y desde } 1995 \text { reproducen la serie «770a002160». }\end{array}$} \\
\hline
\end{tabular}


CUADRO A-5

COTIZACIONES SOCIALES Y PRESTACIONES LIGADAS A ELLAS EN TÉRMINOS DE CONTABILIDAD NACIONAL

(En millones de euros)*

\begin{tabular}{|c|c|c|c|c|c|c|c|c|c|c|}
\hline \multirow[t]{2}{*}{ Año } & \multicolumn{2}{|c|}{$\begin{array}{c}\text { Cotizaciones } \\
\text { Sociales (CN) } \\
\text { (millones de euros) }\end{array}$} & \multicolumn{2}{|c|}{$\begin{array}{c}\text { Prestaciones } \\
\text { Ligadas (CN) } \\
\text { (millones de euros) }\end{array}$} & \multicolumn{2}{|c|}{$\begin{array}{l}\text { 4. Cotizaciones } \\
\text { (\% PIB) }\end{array}$} & \multicolumn{2}{|c|}{$\begin{array}{l}\text { 5. Prestaciones } \\
\text { (\% PIB) }\end{array}$} & \multicolumn{2}{|c|}{$\begin{array}{l}\text { Equilibrio: } \\
\text { 4-5 (\% PIB) }\end{array}$} \\
\hline & $\begin{array}{c}\text { Sin } \\
\text { desem. }\end{array}$ & Desem. & $\begin{array}{c}\text { Sin } \\
\text { desem. }\end{array}$ & Desem. & $\begin{array}{c}\text { Sin } \\
\text { desem. }\end{array}$ & Desem. & $\begin{array}{c}\text { Sin } \\
\text { desem. }\end{array}$ & Desem. & Desem. & $\begin{array}{c}\text { Sin } \\
\text { desem. }\end{array}$ \\
\hline 1995 & - & - & 50.653 & 10.100 & - & - & 11,0 & 2,2 & - & - \\
\hline 1996 & 52.191 & 8.975 & 54.426 & 9.428 & 10,7 & 1,8 & 11,2 & 1,9 & $-0,1$ & $-0,5$ \\
\hline 1997 & 55.666 & 9.596 & 57.028 & 8.879 & 10,7 & 1,9 & 11,0 & 1,7 & 0,1 & $-0,3$ \\
\hline 1998 & 58.839 & 10.494 & 59.458 & 8.249 & 10,6 & 1,9 & 10,7 & 1,5 & 0,4 & $-0,1$ \\
\hline 1999 & 62.953 & 11.664 & 62.752 & 8.009 & 10,6 & 2,0 & 10,6 & 1,3 & 0,6 & 0,0 \\
\hline 2000 & 68.683 & 12.742 & 67.492 & 8.270 & 10,6 & 2,0 & 10,4 & 1,3 & 0,7 & 0,2 \\
\hline 2001 & 75.190 & 13.938 & 71.552 & 8.750 & 10,7 & 2,0 & 10,2 & 1,3 & 0,7 & 0,5 \\
\hline 2002 & 80.128 & 14.875 & 75.755 & 10.924 & 10,7 & 2,0 & 10,1 & 1,5 & 0,5 & 0,6 \\
\hline 2003 & 86.057 & 16.033 & 81.356 & 11.233 & 10,7 & 2,0 & 10,1 & 1,4 & 0,6 & 0,6 \\
\hline 2004 & 92.132 & 17.036 & 87.374 & 12.234 & 10,7 & 2,0 & 10,1 & 1,4 & 0,6 & 0,6 \\
\hline 2005 & 98.989 & 18.471 & 93.494 & 13.065 & 10,6 & 2,0 & 10,0 & 1,4 & 0,6 & 0,6 \\
\hline 2006 & 106.999 & 20.100 & 99.937 & 14.039 & 10,6 & 2,0 & 9,9 & 1,4 & 0,6 & 0,7 \\
\hline 2007 & 115.081 & 21.336 & 108.460 & 15.300 & 10,6 & 2,0 & 10,0 & 1,4 & 0,6 & 0,6 \\
\hline 2008 & 120.225 & 21.824 & 116.072 & 21.048 & 10,8 & 2,0 & 10,4 & 1,9 & 0,1 & 0,4 \\
\hline 2009 & 119.394 & 20.333 & 123.612 & 31.463 & 11,1 & 1,9 & 11,5 & 2,9 & $-1,0$ & $-0,4$ \\
\hline 2010 & 117.976 & 20.673 & 130.455 & 32.238 & 10,9 & 1,9 & 12,1 & 3,0 & $-1,1$ & $-1,2$ \\
\hline 2011 & 117.277 & 20.525 & 134.186 & 29.996 & 11,0 & 1,9 & 12,5 & 2,8 & $-0,9$ & $-1,6$ \\
\hline 2012 & 112.376 & 19.483 & 136.794 & 31.678 & 10,8 & 1,9 & 13,2 & 3,0 & $-1,2$ & $-2,3$ \\
\hline 2013 & 109.279 & 18.938 & 140.958 & 29.805 & 10,7 & 1,8 & 13,7 & 2,9 & $-1,1$ & $-3,1$ \\
\hline 2014 & 110.672 & 19.380 & 146.483 & 24.570 & 10,7 & 1,9 & 14,1 & 2,4 & $-0,5$ & $-3,5$ \\
\hline 2015 & 112.084 & 20.206 & 149.974 & 20.427 & 10,4 & 1,9 & 13,9 & 1,9 & 0,0 & $-3,5$ \\
\hline 2016 & 116.164 & 20.103 & 154.032 & 18.638 & 10,4 & 1,8 & 13,8 & 1,7 & 0,1 & $-3,4$ \\
\hline \multicolumn{11}{|c|}{$\begin{array}{l}\text { * Las cotizaciones y prestaciones ligadas totales son las de la nota anterior. Las «prestaciones totales a los desempleados» son la serie BDSICE } \\
\text { «731105g". La serie de cotizaciones del SPEE está tomada directamente de los Anuarios y el Boletín de Estadísticas Laborales, aunque para el bienio } \\
2015-2016 \text { se ha contado con estimaciones realizadas para este trabajo por la Tesorería General de la SS (y para el trienio 1996-1998 se ha extrapolado } \\
\text { la serie con sus datos de contabilidad de caja). Cálculos propios. Obsérvese que estas series no coinciden con las de Seguridad Social, cuyas cuentas } \\
\text { registraron superávit hasta } 2010 \text { (0,23 por } 100 \text { del PIB) y el punto máximo de déficit en } 2014 \text { fue de }-1,32 \text { por } 100 \text { (S.E.S.S, 2015, Cap. 1, p. 27). }\end{array}$} \\
\hline
\end{tabular}


CUADRO A-6

NÚMERO E IMPORTE MEDIO DE PENSIONES: STOCK TOTAL, ALTAS Y BAJAS * A. TOTAL SISTEMA DE SEGURIDAD SOCIAL. PENSIÓN MEDIA

\begin{tabular}{|c|c|c|c|c|c|c|}
\hline \multirow{2}{*}{ Año } & \multicolumn{3}{|c|}{ Número } & \multicolumn{3}{|c|}{ Importe medio: euros/mes (14 pagas) } \\
\hline & Stock & Altas & Bajas & Stock & Altas & Bajas \\
\hline 1980 & 4.398 .434 & 377.412 & 211.146 & 89,69 & 102,87 & 78,79 \\
\hline 1981 & 4.487 .363 & 453.990 & 231.000 & 103,79 & 125,05 & 95,44 \\
\hline 1982 & 4.716 .110 & 446.216 & 227.810 & 117,20 & 146,32 & 110,04 \\
\hline 1983 & 4.936 .902 & 462.098 & 244.688 & 136,33 & 165,61 & 129,32 \\
\hline 1984 & 5.154 .892 & 443.054 & 245.084 & 151,98 & 204,62 & 142,01 \\
\hline 1985 & 5.311 .784 & 412.603 & 300.626 & 168,55 & 214,48 & 153,55 \\
\hline 1986 & 5.455 .981 & 425.111 & 294.213 & 187,16 & 223,51 & 171,69 \\
\hline 1987 & 5.615 .545 & 415.060 & 272.749 & 201,79 & 240,67 & 184,21 \\
\hline 1988 & 5.785 .492 & 441.673 & 279.510 & 217,13 & 262,59 & 198,87 \\
\hline 1989 & 5.942 .768 & 425.976 & 273.083 & 236,98 & 278,89 & 216,50 \\
\hline 1990 & 6.102 .121 & 439.438 & 283.434 & 259,57 & 300,33 & 236,03 \\
\hline 1991 & 6.253 .364 & 456.606 & 295.254 & 288,62 & 334,52 & 260,45 \\
\hline 1992 & 6.422 .633 & 466.661 & 304.525 & 312,51 & 367,50 & 280,30 \\
\hline 1993 & 6.605 .646 & 584.958 & 323.236 & 335,42 & 404,13 & 303,99 \\
\hline 1994 & 6.822 .424 & 478.070 & 343.989 & 356,10 & 422,93 & 317,34 \\
\hline 1995 & 6.966 .074 & 481.780 & 344.489 & 378,81 & 449,69 & 334,94 \\
\hline 1996 & 7.110 .211 & 478.810 & 335.045 & 402,16 & 466,95 & 352,36 \\
\hline 1997 & 7.279.277 & 483.888 & 342.737 & 417,47 & 473,60 & 367,45 \\
\hline 1998 & 7.410 .732 & 455.456 & 343.567 & 432,32 & 484,51 & 384,58 \\
\hline 1999 & 7.509 .280 & 443.506 & 358.042 & 446,42 & 493,83 & 396,50 \\
\hline 2000 & 7.598 .890 & 447.260 & 359.707 & 468,38 & 520,51 & 409,38 \\
\hline 2001 & 7.677.923 & 428.024 & 353.935 & 494,50 & 548,13 & 429,50 \\
\hline 2002 & 7.745 .782 & 421.012 & 348.888 & 515,96 & 572,18 & 455,78 \\
\hline 2003 & 7.819 .456 & 435.614 & 371.118 & 546,03 & 616,49 & 471,78 \\
\hline 2004 & 7.878 .636 & 426.237 & 357.214 & 576,56 & 674,88 & 502,40 \\
\hline 2005 & 7.979 .707 & 511.362 & 379.915 & 609,74 & 681,80 & 534,67 \\
\hline 2006 & 8.165 .336 & 490.519 & 362.784 & 641,85 & 746,39 & 573,35 \\
\hline 2007 & 8.273 .939 & 487.830 & 376.447 & 673,67 & 791,70 & 611,55 \\
\hline 2008 & 8.390 .796 & 524.500 & 388.664 & 719,66 & 852,11 & 663,17 \\
\hline 2009 & 8.531 .935 & 543.865 & 404.324 & 754,04 & 901,50 & 701,24 \\
\hline 2010 & 8.671 .018 & 534.098 & 400.323 & 779,47 & 946,00 & 730,46 \\
\hline 2011 & 8.805 .164 & 529.812 & 409.145 & 804,94 & 967,59 & 752,08 \\
\hline 2012 & 8.919 .997 & 554.498 & 418.473 & 829,78 & $1.007,33$ & 789,01 \\
\hline 2013 & 9.065 .830 & 554.172 & 410.388 & 856,35 & $1.040,88$ & 824,69 \\
\hline 2014 & 9.201 .080 & 542.443 & 413.893 & 870,99 & $1.041,19$ & 831,86 \\
\hline 2015 & 9.304 .555 & 541.894 & 468.128 & 886,79 & $1.049,60$ & 805,71 \\
\hline 2016 & 9.409 .174 & 560.759 & 446.864 & 903,54 & $1.062,36$ & 817,22 \\
\hline
\end{tabular}


CUADRO A-6

NÚMERO E IMPORTE MEDIO DE PENSIONES: STOCK TOTAL, ALTAS Y BAJAS* B. TOTAL SISTEMA DE SEGURIDAD SOCIAL. PENSIÓN DE JUBILACIÓN

\begin{tabular}{|c|c|c|c|c|c|c|}
\hline \multirow{2}{*}{ Año } & \multicolumn{3}{|c|}{ Número } & \multicolumn{3}{|c|}{ Importe medio } \\
\hline & Stock & Altas & Bajas & Stock & Altas & Bajas \\
\hline 1980 & 2.190 .247 & 151.606 & 106.730 & 99,29 & - & - \\
\hline 1981 & 2.219 .504 & 198.680 & 124.620 & 115,58 & 149,97 & 105,51 \\
\hline 1982 & 2.280 .219 & 173.812 & 122.675 & 131,07 & 174,43 & 119,25 \\
\hline 1983 & 2.327 .058 & 185.076 & 130.534 & 152,09 & 189,65 & 139,92 \\
\hline 1984 & 2.390 .162 & 184.411 & 128.663 & 170,68 & 256,57 & 154,47 \\
\hline 1985 & 2.439 .129 & 186.431 & 152.269 & 191,96 & 270,77 & 169,23 \\
\hline 1986 & 2.493 .946 & 204.899 & 145.146 & 215,43 & 272,84 & 191,99 \\
\hline 1987 & 2.571 .186 & 208.830 & 134.695 & 233,05 & 288,04 & 206,39 \\
\hline 1988 & 2.655 .536 & 218.396 & 139.216 & 251,50 & 318,45 & 222,61 \\
\hline 1989 & 2.730 .367 & 208.533 & 136.783 & 273,75 & 333,94 & 240,27 \\
\hline 1990 & 2.803 .825 & 213.400 & 140.129 & 299,68 & 352,42 & 262,22 \\
\hline 1991 & 2.877 .618 & 226.340 & 144.198 & 331,63 & 390,37 & 288,05 \\
\hline 1992 & 2.963 .822 & 229.915 & 146.816 & 357,85 & 425,16 & 309,14 \\
\hline 1993 & 3.058 .267 & 288.297 & 154.622 & 385,15 & 485,81 & 338,34 \\
\hline 1994 & 3.176 .361 & 246.298 & 161.384 & 411,31 & 500,41 & 353,70 \\
\hline 1995 & 3.265 .191 & 249.505 & 160.856 & 439,02 & 535,58 & 373,77 \\
\hline 1996 & 3.350 .335 & 239.927 & 155.009 & 467,51 & 554,83 & 397,56 \\
\hline 1997 & 3.502 .531 & 226.313 & 160.981 & 487,18 & 573,43 & 416,19 \\
\hline 1998 & 4.400 .863 & 211.462 & 212.408 & 492,63 & 598,20 & 431,92 \\
\hline 1999 & 4.450 .248 & 196.338 & 221.018 & 509,77 & 619,88 & 447,52 \\
\hline 2000 & 4.493 .404 & 207.478 & 213.946 & 535,32 & 644,86 & 471,89 \\
\hline 2001 & 4.545 .617 & 197.892 & 205.754 & 564,98 & 669,99 & 502,06 \\
\hline 2002 & 4.575 .293 & 187.753 & 211.886 & 588,35 & 715,34 & 516,63 \\
\hline 2003 & 4.603 .381 & 190.574 & 217.146 & 620,12 & 772,96 & 542,32 \\
\hline 2004 & 4.619 .622 & 187.104 & 209.819 & 648,91 & 856,13 & 573,86 \\
\hline 2005 & 4.678 .269 & 265.270 & 226.135 & 686,60 & 800,12 & 608,51 \\
\hline 2006 & 4.809 .298 & 235.129 & 215.848 & 722,69 & 922,82 & 657,01 \\
\hline 2007 & 4.863 .256 & 231.784 & 224.885 & 759,98 & 994,34 & 702,08 \\
\hline 2008 & 4.936 .839 & 269.772 & 232.927 & 814,48 & $1.051,70$ & 763,30 \\
\hline 2009 & 5.038 .861 & 287.904 & 244.146 & 854,09 & $1.110,04$ & 808,69 \\
\hline 2010 & 5.140 .554 & 288.172 & 240.624 & 884,04 & $1.172,18$ & 847,20 \\
\hline 2011 & 5.246 .241 & 286.143 & 245.951 & 915,21 & $1.202,07$ & 874,55 \\
\hline 2012 & 5.330 .195 & 308.400 & 259.530 & 946,32 & $1.251,97$ & 897,85 \\
\hline 2013 & 5.451 .465 & 314.204 & 256.718 & 979,49 & $1.295,64$ & 941,07 \\
\hline 2014 & 5.558 .964 & 298.496 & 257.207 & 999,77 & $1.314,68$ & 950,68 \\
\hline 2015 & 5.641 .908 & 289.721 & 277.366 & $1.021,17$ & $1.342,94$ & 943,86 \\
\hline 2016 & 5.731 .951 & 307.511 & 263.878 & $1.042,62$ & $1.332,37$ & 963,30 \\
\hline
\end{tabular}


CUADRO A-7

NÚMERO E IMPORTE MEDIO DE PENSIONES: STOCK TOTAL, ALTAS Y BAJAS A. RÉGIMEN GÉNERAL DE LA SEGURIDAD SOCIAL. PENSIÓN MEDIA

\begin{tabular}{|c|c|c|c|c|c|c|}
\hline \multirow{2}{*}{ Año } & \multicolumn{3}{|c|}{ Número } & \multicolumn{3}{|c|}{ Importe medio: euros/mes (14 pagas) } \\
\hline & Stock & Altas & Bajas & Stock & Altas & Bajas \\
\hline 1980 & 1.636 .386 & 187.270 & 98.761 & 95,32 & nd & nd \\
\hline 1981 & 1.710 .535 & 227.136 & 109.192 & 111,69 & 148,46 & 100,09 \\
\hline 1982 & 1.788 .997 & 242.859 & 115.363 & 137,76 & 170,01 & 113,78 \\
\hline 1983 & 1.916 .293 & 247.979 & 125.132 & 160,84 & 198,31 & 134,78 \\
\hline 1984 & 2.057 .595 & 265.359 & 129.499 & 182,64 & 240,13 & 149,68 \\
\hline 1985 & 2.182 .019 & 234.929 & 163.455 & 204,85 & 252,79 & 161,31 \\
\hline 1986 & 2.292 .486 & 239.674 & 156.144 & 227,95 & 258,00 & 181,68 \\
\hline 1987 & 2.408 .926 & 238.709 & 144.869 & 245,86 & 278,71 & 195,73 \\
\hline 1988 & 2.536 .224 & 253.022 & 146.604 & 264,35 & 303,49 & 212,80 \\
\hline 1989 & 2.656 .814 & 249.288 & 146.323 & 287,93 & 320,28 & 231,52 \\
\hline 1990 & 2.773 .121 & 255.454 & 153.164 & 315,02 & 341,64 & 252,91 \\
\hline 1991 & 2.888.097 & 270.942 & 158.482 & 349,27 & 381,55 & 279,19 \\
\hline 1992 & 3.027 .596 & 288.088 & 165.578 & 377,97 & 419,25 & 301,00 \\
\hline 1993 & 3.191 .251 & 408.409 & 180.798 & 405,58 & 447,18 & 329,73 \\
\hline 1994 & 3.399 .865 & 305.417 & 192.513 & 430,47 & 484,52 & 346,85 \\
\hline 1995 & 3.536 .146 & 314.173 & 192.051 & 458,38 & 515,75 & 369,04 \\
\hline 1996 & 3.675 .016 & 312.277 & 187.361 & 486,45 & 531,94 & 390,81 \\
\hline 1997 & 3.827 .316 & 314.023 & 191.881 & 504,52 & 539,81 & 410,91 \\
\hline 1998 & 3.951 .467 & 293.134 & 193.788 & 522,05 & 554,22 & 431,10 \\
\hline 1999 & 4.047 .674 & 277.925 & 201.807 & 538,62 & 568,34 & 446,62 \\
\hline 2000 & 4.134 .035 & 283.740 & 205.242 & 563,40 & 596,77 & 459,32 \\
\hline 2001 & 4.210 .229 & 257.836 & 185.946 & 594,84 & 649,67 & 510,18 \\
\hline 2002 & 4.281 .017 & 248.957 & 171.205 & 620,38 & 692,44 & 565,62 \\
\hline 2003 & 4.360 .875 & 264.591 & 185.394 & 656,40 & 739,41 & 581,48 \\
\hline 2004 & 4.439 .153 & 267.698 & 181.910 & 693,01 & 804,18 & 618,96 \\
\hline 2005 & 4.526 .905 & 295.768 & 197.842 & 731,79 & 853,63 & 656,45 \\
\hline 2006 & 4.636.724 & 309.986 & 191.822 & 771,62 & 894,47 & 702,89 \\
\hline 2007 & 4.745 .559 & 314.413 & 202.876 & 807,64 & 939,06 & 749,32 \\
\hline 2008 & 4.860 .558 & 341.158 & 214.096 & 861,17 & $1.008,62$ & 813,65 \\
\hline 2009 & 4.992 .578 & 359.407 & 226.942 & 899,56 & $1.056,91$ & 857,90 \\
\hline 2010 & 5.123 .872 & 358.184 & 230.147 & 926,93 & $1.104,86$ & 889,64 \\
\hline 2011 & 5.254 .901 & 360.770 & 237.916 & 955,27 & $1.119,84$ & 913,80 \\
\hline 2012 & 6.009 .563 & 417.858 & 278.754 & 935,24 & $1.108,46$ & 908,86 \\
\hline 2013 & 6.253 .735 & 417.783 & 281.277 & 955,79 & $1.132,91$ & 941,65 \\
\hline 2014 & 6.454 .006 & 417.266 & 289.671 & 965,81 & $1.125,86$ & 940,20 \\
\hline 2015 & 6.566 .942 & 420.470 & 327.860 & 982,22 & $1.137,23$ & 905,75 \\
\hline 2016 & 6.681 .253 & 437.248 & 314.950 & 999,80 & $1.152,74$ & 916,12 \\
\hline
\end{tabular}


CUADRO A-7

NÚMERO E IMPORTE MEDIO DE PENSIONES: STOCK TOTAL, ALTASY BAJAS

B. RÉGIMEN GENERAL DE LA SEGURIDAD SOCIAL. PENSIÓN DE JUBILACIÓN

\begin{tabular}{|c|c|c|c|c|c|c|}
\hline \multirow{2}{*}{ Año } & \multicolumn{3}{|c|}{ Número } & \multicolumn{3}{|c|}{ Importe medio } \\
\hline & Stock & Altas & Bajas & Stock & Altas & Bajas \\
\hline 1981 & 757.667 & 105.650 & 58.586 & nd & 178,14 & 108,98 \\
\hline 1982 & 782.743 & 102.842 & 61.008 & 167,78 & 200,07 & 124,52 \\
\hline 1983 & 820.268 & 97.456 & 65.287 & 195,15 & 242,04 & 147,20 \\
\hline 1984 & 872.548 & 120.585 & 66.879 & 224,11 & 295,29 & 164,98 \\
\hline 1985 & 931.583 & 116.099 & 82.098 & 254,27 & 311,64 & 180,43 \\
\hline 1986 & 988.947 & 126.238 & 76.295 & 284,17 & 308,19 & 206,97 \\
\hline 1987 & 1.054 .977 & 129.549 & 72.235 & 306,30 & 328,53 & 222,53 \\
\hline 1988 & 1.126 .995 & 136.353 & 73.681 & 328,11 & 359,72 & 242,71 \\
\hline 1989 & 1.195 .422 & 133.871 & 74.795 & 354,55 & 375,35 & 259,66 \\
\hline 1990 & 1.260 .297 & 135.970 & 77.954 & 385,91 & 392,58 & 284,39 \\
\hline 1991 & 1.326 .412 & 148.793 & 79.840 & 424,05 & 432,70 & 313,06 \\
\hline 1992 & 1.408 .347 & 158.503 & 82.235 & 455,43 & 469,69 & 336,76 \\
\hline 1993 & 1.502 .737 & 214.176 & 89.118 & 487,98 & 534,50 & 373,23 \\
\hline 1994 & 1.621 .364 & 174.688 & 93.587 & 519,22 & 555,90 & 392,84 \\
\hline 1995 & 1.711 .415 & 179.331 & 93.474 & 552,41 & 596,59 & 417,75 \\
\hline 1996 & 1.796 .111 & 169.774 & 90.856 & 586,09 & 615,40 & 446,70 \\
\hline 1997 & 1.901 .148 & 158.430 & 94.929 & 609,37 & 637,41 & 470,71 \\
\hline 1998 & 2.288 .380 & 144.546 & 117.358 & 618,13 & 675,21 & 494,78 \\
\hline 1999 & 2.335 .065 & 127.178 & 121.714 & 639,92 & 715,91 & 516,16 \\
\hline 2000 & 2.375.269 & 136.822 & 119.040 & 670,76 & 739,59 & 543,04 \\
\hline 2001 & 2.419 .491 & 116.647 & 103.610 & 708,38 & 826,19 & 623,70 \\
\hline 2002 & 2.449 .596 & 106.499 & 99.528 & 737,91 & 922,45 & 670,55 \\
\hline 2003 & 2.484 .551 & 112.706 & 102.828 & 777,66 & 980,15 & 704,22 \\
\hline 2004 & 2.519 .983 & 119.204 & 101.775 & 812,84 & $1.053,78$ & 742,98 \\
\hline 2005 & 2.567 .028 & 141.214 & 113.593 & 859,72 & $1.101,94$ & 778,52 \\
\hline 2006 & 2.630 .684 & 146.014 & 110.567 & 909,20 & $1.159,14$ & 837,88 \\
\hline 2007 & 2.686 .479 & 148.758 & 117.970 & 953,55 & $1.222,14$ & 892,30 \\
\hline 2008 & 2.755 .683 & 176.404 & 125.854 & $1.020,54$ & $1.280,15$ & 968,76 \\
\hline 2009 & 2.844 .327 & 192.309 & 135.743 & $1.066,85$ & $1.331,13$ & $1.018,41$ \\
\hline 2010 & 2.933 .988 & 196.055 & 137.593 & $1.100,48$ & $1.393,40$ & $1.062,29$ \\
\hline 2011 & 3.028 .236 & 198.600 & 142.359 & $1.135,98$ & $1.407,09$ & $1.092,72$ \\
\hline 2012 & 3.458 .051 & 235.197 & 170.614 & $1.112,12$ & $1.389,91$ & $1.059,20$ \\
\hline 2013 & 3.656 .674 & 237.689 & 175.277 & $1.132,24$ & $1.424,58$ & $1.094,78$ \\
\hline 2014 & 3.814 .657 & 233.287 & 180.220 & $1.143,16$ & $1.425,67$ & $1.090,61$ \\
\hline 2015 & 3.899 .652 & 229.025 & 192.731 & $1.165,47$ & $1.460,30$ & $1.083,19$ \\
\hline 2016 & 3.992 .042 & 244.879 & 184.322 & $1.187,66$ & $1.451,07$ & $1.103,15$ \\
\hline
\end{tabular}


CUADRO A-8

CRECIMIENTO DE GASTO EN PENSIONES: EFECTOS DE POBLACIÓN, REVALORIZACIÓNY SUSTITUCIÓN *

A. PENSIONES MEDIAS

\begin{tabular}{|c|c|c|c|c|c|c|c|c|}
\hline \multirow{2}{*}{ Año } & \multicolumn{2}{|c|}{ Total sistema } & \multicolumn{2}{|c|}{ Efectos } & \multicolumn{2}{|c|}{ Régimen General } & \multicolumn{2}{|c|}{ Efectos } \\
\hline & GP & $E P_{t}$ & $E_{t}$ & $\mathrm{ES}_{\mathrm{t}}$ & GP & $E P_{t}$ & $E_{t}$ & $\mathrm{ES}_{\mathrm{t}}$ \\
\hline 1981 & 1,181 & 1,020 & 1,085 & 1,066 & 1,225 & 1,045 & 1,069 & 1,096 \\
\hline 1982 & 1,187 & 1,051 & 1,092 & 1,034 & 1,290 & 1,046 & 1,124 & 1,097 \\
\hline 1983 & 1,218 & 1,047 & 1,126 & 1,033 & 1,251 & 1,071 & 1,106 & 1,056 \\
\hline 1984 & 1,164 & 1,044 & 1,075 & 1,037 & 1,219 & 1,074 & 1,066 & 1,065 \\
\hline 1985 & 1,143 & 1,030 & 1,084 & 1,023 & 1,189 & 1,060 & 1,093 & 1,026 \\
\hline 1986 & 1,141 & 1,027 & 1,087 & 1,022 & 1,169 & 1,051 & 1,088 & 1,023 \\
\hline 1987 & 1,110 & 1,029 & 1,058 & 1,019 & 1,133 & 1,051 & 1,056 & 1,021 \\
\hline 1988 & 1,109 & 1,030 & 1,052 & 1,022 & 1,132 & 1,053 & 1,051 & 1,023 \\
\hline 1989 & 1,121 & 1,027 & 1,070 & 1,020 & 1,141 & 1,048 & 1,068 & 1,020 \\
\hline 1990 & 1,125 & 1,027 & 1,075 & 1,019 & 1,142 & 1,044 & 1,074 & 1,019 \\
\hline 1991 & 1,139 & 1,025 & 1,087 & 1,023 & 1,155 & 1,041 & 1,082 & 1,025 \\
\hline 1992 & 1,112 & 1,027 & 1,061 & 1,020 & 1,134 & 1,048 & 1,060 & 1,021 \\
\hline 1993 & 1,104 & 1,028 & 1,033 & 1,039 & 1,131 & 1,054 & 1,021 & 1,051 \\
\hline 1994 & 1,096 & 1,033 & 1,052 & 1,009 & 1,131 & 1,065 & 1,064 & 0,998 \\
\hline 1995 & 1,086 & 1,021 & 1,043 & 1,020 & 1,108 & 1,040 & 1,043 & 1,021 \\
\hline 1996 & 1,084 & 1,021 & 1,042 & 1,019 & 1,103 & 1,039 & 1,043 & 1,017 \\
\hline 1997 & 1,063 & 1,024 & 1,026 & 1,012 & 1,080 & 1,041 & 1,028 & 1,009 \\
\hline 1998 & 1,054 & 1,018 & 1,024 & 1,011 & 1,068 & 1,032 & 1,026 & 1,008 \\
\hline 1999 & 1,046 & 1,013 & 1,022 & 1,011 & 1,057 & 1,024 & 1,023 & 1,008 \\
\hline 2000 & 1,062 & 1,012 & 1,035 & 1,013 & 1,068 & 1,021 & 1,033 & 1,013 \\
\hline 2001 & 1,067 & 1,010 & 1,043 & 1,013 & 1,075 & 1,018 & 1,043 & 1,013 \\
\hline 2002 & 1,053 & 1,009 & 1,030 & 1,013 & 1,060 & 1,017 & 1,029 & 1,013 \\
\hline 2003 & 1,068 & 1,010 & 1,044 & 1,014 & 1,078 & 1,019 & 1,043 & 1,014 \\
\hline 2004 & 1,064 & 1,008 & 1,038 & 1,018 & 1,075 & 1,018 & 1,038 & 1,018 \\
\hline 2005 & 1,071 & 1,013 & 1,038 & 1,019 & 1,077 & 1,020 & 1,036 & 1,020 \\
\hline 2006 & 1,077 & 1,023 & 1,043 & 1,009 & 1,080 & 1,024 & 1,035 & 1,018 \\
\hline 2007 & 1,064 & 1,013 & 1,033 & 1,016 & 1,071 & 1,023 & 1,030 & 1,016 \\
\hline 2008 & 1,083 & 1,014 & 1,048 & 1,020 & 1,092 & 1,024 & 1,046 & 1,020 \\
\hline 2009 & 1,065 & 1,017 & 1,030 & 1,017 & 1,073 & 1,027 & 1,027 & 1,017 \\
\hline 2010 & 1,051 & 1,016 & 1,017 & 1,017 & 1,058 & 1,026 & 1,014 & 1,016 \\
\hline 2011 & 1,049 & 1,015 & 1,018 & 1,015 & 1,057 & 1,026 & 1,017 & 1,013 \\
\hline 2012 & 1,044 & 1,013 & 1,012 & 1,019 & 1,120 & 1,144 & 1,075 & 0,911 \\
\hline 2013 & 1,049 & 1,016 & 1,016 & 1,016 & 1,063 & 1,041 & 1,025 & 0,997 \\
\hline 2014 & 1,032 & 1,015 & 1,004 & 1,013 & 1,043 & 1,032 & 1,010 & 1,001 \\
\hline 2015 & 1,030 & 1,011 & 1,006 & 1,013 & 1,035 & 1,017 & 1,006 & 1,011 \\
\hline 2016 & 1,030 & 1,011 & 1,002 & 1,017 & 1,036 & 1,017 & 1,002 & 1,016 \\
\hline
\end{tabular}


CUADRO A-8 CRECIMIENTO DE GASTO EN PENSIONES: EFECTOS DE POBLACIÓN, REVALORIZACIÓN Y SUSTITUCIÓN * B. PENSIONES DE JUBILACIÓN

\begin{tabular}{|c|c|c|c|c|c|c|c|c|}
\hline \multirow{2}{*}{ Año } & \multicolumn{2}{|c|}{ Total sistema } & \multicolumn{2}{|c|}{ Efectos } & \multicolumn{2}{|c|}{ Régimen General } & \multicolumn{2}{|c|}{ Efectos } \\
\hline & GP & $E P_{t}$ & $E R_{t}$ & $\mathrm{ES}_{\mathrm{t}}$ & GP & $\mathrm{EP}_{\mathrm{t}}$ & $E R_{t}$ & $\mathrm{ES}_{\mathrm{t}}$ \\
\hline 1981 & 1,180 & 1,013 & 1,097 & 1,061 & nd & nd & nd & nd \\
\hline 1982 & 1,140 & 1,027 & 1,076 & 1,032 & nd & 1,033 & nd & nd \\
\hline 1983 & 1,184 & 1,021 & 1,121 & 1,035 & 1,219 & 1,048 & 1,102 & 1,056 \\
\hline 1984 & 1,153 & 1,027 & 1,070 & 1,049 & 1,222 & 1,064 & 1,059 & 1,084 \\
\hline 1985 & 1,148 & 1,020 & 1,082 & 1,039 & 1,211 & 1,068 & 1,092 & 1,039 \\
\hline 1986 & 1,147 & 1,022 & 1,083 & 1,037 & 1,186 & 1,062 & 1,081 & 1,034 \\
\hline 1987 & 1,115 & 1,031 & 1,052 & 1,028 & 1,150 & 1,067 & 1,051 & 1,026 \\
\hline 1988 & 1,115 & 1,033 & 1,047 & 1,031 & 1,144 & 1,068 & 1,044 & 1,026 \\
\hline 1989 & 1,119 & 1,028 & 1,061 & 1,026 & 1,146 & 1,061 & 1,058 & 1,021 \\
\hline 1990 & 1,124 & 1,027 & 1,069 & 1,024 & 1,148 & 1,054 & 1,069 & 1,018 \\
\hline 1991 & 1,136 & 1,026 & 1,076 & 1,029 & 1,156 & 1,052 & 1,070 & 1,027 \\
\hline 1992 & 1,111 & 1,030 & 1,054 & 1,024 & 1,140 & 1,062 & 1,053 & 1,020 \\
\hline 1993 & 1,111 & 1,032 & 1,026 & 1,049 & 1,143 & 1,067 & 1,015 & 1,056 \\
\hline 1994 & 1,109 & 1,039 & 1,050 & 1,017 & 1,148 & 1,079 & 1,061 & 1,003 \\
\hline 1995 & 1,097 & 1,028 & 1,039 & 1,028 & 1,123 & 1,056 & 1,039 & 1,024 \\
\hline 1996 & 1,093 & 1,026 & 1,041 & 1,023 & 1,113 & 1,049 & 1,043 & 1,017 \\
\hline 1997 & 1,089 & 1,045 & 1,047 & 0,995 & 1,101 & 1,058 & 1,045 & 0,995 \\
\hline 1998 & 1,271 & 1,256 & 1,245 & 0,812 & 1,221 & 1,204 & 1,181 & 0,859 \\
\hline 1999 & 1,046 & 1,011 & 1,036 & 0,999 & 1,056 & 1,020 & 1,036 & 1,000 \\
\hline 2000 & 1,060 & 1,010 & 1,045 & 1,005 & 1,066 & 1,017 & 1,041 & 1,007 \\
\hline 2001 & 1,068 & 1,012 & 1,055 & 1,001 & 1,076 & 1,019 & 1,055 & 1,001 \\
\hline 2002 & 1,048 & 1,007 & 1,038 & 1,003 & 1,055 & 1,012 & 1,036 & 1,006 \\
\hline 2003 & 1,060 & 1,006 & 1,049 & 1,005 & 1,069 & 1,014 & 1,047 & 1,007 \\
\hline 2004 & 1,050 & 1,004 & 1,036 & 1,010 & 1,060 & 1,014 & 1,033 & 1,011 \\
\hline 2005 & 1,072 & 1,013 & 1,045 & 1,012 & 1,077 & 1,019 & 1,043 & 1,014 \\
\hline 2006 & 1,082 & 1,028 & 1,057 & 0,996 & 1,084 & 1,025 & 1,047 & 1,010 \\
\hline 2007 & 1,063 & 1,011 & 1,042 & 1,010 & 1,071 & 1,021 & 1,038 & 1,011 \\
\hline 2008 & 1,088 & 1,015 & 1,058 & 1,013 & 1,098 & 1,026 & 1,055 & 1,014 \\
\hline 2009 & 1,070 & 1,021 & 1,039 & 1,010 & 1,079 & 1,032 & 1,036 & 1,009 \\
\hline 2010 & 1,056 & 1,020 & 1,024 & 1,011 & 1,064 & 1,032 & 1,021 & 1,010 \\
\hline 2011 & 1,057 & 1,021 & 1,027 & 1,008 & 1,065 & 1,032 & 1,026 & 1,006 \\
\hline 2012 & 1,051 & 1,016 & 1,018 & 1,016 & 1,118 & 1,142 & 1,072 & 0,913 \\
\hline 2013 & 1,059 & 1,023 & 1,025 & 1,010 & 1,077 & 1,057 & 1,037 & 0,982 \\
\hline 2014 & 1,041 & 1,020 & 1,013 & 1,008 & 1,053 & 1,043 & 1,020 & 0,990 \\
\hline 2015 & 1,037 & 1,015 & 1,013 & 1,008 & 1,042 & 1,022 & 1,013 & 1,006 \\
\hline 2016 & 1,037 & 1,016 & 1,010 & 1,011 & 1,043 & 1,024 & 1,009 & 1,010 \\
\hline
\end{tabular}




\section{PENSIONES NO CONTRIBUTIVAS DE LA SS Y PP. ASISTENCIALES}

CUADRO A-9

PENSIONES ASISTENCIALES Y NO CONTRIBUTIVAS: NÚMERO Y CLASES (1986-2004)*

\begin{tabular}{|c|c|c|c|c|c|c|}
\hline \multirow{2}{*}{ Año } & \multicolumn{3}{|c|}{ Pensiones asistenciales } & \multicolumn{3}{|c|}{ Pensiones no contributivas } \\
\hline & Total & Vejez & Enfermedad & Total & Vejez & Enfermedad \\
\hline 1986 & 337.607 & 162.538 & 173.739 & - & - & - \\
\hline 1987 & 331.450 & 164.415 & 165.252 & - & - & - \\
\hline 1988 & 330.570 & 167.916 & 162.201 & - & - & - \\
\hline 1989 & 333.613 & 172.710 & 160.902 & - & - & - \\
\hline 1990 & 327.831 & 166.626 & 161.206 & - & - & - \\
\hline 1991 & 331.825 & 172.870 & 158.955 & - & - & - \\
\hline 1992 & 319.197 & 173.957 & 145.240 & 80.074 & 21.170 & 58.904 \\
\hline 1993 & 272.332 & 155.453 & 116.879 & 188.890 & 70.294 & 118.596 \\
\hline 1994 & 227.532 & 133.282 & 94.250 & 268.973 & 114.487 & 154.486 \\
\hline 1995 & 190.797 & 115.062 & 75.735 & 323.935 & 147.872 & 176.063 \\
\hline 1996 & 154.520 & 95.427 & 59.094 & 374.305 & 178.202 & 196.104 \\
\hline 1997 & 123.182 & 77.103 & 46.079 & 409.850 & 201.775 & 208.075 \\
\hline 1998 & 99.849 & 63.724 & 36.124 & 437.527 & 220.561 & 216.966 \\
\hline 1999 & 82.153 & 54.211 & 27.942 & 457.619 & 234.185 & 223.434 \\
\hline 2000 & 68.058 & 46.599 & 21.460 & 471.275 & 242.416 & 228.859 \\
\hline 2001 & 57.795 & 40.750 & 17.045 & 481.586 & 205.098 & 276.488 \\
\hline 2002 & 49.433 & 35.892 & 13.541 & 485.796 & 207.540 & 278.256 \\
\hline 2003 & 42.665 & 31.794 & 10.871 & 488.347 & 207.193 & 281.154 \\
\hline 2004 & 36.761 & 28.273 & 8.488 & 488.472 & 207.025 & 281.448 \\
\hline \multicolumn{7}{|c|}{$\begin{array}{l}\text { * La cuantía anual de las pensiones asistenciales es fija desde el año } 2000: 2.098 \text { €/año. La de la pensión no contributiva individual pasó de } 2.187,7 \\
\text { a 5.150,6 } € \text { /año entre } 1991 \text { y } 2016 \text { (de 156,3 a } 367,9 \text { €/mes en } 14 \text { pagas). El requisito de acceso consiste en carecer de rentas anuales superiores a la } \\
\text { cuantía de la pensión, reduciéndose esta en caso de existir otras rentas, en función de su cuantía de las mismas: http://imserso.es//nterPresent1/groups } \\
\text { imserso/documents/binario/pncresumen2017.pdf }\end{array}$} \\
\hline
\end{tabular}

CUADRO A-10

PENSIONES NO CONTRIBUTIVAS: NÚMERO, PENSIÓN ANUAL Y GASTO MÁXIMO/AÑO

\begin{tabular}{|c|c|c|c|c|c|c|c|}
\hline Año & $\begin{array}{c}\text { Total } \\
\text { Pensiones }\end{array}$ & $\begin{array}{l}\text { Pensiones } \\
\text { Jubilación }\end{array}$ & $\begin{array}{l}\text { Pensiones } \\
\text { Incapacidad }\end{array}$ & $\begin{array}{l}\text { Pensión } \\
\text { anual € }\end{array}$ & $\begin{array}{l}\text { Gasto máx. } \\
\text { (mill. €) }\end{array}$ & $\begin{array}{c}\text { Tas. Var. } \\
\text { Pensión \% }\end{array}$ & $\begin{array}{l}\text { Tas. Var. } \\
\text { Gasto \% }\end{array}$ \\
\hline 2005 & 484.508 & 279.189 & 205.319 & 4.043 & 1.959 & - & - \\
\hline 2006 & 481.764 & 276.920 & 204.844 & 4.222 & 2.034 & 4,4 & 3,8 \\
\hline 2007 & 474.382 & 270.980 & 203.401 & 4.374 & 2.075 & 3,6 & 2,0 \\
\hline 2008 & 464.724 & 265.314 & 199.410 & 4.598 & 2.137 & 5,1 & 3,0 \\
\hline 2009 & 458.034 & 260.908 & 197.126 & 4.709 & 2.157 & 2,4 & 0,9 \\
\hline 2010 & 453.295 & 257.136 & 196.159 & 4.756 & 2.156 & 1,0 & 0,0 \\
\hline 2011 & 449.006 & 254.295 & 194.712 & 4.803 & 2.157 & 1,0 & 0,0 \\
\hline 2012 & 446.425 & 251.549 & 194.876 & 4.957 & 2.213 & 3,2 & 2,6 \\
\hline 2013 & 446.292 & 250.815 & 195.478 & 5.109 & 2.280 & 3,0 & 3,0 \\
\hline 2014 & 449.631 & 252.328 & 197.303 & 5.123 & 2.303 & 0,3 & 1,0 \\
\hline 2015 & 452.729 & 253.838 & 198.891 & 5.137 & 2.325 & 0,3 & 1,0 \\
\hline 2016 & 454.503 & 254.741 & 199.762 & 5.151 & 2.341 & 0,3 & 0,7 \\
\hline
\end{tabular}




\section{PENSIONES DE CLASES PASIVAS (metodología SEEPROS)}

CUADRO A-11

NÚMERO DE PENSIONES DE CLASES PASIVAS POR TIPO

\begin{tabular}{|c|c|c|c|c|c|c|}
\hline Año & Total & Jubilación & Incapacidad & Viudedad & Orfandad & Otras \\
\hline 2010 & 593.137 & 278.445 & 39.971 & 176.868 & 85.619 & 12.234 \\
\hline 2011 & 600.233 & 291.882 & 42.872 & 170.966 & 82.863 & 11.650 \\
\hline 2012 & 602.878 & 304.507 & 42.332 & 164.940 & 80.006 & 11.093 \\
\hline 2013 & 610.474 & 321.914 & 41.665 & 159.618 & 76.764 & 10.513 \\
\hline 2014 & 614.667 & 335.797 & 41.126 & 154.617 & 73.217 & 9.910 \\
\hline 2015 & 618.758 & 350.287 & 40.400 & 149.110 & 69.626 & 9.335 \\
\hline 2016 & 625.634 & 365.817 & 39.866 & 144.860 & 66.261 & 8.830 \\
\hline \multicolumn{7}{|c|}{ Funcionarios civiles } \\
\hline Año & Total & Jubilación & Incapacidad & Viudedad & Orfandad & Otras \\
\hline 2010 & 336.646 & 201.566 & 25.168 & 73.779 & 33.203 & 2.930 \\
\hline 2011 & 347.552 & 218.337 & 26.166 & 69.956 & 30.317 & 2.776 \\
\hline 2012 & 360.864 & 233.189 & 25.672 & 69.995 & 29.358 & 2.650 \\
\hline 2013 & 377.378 & 251.626 & 24.857 & 70.115 & 28.297 & 2.483 \\
\hline 2014 & 390.150 & 266.458 & 24.099 & 70.227 & 27.077 & 2.289 \\
\hline 2015 & 403.617 & 282.023 & 23.280 & 70.336 & 25.867 & 2.111 \\
\hline 2016 & 418.232 & 298.079 & 22.770 & 70.710 & 24.736 & 1.937 \\
\hline \multicolumn{7}{|c|}{ Funcionarios militares } \\
\hline Año & Total & Jubilación & Incapacidad & Viudedad & Orfandad & Otras \\
\hline 2010 & 203.865 & 68.086 & 13.487 & 76.279 & 37.044 & 8.969 \\
\hline 2011 & 205.103 & 66.232 & 15.433 & 77.161 & 37.744 & 8.533 \\
\hline 2012 & 199.362 & 65.389 & 15.439 & 73.953 & 36.485 & 8.096 \\
\hline 2013 & 194.786 & 65.378 & 15.640 & 71.009 & 35.044 & 7.715 \\
\hline 2014 & 190.146 & 65.207 & 15.901 & 68.183 & 33.534 & 7.321 \\
\hline 2015 & 184.790 & 64.873 & 16.034 & 65.104 & 31.853 & 6.926 \\
\hline 2016 & 180.513 & 64.907 & 16.042 & 62.525 & 30.434 & 6.605 \\
\hline \multicolumn{7}{|c|}{$\begin{array}{l}\text { * Los datos sobre pensiones de los Cuadros A-11, A-12 y A-13 se han extraído del Boletín Estadístico de las Pensiones de Clases Pasivas de los meses } \\
\text { de noviembre de cada año, facilitados por la Subdirección General de Gestión de Clases Pasivas, que excluye el impacto de las pagas extraordinarias. } \\
\text { Para los cálculos anualizados del Cuadro A-14, véase la nota al mismo. }\end{array}$} \\
\hline
\end{tabular}




\section{EL SISTEMA ESPAÑOL DE PENSIONES EN EL SIGLO XXI}

CUADRO A-12

GASTO TOTAL EN PENSIONES DE CLASES PASIVAS POR TIPO

Millones de euros al mes (14 mensualidades)

\begin{tabular}{|c|c|c|c|c|c|c|}
\hline Año & Gasto total & Jubilación & Incapacidad & Viudedad & Orfandad & Otras \\
\hline 2010 & 764,966 & 511,645 & 72,721 & 133,870 & 33,509 & 13,221 \\
\hline 2011 & 811,559 & 552,332 & 79,401 & 133,318 & 33,284 & 13,224 \\
\hline 2012 & 846,000 & 588,618 & 79,701 & 131,787 & 32,714 & 13,180 \\
\hline 2013 & 889,457 & 634,203 & 79,102 & 131,476 & 32,183 & 12,493 \\
\hline 2014 & 918,686 & 668,180 & 78,371 & 129,222 & 30,919 & 11,995 \\
\hline 2015 & 949,530 & 704,222 & 77,220 & 126,908 & 29,707 & 11,473 \\
\hline 2016 & 983,978 & 742,367 & 76,408 & 125,519 & 28,610 & 11,075 \\
\hline \multicolumn{7}{|c|}{ Funcionarios civiles } \\
\hline Año & Total & Jubilación & Incapacidad & Familiares & Orfandad & Otras \\
\hline 2010 & 508,422 & 384,663 & 47,968 & 59,267 & 13,382 & 3,142 \\
\hline 2011 & 552,810 & 427,300 & 50,620 & 59,088 & 12,759 & 3,043 \\
\hline 2012 & 589,424 & 463,561 & 50,322 & 59,954 & 12,585 & 3,001 \\
\hline 2013 & 633,097 & 507,192 & 49,019 & 61,604 & 12,429 & 2,853 \\
\hline 2014 & 665,356 & 540,785 & 47,993 & 62,049 & 11,940 & 2,589 \\
\hline 2015 & 699,715 & 576,591 & 46,375 & 62,794 & 11,566 & 2,389 \\
\hline 2016 & 736,200 & 613,577 & 45,508 & 63,722 & 11,206 & 2,186 \\
\hline \multicolumn{7}{|c|}{ Funcionarios militares } \\
\hline Año & Total & Jubilación & Incapacidad & Familiares & Orfandad & Otras \\
\hline 2010 & 229,708 & 121,201 & 23,881 & 58,637 & 16,053 & 9,937 \\
\hline 2011 & 234,438 & 120,210 & 27,927 & 59,753 & 16,513 & 10,035 \\
\hline 2012 & 234,685 & 121,142 & 28,549 & 58,800 & 16,164 & 10,030 \\
\hline 2013 & 236,672 & 123,746 & 29,268 & 58,200 & 15,912 & 9,546 \\
\hline 2014 & 235,766 & 124,658 & 29,590 & 56,916 & 15,329 & 9,273 \\
\hline 2015 & 234,438 & 125,384 & 30,080 & 55,361 & 14,658 & 8,956 \\
\hline 2016 & 234,350 & 126,968 & 30,154 & 54,345 & 14,121 & 8,762 \\
\hline
\end{tabular}


CUADRO A-13

IMPORTE MEDIO DE LAS PENSIONES DE CLASES PASIVAS POR TIPO

Euros al mes (14 mensualidades)

\begin{tabular}{|c|c|c|c|c|c|c|}
\hline Año & Total & Jubilación & Incapacidad & Viudedad & Orfandad & Otras \\
\hline 2010 & $1.289,7$ & $1.837,5$ & $1.819,3$ & 756,9 & 391,4 & $1.080,7$ \\
\hline 2011 & $1.352,1$ & $1.892,3$ & $1.852,0$ & 779,8 & 401,7 & $1.135,1$ \\
\hline 2012 & $1.403,3$ & $1.933,0$ & $1.882,8$ & 799,0 & 408,9 & $1.188,2$ \\
\hline 2013 & $1.457,0$ & $1.970,1$ & $1.898,5$ & 823,7 & 419,2 & $1.188,4$ \\
\hline 2014 & $1.494,6$ & $1.989,8$ & $1.905,6$ & 835,8 & 422,3 & $1.210,4$ \\
\hline 2015 & $1.534,6$ & $2.010,4$ & $1.911,4$ & 851,1 & 426,7 & $1.229,1$ \\
\hline 2016 & $1.572,8$ & $2.029,3$ & $1.916,6$ & 866,5 & 431,8 & $1.254,2$ \\
\hline \multicolumn{7}{|c|}{ Funcionarios civiles } \\
\hline Año & Total & Jubilación & Incapacidad & Viudedad & Orfandad & Otras \\
\hline 2010 & $1.510,3$ & $1.908,4$ & $1.905,9$ & 803,3 & 403,0 & $1.072,2$ \\
\hline 2011 & $1.590,6$ & $1.957,1$ & $1.934,6$ & 844,6 & 420,9 & $1.096,1$ \\
\hline 2012 & $1.633,4$ & $1.987,9$ & $1.960,2$ & 856,6 & 428,7 & $1.132,6$ \\
\hline 2013 & $1.677,6$ & $2.015,7$ & $1.972,1$ & 878,6 & 439,2 & $1.148,8$ \\
\hline 2014 & $1.705,4$ & $2.029,5$ & $1.991,5$ & 883,6 & 441,0 & $1.130,9$ \\
\hline 2015 & $1.733,6$ & $2.044,5$ & $1.992,0$ & 892,8 & 447,2 & $1.131,5$ \\
\hline 2016 & $1.760,3$ & $2.058,4$ & $1.998,6$ & 901,2 & 453,0 & $1.128,3$ \\
\hline \multicolumn{7}{|c|}{ Funcionarios militares } \\
\hline Año & Total & Jubilación & Incapacidad & Viudedad & Orfandad & Otras \\
\hline 2010 & $1.126,8$ & $1.780,1$ & $1.770,7$ & 768,7 & 433,3 & $1.107,9$ \\
\hline 2011 & $1.143,0$ & $1.815,0$ & $1.809,6$ & 774,4 & 437,5 & $1.176,0$ \\
\hline 2012 & $1.177,2$ & $1.852,6$ & $1.849,2$ & 795,1 & 443,0 & $1.238,9$ \\
\hline 2013 & $1.215,0$ & $1.892,8$ & $1.871,4$ & 819,6 & 454,0 & $1.237,3$ \\
\hline 2014 & $1.239,9$ & $1.911,7$ & $1.860,9$ & 834,8 & 457,1 & $1.266,6$ \\
\hline 2015 & $1.268,7$ & $1.932,8$ & $1.876,0$ & 850,4 & 460,2 & $1.293,0$ \\
\hline 2016 & $1.298,2$ & $1.956,2$ & $1.879,7$ & 869,2 & 464,0 & $1.326,6$ \\
\hline
\end{tabular}


CUADRO A-14

IMPORTE MEDIO ANUAL DE LAS PENSIONES DE CLASES PASIVAS POR TIPO ESTIMADAS COMO \% DE LA REMUNERACIÓN ANUAL POR ASALARIADO EN LAS AAPP*

\begin{tabular}{|c|c|c|c|c|c|c|}
\hline Año & Total & Jubilación & Incapacidad & Viudedad & Orfandad & Otras \\
\hline 2010 & 49,0 & 69,8 & 69,1 & 28,8 & 14,9 & 41,1 \\
\hline 2011 & 52,2 & 73,1 & 71,5 & 30,1 & 15,5 & 43,8 \\
\hline 2012 & 56,8 & 78,2 & 76,2 & 32,3 & 16,5 & 48,1 \\
\hline 2013 & 58,4 & 79,0 & 76,1 & 33,0 & 16,8 & 47,6 \\
\hline 2014 & 59,8 & 79,6 & 76,3 & 33,5 & 16,9 & 48,4 \\
\hline 2015 & 59,9 & 78,5 & 74,6 & 33,2 & 16,7 & 48,0 \\
\hline 2016 & 61,0 & 78,7 & 74,3 & 33,6 & 16,7 & 48,6 \\
\hline \multicolumn{7}{|c|}{ Funcionarios civiles } \\
\hline Año & Total & Jubilación & Incapacidad & Viudedad & Orfandad & Otras \\
\hline 2010 & 57,4 & 72,5 & 72,4 & 30,5 & 15,3 & 40,7 \\
\hline 2011 & 61,4 & 75,6 & 74,7 & 32,6 & 16,3 & 42,3 \\
\hline 2012 & 66,1 & 80,4 & 79,3 & 34,7 & 17,3 & 45,8 \\
\hline 2013 & 67,2 & 80,8 & 79,0 & 35,2 & 17,6 & 46,0 \\
\hline 2014 & 68,3 & 81,2 & 79,7 & 35,4 & 17,6 & 45,3 \\
\hline 2015 & 67,7 & 79,8 & 77,8 & 34,9 & 17,5 & 44,2 \\
\hline 2016 & 68,3 & 79,8 & 77,5 & 35,0 & 17,6 & 43,8 \\
\hline \multicolumn{7}{|c|}{ Funcionarios militares } \\
\hline Año & Total & Jubilación & Incapacidad & Viudedad & Orfandad & Otras \\
\hline 2010 & 42,8 & 67,6 & 67,3 & 29,2 & 16,5 & 42,1 \\
\hline 2011 & 44,1 & 70,1 & 69,9 & 29,9 & 16,9 & 45,4 \\
\hline 2012 & 47,6 & 75,0 & 74,8 & 32,2 & 17,9 & 50,1 \\
\hline 2013 & 48,7 & 75,9 & 75,0 & 32,9 & 18,2 & 49,6 \\
\hline 2014 & 49,6 & 76,5 & 74,5 & 33,4 & 18,3 & 50,7 \\
\hline 2015 & 49,5 & 75,5 & 73,2 & 33,2 & 18,0 & 50,5 \\
\hline 2016 & 50,4 & 75,9 & 72,9 & 33,7 & 18,0 & 51,5 \\
\hline \multicolumn{7}{|c|}{$\begin{array}{l}\text { * La serie de «Remuneración por asalariado» se obtiene por cociente de las series BDSICE «996146d» y «998046d», correspondientes a la } \\
\text { «Remuneración de Ocupados en AA.PP., Defensa, SS, Educación, Sanidad y Servicios Sociales» y al «Número de Ocupados» en esos sectores, según } \\
\text { la CN (base: } 2008 \text { ), corregida de efectos estacionales y calendario (CVEC). Las cifras de pensiones corresponden al Cuadro A-13, elevándolas a total } \\
\text { anual sumando catorce pagas (puede comprobarse que la ratio entre pensión media de trimestres con paga extraordinaria y sin paga extraordinaria es } \\
4 / 3 \text {, calculadas con los datos de pagos mensuales y número de pensiones/mes publicados en: http://www.clasespasivas.sepg.pap.minhafp.gob.es/ } \\
\text { sitios/clasespasivas/es-ES/Estadisticas/nformes/Paginas/Pension.aspx). }\end{array}$} \\
\hline \multicolumn{7}{|c|}{ Fuente: elaboración propia. } \\
\hline
\end{tabular}



BOLETÍN ECONÓMICO DE INFORMACIÓN COMERCIAL ESPAÑOLA (BICE) ISSN 0214-8307

\section{SUSCRIPCIÓN ANUAL}

\begin{tabular}{|c|c|c|c|}
\hline & $\begin{array}{l}\text { ESPAÑA } \\
1 \text { año }\end{array}$ & $\begin{array}{c}\text { UNIÓN EUROPEA } \\
1 \text { año }\end{array}$ & $\begin{array}{c}\text { RESTO DEL } \\
\text { MUNDO } \\
1 \text { año }\end{array}$ \\
\hline SUSCRIPCIÓN & $65,00 €$ & $85,00 €$ & $85,00 €$ \\
\hline $\begin{array}{l}\text { Gastos de envío } \\
\text { España }\end{array}$ & $5,76 €$ & $24,36 €$ & $30,00 €$ \\
\hline $\begin{array}{l}\text { Más } 4 \% \text { de IVA. } \\
\text { Excepto Canarias, Ceuta y Melilla }\end{array}$ & $2,83 €$ & & \\
\hline TOTAL & $73,59 €$ & $109,36 €$ & $115,00 €$ \\
\hline
\end{tabular}

\section{EJEMPLARES SUELTOS}

\begin{tabular}{|c|c|c|c|}
\hline \multicolumn{4}{|c|}{ BOLETÍN ECONÓMICO DE INFORMACIÓN COMERCIAL ESPAÑOLA } \\
\hline & $\begin{array}{l}\text { ESPAÑA } \\
1 \text { ejemplar }\end{array}$ & $\begin{array}{c}\text { UNIÓN EUROPEA } \\
1 \text { ejemplar }\end{array}$ & $\begin{array}{c}\text { RESTO DEL } \\
\text { MUNDO } \\
1 \text { ejemplar }\end{array}$ \\
\hline NÚMERO SUELTO & $7,00 €$ & $9,00 €$ & $9,00 €$ \\
\hline $\begin{array}{l}\text { Gastos de envío } \\
\text { España }\end{array}$ & $0,48 €$ & $2,03 €$ & $2,50 €$ \\
\hline $\begin{array}{l}\text { Más } 4 \% \text { de IVA. } \\
\text { Excepto Canarias, Ceuta y Melilla }\end{array}$ & $0,30 €$ & & \\
\hline TOTAL & $7,78 €$ & $11,03 €$ & $11,50 €$ \\
\hline \multicolumn{4}{|c|}{ BOLETÍN ECONÓMICO DE INFORMACIÓN COMERCIAL ESPAÑOLA } \\
\hline & $\begin{array}{l}\text { ESPAÑA } \\
1 \text { ejemplar }\end{array}$ & $\begin{array}{c}\text { UNIÓN EUROPEA } \\
1 \text { ejemplar }\end{array}$ & $\begin{array}{l}\text { RESTO DEL } \\
\text { MUNDO } \\
1 \text { ejemplar }\end{array}$ \\
\hline $\begin{array}{l}\text { NÚMERO SUELTO } \\
\text { EXTRAORDINARIO }\end{array}$ & $12,00 €$ & $15,00 €$ & $15,00 €$ \\
\hline Gastos de envío España & $0,48 €$ & $2,03 €$ & $2,50 €$ \\
\hline $\begin{array}{l}\text { Más } 4 \% \text { de IVA. } \\
\text { Excepto Canarias, Ceuta y Melilla }\end{array}$ & $0,50 €$ & & \\
\hline TOTAL & $12,98 €$ & $17,03 €$ & $17,50 €$ \\
\hline
\end{tabular}

\section{DATOS}

Nombre y apellidos

Empresa

Domicilio

D.P.

N.I.F.

Teléf.

Email

\section{DATOS DEL EDITOR:}

NIF:S2800568D

Transferencia a la cuenta de ingresos por venta de publicaciones del Ministerio de Economía y Competitividad.

IBERCAJA. Calle Alcalá 29. 28014 MADRID (ESPAÑA) CÓDIGO CUENTA CLIENTE: 2085-9252-07-0330598330 CÓDIGO BIC DE IBERCAJA: CAZRES2Z

IBAN: ES47 2085-9252-07-0330598330

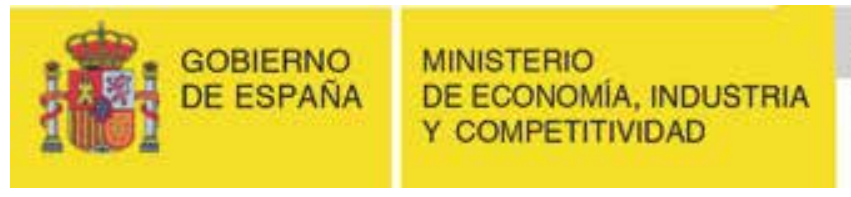




\section{NORMAS DE ESTILO DE PUBLICACIÓN}

La persona o personas interesadas en presentar un artículo para su publicación en el Boletín de Información Comercial Española (BICE) deberán enviar el artículo en formato Microsoft Word a la dirección de correo electrónico revistasice.sscc@comercio.mineco.es

El documento debe cumplir las siguientes características:

1. Ser material original no publicado ni presentado en otro medio de difusión.

2. La extensión total del trabajo (incluyendo cuadros, gráficos, tablas, notas, etcétera) no debe ser inferior a 15 páginas ni superior a 20. La fuente será Times New Roman, tamaño 12 y espaciado doble. Estar paginado en la parte inferior derecha de cada página.

3. En la primera página se hará constar el título del artículo que deberá ser breve, claro, preciso e informativo y la fecha de conclusión del mismo. Nombre y dos apellidos del autor o autores, filiación institucional, dirección, teléfono y correo electrónico de cada uno de ellos, así como la forma en que desean que sus datos aparezcan.

4. En la segunda página del texto se incluirá:

- El título.

- Un resumen del trabajo con una extensión máxima de 10 líneas con la siguiente estructura: objetivo, método y principal resultado o conclusión.

- De 2 a 6 palabras clave que no sean coincidentes con el título.

- De 1 a 5 códigos de materias del Journal of Economic Literature (clasificación JEL) para lo cual pueden acceder a la siguiente dirección electrónica:

https://www.aeaweb.org/jel/guide/jel.php

5. En las siguientes páginas se incluirán el texto, la información gráfica y la bibliografía con la siguiente organización.

- Se incluirá, por este orden, introducción, desarrollo, conclusiones y bibliografía y anexos si los hubiera. Los apartados y subapartados se numerarán en arábigos respondiendo a una sucesión continuada utilizando un punto para separar los niveles de división, según el siguiente modelo:

\section{Título del apartado}

\subsection{Título del apartado}

\subsubsection{Título del apartado}

\section{Título del apartado}

- Las notas de pie de página irán integradas en el texto y su contenido debe estar al final de su misma página en tamaño 10 y espacio sencillo.

- En un archivo Excel independiente se incluirá la representación gráfica (cuadros, gráficos, diagramas, figuras, etc.), que debe llevar título, estar numerada y referenciada en el texto.

En la parte inferior se incluirá la fuente de información y/o notas aclaratorias.

- Las citas de libros y artículos en el texto, se indicarán entre paréntesis con el apellido del autor y el año. Ej.: (Martínez, 1991).

- Las referencias a siglas deben ir acompañadas, en la primera ocasión en que se citen, de su significado completo.

- La bibliografía se ordenará alfabéticamente siguiendo las normas de la American Psychological Association (Harvard-APA): http://cibem.org/paginas/img/apa6.pdf

Libros

APELLIDOS, A.A. (año de publicación). Título del libro (edición) (volumen). Ciudad: Editorial.

Artículo en revista científica

APELLIDOS, A.A. (año de publicación). «Título del artículo». Título de la revista, volumen (número), números de páginas.

\section{Documento en línea}

APELLIDOS, A.A. u ORGANISMO (año, mes de publicación). Título, [en línea]. Ciudad: Editorial. Disponible en:

http://cenamb.rect.ucv.ve/siamaz/dicciona/canaima/canaima2.htm [Recuperado: 2000, 3 de junio]. 